University of Louisville

ThinkIR: The University of Louisville's Institutional Repository

$5-2006$

\title{
Using the Theory of Reasoned Action to examine the gambling behaviors of college athletes and other students.
}

Robert Gene Thrasher

University of Louisville

Follow this and additional works at: https://ir.library.louisville.edu/etd

\section{Recommended Citation}

Thrasher, Robert Gene, "Using the Theory of Reasoned Action to examine the gambling behaviors of college athletes and other students." (2006). Electronic Theses and Dissertations. Paper 1442.

https://doi.org/10.18297/etd/1442

This Doctoral Dissertation is brought to you for free and open access by ThinkIR: The University of Louisville's Institutional Repository. It has been accepted for inclusion in Electronic Theses and Dissertations by an authorized administrator of ThinkIR: The University of Louisville's Institutional Repository. This title appears here courtesy of the author, who has retained all other copyrights. For more information, please contact thinkir@louisville.edu. 
USING THE THEORY OF REASONED ACTION TO EXAMINE THE GAMBLING BEHAVIORS OF COLLEGE ATHLETES AND OTHER STUDENTS

\author{
By \\ Robert Gene Thrasher, Jr. \\ B.S. University of Louisville, 1979 \\ M.S. University of Louisville, 2003
}

A Dissertation Submitted to the Faculty of the Graduate School of the University of Louisville in Partial Fulfillment of the Requirements for the Degree

Doctor of Philosophy

Department of Education and Human Development

University of Louisville

Louisville, Kentucky

May 2006 
Copyright 2006 by Robert Gene Thrasher, Jr.

All rights reserved 


\section{DEDICATION}

It is with great pleasure that I dedicate this dissertation to my mother, Dorothy and my brother, Steve. I know they are watching down from heaven and are as proud of this work as I am. 


\section{ACKNOWLEDGEMENTS}

I would like to thank Dr. Dan F. Mahony for his guidance through this research project. His devotion and leadership provided me the ability to finish this project. I would also like to thank Dr. Damon P.S. Andrew for his devoted work on this project. I would also like to thank the other members of my dissertation committee Dr. Chris Greenwell, Dr. Bill Weinberg and Dr. Tom Reio for their contributions to this project. Thanks to all of you this dream of mine became reality.

I would also like to acknowledge my family for supporting me through this project. They were at times skeptical, but in the end they provided me with the needed support to finish the job. I would also like to thank the many professors I was able to gain knowledge from. They are greatly appreciated, and I feel part of them is in this work. Finally, thanks to Ellen for believing in me and this project, she knew how much this project meant to me and she supported all the decisions I had to make to finish it. 


\section{ABSTRACT \\ USING THE THEORY OF REASONED ACTION TO EXAMINE THE GAMBLING BEHAVIOR OF COLLEGE ATHLETES AND OTHER STUDENTS

\author{
Robert Gene Thrasher, Jr.
}

May 3, 2006

Legal and illegal gambling opportunities are readily available to students on college campuses and surrounding areas (Saum, 1999). College students are at an age that is highly impressionable, experimental, and prime to taking risks while ignoring the potential consequences (Oster, 1992). Because of their desire for competition, college student athletes may be highly susceptible to the lure of gambling. While the rates of pathological gambling are high for college students, the rates for the subpopulation of college student athletes are posited to be even higher (Rockey, Beason, Lee, Stewart, \& Gilbert, 1997).

The general purpose of the current study was to examine the gambling behavior of college students and, in particular, college student athletes. Specifically, this study examined the relationships among subjective norms, gambling attitudes, gambling motivations, locus of control, and gambling intentions on the gambling behavior of college students. The goal of this study was to assess gambling in a specific population with easy access to gambling and to evaluate the adequacy of a modified Theory of Reasoned Action (TRA) (Ajzen \& Fishbein, 1980) for predicting gambling frequency and gambling behavior. Several studies have used the TRA to examine gambling behavior 
(Cummings \& Corney, 1989; Moore \& Ohtsuka, 1997, 1999; Oh \& Hsu, 2001). All of these studies have found the TRA to be an effective instrument when examining gambling behavior. However, the researcher chose to modify the TRA in the current study by adding two moderating variables, intrinsic motivation and locus of control, to the conceptual model in order to provide a better conceptual model for future research.

The population $(N=345)$ was recruited from Health and Sport Sciences Department classes at the University of Louisville. The average age of the participants was 21.1 years. Participants completed a self-reported survey containing 90 items and it was completed during class time. Evidence of the validity and reliability of each instrument in the survey was provided. With the exception of the Gambling Motivation Scale for Intrinsic Motivation to Experience Stimulation, estimates of internal consistency for each scale were acceptable as coefficient alphas ranged from .76 to .90 .

The current study found males reported statistically more positive attitudes towards gambling than females, but did not report statistically different subjective norms. Student athletes reported no significant differences in attitudes or subjective norms when compared to other students. The current study also found that attitudes and subjective norms both significantly and positively predicted gambling intentions. However, the portion of the variance predicted by each was low. Gambling intentions significantly and positively predicted gambling behavior in terms of specific gambling types, but gambling intentions did not significantly and positively predict gambling behavior in terms of amount of money gambled.

The results indicated the addition of the moderating variable in the TRA was appropriate. In the case of intrinsic motivation, both intrinsic motivation to know and 
intrinsic motivation to accomplish significantly moderated the relationship between gambling attitudes and gambling intentions, predicting $1 \%$ and $2 \%$ of the accounted variance respectively. In addition, all three locus of control variables, internal locus of control, chance locus of control, and powerful others locus of control were found to be significant moderators of the relationship between gambling attitudes and gambling intentions. The interaction of the gambling attitudes and the locus of control variables accounted for $5 \%$ (internal), $8 \%$ (chance), and 10\% (powerful others) of the variance in gambling intentions.

The current study found that (1) there were differences in gambling attitudes between men and women, (2) attitudes and subjective norms predicted gambling intentions and intentions predicted gambling activities, and (3) motivations and locus of control moderated the relationship between gambling attitudes and gambling intentions. These results should be useful to athletic departments and student affairs officers, who are developing strategies to deal with gambling problems on campuses. In addition, the results relative to the revised TRA should be helpful to future researchers in this area. Future research should focus on additional psychological traits such as sensation seeking, aptitude, self-esteem, impulsivity, boredom, venturesomeness, passion, chasing, coping or escape as moderating variables that may influence gambling behavior among student athletes and other students. The findings of the current study may serve as the basis for the construction of a gambling model that could lead to important findings in the examination of college student gambling behavior. This research represents an important step in understanding gambling behavior, but much work in this area is still needed. 


\section{TABLE OF CONTENTS}

ACKNOWEDGEMENTS

ABSTRACT

LIST OF TABLES _ _ _ . . . xii

LIST OF FIGURES

I. INTRODUCTION

History of Gambling in the United States

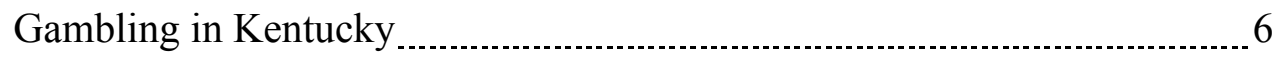

Public Health Issue

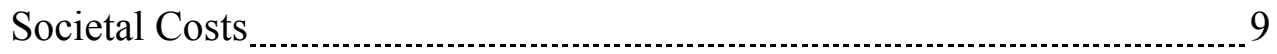

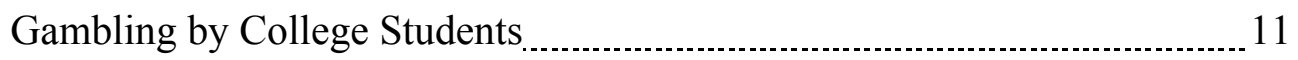

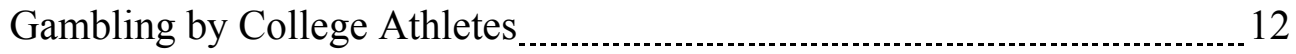

Negative Aspects of Gambling for the University .................................. 13

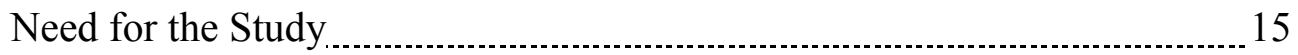

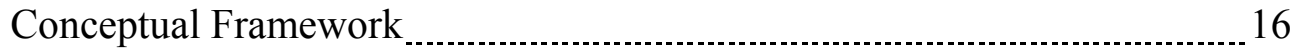

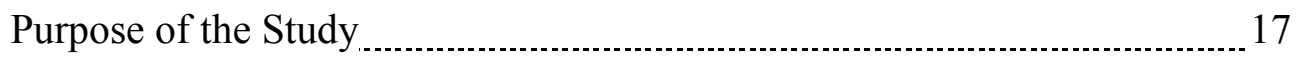

Research Questions

Definitions 18

Delimitations

Limitations 
II. LITERATURE REVIEW 22

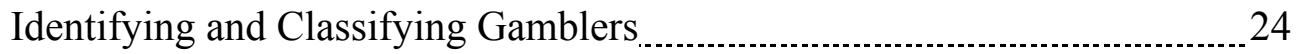

Theories of Gambling

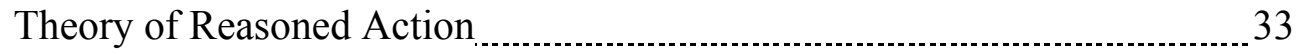

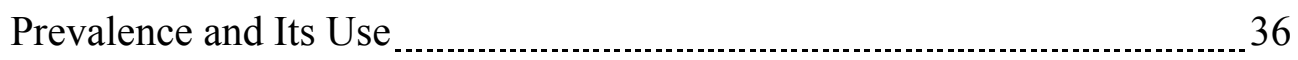

Existing Measuring Instruments

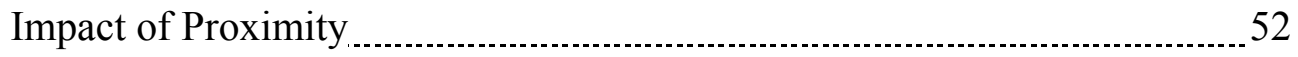

Motivations

Sensation Seeking

Venuresomeness, Impulsivity, and Boredom …………................................... 67

Passion $\quad 70$

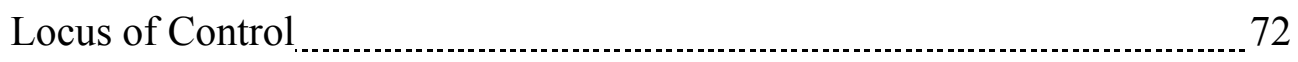

Attitudes

Cognitions $\quad 80$

Gambling Among College Students

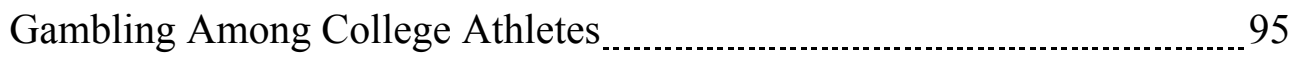

Conclusion $\quad 102$

III. METHDOLOGY

Study Purpose $\ldots \ldots$

Research Hypotheses $\ldots \ldots \ldots$

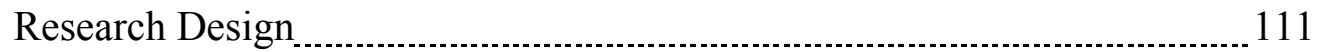

Participants $\ldots \ldots$

Instrumentation $\ldots$ 
Data Collection

Moderating Variables

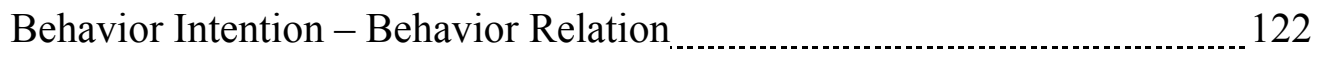

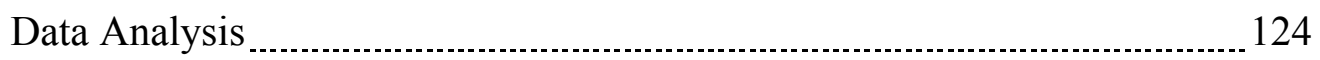

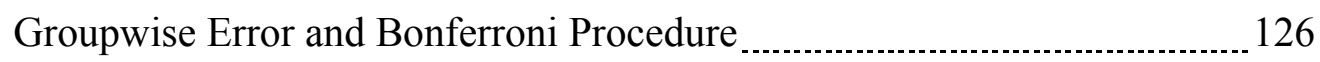

Summary

IV. RESULTS _ _ _ 128

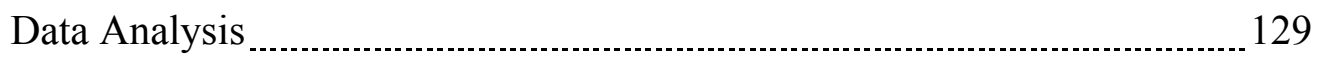

Demographic Variables _........................................................... 129

Reliability of the Survey Instrument ................................................. 130

Hypotheses Testing

$\mathrm{H} 1-\mathrm{H} 4$

$\mathrm{H} 5-\mathrm{H} 7 \ldots \ldots \ldots$

H8 - H9 _

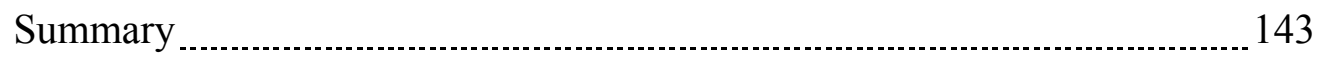

V. DISCUSSION 146

Findings

Attitudes Towards Gambling _........................................................ 148

Subjective Norms $\quad 150$

Gambling Attitudes and Gambling Intentions _............................... 151

Subjective Norms and Gambling Intentions _................................ 152

Gambling Intentions and Gambling Behavior …………............ 153

Intrinsic Motivations on Gambling Attitudes and Intentions _........... 157 
Recommendations $\ldots$

Conclusions $\ldots$

REFERENCES

APPENDIX A

APPENDIX B

APPENDIX C

APPENDIX D

CIRRICULUM VITAE _ 201 


\section{LIST OF TABLES}

TABLE

PAGE

1. Reliability Estimates of the Instrument 131

2. Means and Standard Deviations of Gambling Attitudes and Subjective Norms by Gender and Athletic Status

3. Summary of Regression Analysis for Attitudes Predicting Gambling Intentions

4. Summary of Regression Analysis for Subjective Norms Predicting Intentions

5. Summary of Regression Analysis for Intentions Predicting Gambling Behavior

6. Hierarchical Regression Analysis for the Interaction Effect Intrinsic Motivation to Know and Gambling Attitudes on Gambling Intentions

7. Hierarchical Regression Analysis for the Interaction Effect Intrinsic Motivation to Accomplish and Gambling Attitudes on Gambling Intentions 138

8. Hierarchical Regression Analysis for the Interaction Effect Internal Locus of Control and Gambling Attitudes on Gambling Intentions

9. Hierarchical Regression Analysis for the Interaction Effect Chance Locus of Control and Gambling Attitudes on Gambling Intentions 141

10. Hierarchical Regression Analysis for the Interaction Effect Powerful Others Locus of Control and Gambling Attitudes on Gambling Intentions 142

11. Comparison to Other Studies of College Students 147 


\section{LIST OF FIGURES}

$\begin{array}{ll}\text { FIGURE } & \text { PAGE }\end{array}$

1. Conceptual Framework of the Study $\ldots$

2. Graphic Representation of the Hypotheses $\ldots \ldots$

3. Moderating Variable: Intrinsic Motivation _............................................ 119

4. Moderating Variable: Locus of Control $\ldots$ 


\section{CHAPTER I}

\section{INTRODUCTION}

Gambling has been popular for a long time, and its popularity continues to increase (Sullivan, 1972). Gambling, whether legal or illegal, is readily available to students on college campuses and surrounding areas (Saum, 1999). College students are at an age that is highly impressionable, experimental, and prime to taking risks, while ignoring the potential consequences (Oster, 1992). Research based on information that indirectly included college students, suggested gambling is not only readily available but is rampant on college campuses (Derevensky \& Gupta, 2000; Saum, 1999). However, much is unknown relative to the gambling behavior of college student athletes and other students or what impacts their gambling intentions. The current study will attempt to help fill the gap.

To accomplish this purpose, the present study will focus on college students at the University of Louisville in Louisville, Kentucky. Kentucky has numerous gambling opportunities, both legal and illegal. These include pari-mutuel wagering, state lottery, and charitable gaming in the form of bingos, pull-tabs, and chances. The market is further saturated by a riverboat gambling facility located approximately ten miles from the University of Louisville campus in Harrison County, Indiana. The proximity of a variety of gambling options makes this setting ideal for the current study. 
History of Gambling in the United States

Games of chance have existed throughout human history. Kusyszyan (1977) stated that early humans used the gambling process to select individuals for certain tasks, provide entertainment, exchange property, or settle disputes. The Cambridge International Dictionary (1999) defines "gamble" as "to play games of chance for money or reward." Despite ongoing concerns related to gambling, legalized gambling exists in 48 of the 50 United States.

According to Nelson Rose (1995), there have been three distinct time periods in the history of legalized gambling in the United States. As early as 1612, the Virginia Company of Jamestown petitioned the King of England for the permission to conduct a lottery, mainly in England, to finance the struggling Virginia colony (Findlay, 1986). Later, George Washington's army was financed with a national lottery. The University of North Carolina, chartered in 1789, was initially funded by lotteries (Mississippi Council on Problem and Compulsive Gambling, 1999). Following the end of the Revolutionary War, lotteries were used to improve public services throughout the southern United States (Westphal, Rush, Stevens, \& Johnson, 2000). For example, Tennessee and Georgia used lotteries to finance public hospitals and county schools, respectively (Sullivan, 1972).

Lotteries were not the only form of gambling during this period. Wagering on horse racing was a very popular form of gambling. The first modern racetrack was built on Long Island in 1665 (Sullivan, 1972). However, it was in the southern states that gambling flourished. The South tended to have a more open attitude towards gambling than the northern states. The government used gambling-related funds for public works 
projects. While attempting to control adverse effects of gambling on individuals through legislation, the government has demonstrated ambivalence toward gambling that waxed and waned throughout the historical cycles of the United States (Westphal et al., 2000).

In the 1830s, legislation began to appear that prohibited gambling (Westphal et al., 2000). These laws marked the beginning of the second wave of gambling in the United States. North Carolina, South Carolina, and Georgia passed laws making it illegal to gamble in public places. Tennessee, Mississippi, Louisiana, Florida, and Kentucky soon passed similar laws. By 1840, 12 states in the South had passed laws prohibiting lotteries. By 1864, only four states had lotteries (Ciaffone, 1991).

The Louisiana State Lottery dominated gambling in the South during this period (National Institute of Law Enforcement and Criminal Justice, 1977). Chartered in 1868, the state of Louisiana granted a 25 -year monopoly and a $\$ 40,000.00$ tax exemption to the Louisiana State Lottery Company (Westphal et al., 2000). Lottery tickets from Louisiana appeared in every state of the union (National Institute of Law Enforcement and Criminal Justice, 1977).

Anti-gambling legislation from 1878 to 1894 reflected a resurgence of political attention on gambling (Westphal et al., 2000). In 1878, Kentucky, Alabama, and Georgia passed legislation prohibiting the sale of Louisiana State Lottery Tickets (Sullivan, 1972). Although the legislature of Louisiana withdrew the charter of the Louisiana State Lottery Company in 1879 , the Louisiana Lottery Company was soon back in business. However, in 1894, federal law banned the sale of Louisiana State Lottery Tickets. This ban would last until 1930.

The third wave of legalized gambling began in 1931, when the state of Nevada re- 
legalized casino gambling. During the 1930s, 21 states authorized pari-mutuel wagering on horse racing. Charitable gambling like raffles and bingos also spread during this period. Nevada enjoyed a monopoly on casino gambling until New Jersey legalized casino-style gambling in 1976. In 1964, New Hampshire became the first state to relegalize a state lottery. New York followed in 1966, and New Jersey in 1970. By 1975, ten other states had legalized lotteries. In 1991, the first riverboat casinos opened in Illinois and Iowa. By 1995, riverboat casinos also existed in Indiana, Mississippi, and Missouri. Today, gambling is a socially accepted form of entertainment, and opportunities to gamble continue to grow (Shapira, Ferguson, Frost-Pineda, \& Gold, 2002). A map of the United States where legal gambling is offered is contained in Appendix A.

\section{Gambling Available to Kentuckians}

As was true in the United States in general, the role of gambling and games of chance has a long history in Kentucky. Legalized gambling in Kentucky consists of parimutuel wagering, state lottery, and charitable gaming in the forms of bingos, pull-tabs and non-wheel-type games (Kentucky Legislative Research Committee, 2003).

However, casino-style gambling is also available on Kentucky's border. Indiana, Illinois, Missouri, and West Virginia all have some type of casino-style gambling. These casinostyle gambling establishments offer essentially the same entertainment as land-based casinos. Since 1991, 60 riverboat casinos opened and these casinos captured $20 \%$ of the casino market in the United States (Kentucky Legislative Research Committee, 2003). It is estimated that 460,000 Kentuckians visit riverboat casinos annually (Kentucky Legislative Research Committee, 2003). 
In 1988, residents of the state of Kentucky voted to allow the establishment of a state lottery. The Kentucky Lottery Corporation operates in every county of the Commonwealth featuring several types of games. These include pull-tabs, scratch-offs, and number games. A study by the Kentucky Lottery Corporation (1998) estimated 55\% of adults played some type of lottery game in the past year and found lottery players are more likely to be engaged in other forms of gambling.

Lottery sales bring big profits to the state. In the fiscal year 1999, lotteries in the United States earned profits of over \$12 billion dollars (Kentucky Legislative Research Committee, 2003). In the same year, the Kentucky Lottery reported profits of $\$ 161.8$ million dollars. Of all the lottery sales in Kentucky in 1999, $21 \%$ of the total sales occurred in Jefferson County, the location of the current study. The legal age to play the lottery in Kentucky is 18 years; however, several studies have reported adolescents purchasing lottery tickets well under the age of 18 (Ciaffone, 1991; Gilliland, 2003; Griffiths, 1996).

Charitable gaming is one of the most popular forms of gambling in the United States. In 1992, the Kentucky Constitution was amended to allow for charitable gaming. Kentucky has consistently ranked within the top six states in gross receipts (handle) in charitable gaming (Kentucky Legislative Research Committee, 2003). Charitable gaming in Kentucky consists of bingos, pull-tabs, and other forms of non-cash prize wheels. In 2002, Jefferson County reported total gross receipts of nearly $\$ 200$ million in charitable gaming (Kentucky Legislative Research Committee, 2003).

Pari-mutuel wagering on horse racing is another legalized segment of gambling in 
Kentucky. Horse racing was popular in the streets of Virginia and was a natural for the settlers coming through the Cumberland Gap into Kentucky. After the Revolutionary War, more and more immigrants poured into Kentucky and horse racing became part of the state's tradition. In particular, the Kentucky Derby, run for 132 continuous years in Jefferson County, is one of the most famous U.S. sporting events.

In 1797, Kentucky's first Jockey Club was formed at a formal race meet, recognized as the Lexington Jockey Club (Renau, 1995). In 1826, 60 prominent Bluegrass businessmen organized the Kentucky Association for the Improvements of Breeds of Stock (Renau, 1995). The first Kentucky Association race meet took place at the mile-long, circular Old William Track in Lees Woods (Renau, 1995). In 1832, a racetrack was constructed in Lexington, becoming America's second mile-long, fenced, dirt track (Renau, 1995). Racing made its way to Jefferson County through the Louisville and Nashville Railroad (Renau, 1995). Townspeople with English roots organized the Louisville Jockey Club and arranged horse races down by the Ohio River (Renau, 1995). Soon, the Louisville Jockey Club founded Churchill Downs, and horse racing had a significant foothold to last through the years.

Wagering on the outcome of horse races has been an integral part of the appeal of the sport since prehistory and perhaps is the sole reason horse racing has survived as a major professional sporting event (Renau, 1995). All wagering at American racetracks is handled under the pari-mutuel wagering system. Pierre Oller, a Frenchman, developed this system in the late $19^{\text {th }}$ century. Under this system, a fixed percentage (14-25\%) of the total amount wagered is taken out for track operating expenses, the remaining sum is divided by the number of individual wagers to determine the payoff, or return on each bet 
(Renau, 1995). Racetracks offer all types of wagers to encourage patrons to bet on the horse races. These wagers include win-place-show betting, exactas, quinellas, trifectas, pick-threes, pick-fours, pick-sixes, daily doubles, and late daily doubles.

Gambling as a Public Health Issue

By 2004, Americans enjoyed a variety of gaming options. Nearly one of every ten dollars of American entertainment money is spent on gambling. Shaffer (2003) states the field of gambling studies is in the midst of an important paradigm shift. Many researchers are now examining gambling activity from a public health perspective. Shaffer (2003) states four principles provide the basis for a public health perspective on gambling: (a) scientific research is the foundation of public health knowledge; (b) public health knowledge derives from population-based observations; (c) health initiatives are proactive (e.g., health promotion and prevention are primary while treatment is secondary); and (d) public health is balanced and considers both the costs and benefits of gambling.

Just as burns are classified into degrees, cancer into stages, and diabetes into types, public health workers divide the prevalence of gambling into levels (Shaffer, 2003). Gambling researchers use levels ranging from zero to four to describe the prevalence of gambling-related disorders (Shaffer, 2003). It is important to research gambling from a health perspective to develop new techniques to prevent and treat the problems associated with problem or pathological gambling (Shaffer, 2003).

Gambling is a very prevalent legalized activity that can be considered a non-drugrelated behavior with addictive potential (Potenza, Fiellin, Heninger, Rounsaville, \& Mazure, 2002). Few studies have systematically explored the relationships between 
patrons of gambling and health status (Potenza et al., 2002). As opportunities for gambling become more accessible, especially through lotteries and electronic videogaming machines, it is likely that more people will develop serious gambling problems (Darbyshire, Oster, \& Carrig, 2001). Korn and Shaffer (2002) suggested by understanding gambling and its potential effects on the public's health, policy makers and practitioners could minimize the negative results and appreciate its potential benefits.

\section{Societal Costs}

Gambling as a behavior is a social problem that is not limited to a specific group or population, even though there is speculation this behavior pattern may be more common among various groups, including athletes (Keteyian, 1986). While two percent of the general population of the United States is estimated to be pathological or problem gamblers, this percentage increases approximately to six percent for college students (Volberg, 1996). Over the past decade or so, researchers have found increasing evidence appearing to demonstrate pathological or problem gambling may overlap other addictions (Lesieur et al., 1991). Gambling is expanding across the nation, with $68 \%$ of the population reporting they have gambled in the past year (Kelly, 1999). This expansion has led to a variety of societal costs including increased bankruptcies, increased domestic violence, higher suicide rates, higher divorce rates, increased crime, increased cases of loss of employment, and increased involvement of underage youth.

The costs associated with problem and pathological gambling occur in the following areas: (a) employment costs from loss of employment and productivity, (b) welfare costs paid by taxpayers for income assistance and medical services, (c) unpaid debt borne by creditors, (d) theft, including embezzlement and fraud, (e) criminal and 
civil court costs and legal fees, (f) police and security costs from potential crime increases and increases in populations near gambling centers, and $(\mathrm{g})$ treatment cost associated with problem and pathological gambling (Kentucky Legislative Committee, 2003). However, it is difficult to measure social costs because (a) these costs are difficult to conceptualize and categorize, (b) some costs are hidden or cannot be accurately measured, (c) costs can be difficult to attribute solely to gambling, and (d) it may not be possible to isolate the additional costs from legalized gambling from the other forms of gambling (Kentucky Legislative Committee, 2003). Still, there appears to be a large and increasing societal cost of gambling even if researchers have yet to place an exact dollar value on that cost.

The act of buying a lottery ticket, playing the slots, betting the horses or filling out a bingo card has swelled to a $\$ 3$ billion-a-year business in Kentucky and Indiana (Schneider \& Stedman, 2002). As recently as the mid-1980s, someone who wanted to gamble legally in Kentucky or Indiana had only two options: to play bingo or bet on a live race at a Kentucky race track (Schneider \& Stedman, 2002). Today, there are far more options. Still, Kentucky and Indiana have lagged behind in identifying and offering adequate treatment to problem or pathological gamblers. The Kentucky General Assembly has not offered to recognize the estimated 82,300 problem or pathological gamblers whereas, Indiana has offered up about $\$ 1.9$ million in 2001 for public awareness, a helpline, and treatment (Stedman, 2002). Even with the available treatment in Indiana, few of the estimated 121,600 problem gamblers have sought help (Stedman, 2002). Other states including Iowa, Oregon, and Connecticut have led the way in providing treatment to problem and pathological gamblers. Kentucky's contribution to 
gambling treatment has come through the Kentucky Lottery Corporation, and it has been minimal. The current study hopes to provide college administrators, legislative members, gambling industry executives, and the governor with possible alternatives for treatment and possibly prevention.

\section{Gambling by College Students}

As previously discussed, college students represent a proportion of the general population highly susceptible to problem gambling. However, college student gambling has largely been overlooked in the study of risk-taking behavior. Gambling is defined as any risky behavior, based on a combination of skill or chance, or both, in which something of value can be won or lost (Kassinove, 1996). Many gambling opportunities are available to college students. The legal age to gamble in many states is 18 years. The college years represent a heightened risk for developing gambling problems because this period is associated with a wide range of at-risk behaviors. As legalized gambling continues to grow and become more socially acceptable, universities must begin to track the impact of gambling on students.

A meta-analysis of published studies on college students estimated the prevalence rate of problem gambling among college students at 5.6\%, approximately three times the rate found in adults (Shaffer \& Hall, 1997). Although pathological and problem gambling may not manifest any physical symptoms, its social and economic impact on college students has been documented in two prior studies (Lesieur et al, 1991; Ladouceur, 1994). Ladouceur (1994) evaluated the prevalence of pathological gambling among college students in Quebec City and found gambling practices are widespread among college students as. Lesieur et al. (1991) found gambling is widespread among 
college students in the United States. Lesieur et al. (1991) reported rates of pathological and problem gambling among college students are four to eight

times higher than the general adult population.

\section{Gambling by College Athletes}

One segment of college students who may be highly susceptible to the lure of gambling is college athletes. College student athletes crave competition. There have been previous attempts at quantifying gambling behavior of college student athletes. Cullen and Latessa (1996) found 25\% of Division I football and basketball players indicated they had bet on college sports. Cross and Vollano (1999) found over 45\% of Division I men's basketball and football student-athletes gambled on sports while attending college. Although the National Collegiate Athletic Association (NCAA) has rules strictly prohibiting athletes from participating in gambling, an increased number of gambling cases are reported each year.

While, student athletes are not the only students involved in gambling on college campuses, more attention is given when they get caught. This can have a negative impact on the players, the athletic department, and the image of the university. For example, when star University of Maryland quarterback was caught wagering \$200 on six football and basketball games, he was suspended for the first eight games of his senior season and the incident received considerable media coverage (Rockey et al, 1997). In 1996, Boston College suspended several players from its football team due to alleged gambling violations. The student athletes involved at Boston College were betting with an oncampus bookie. The majority of the bets were for $\$ 50$ dollars or less, with two bets for 
$\$ 800$ and $\$ 1000$ (Moran, 1996). The players eventually had large gambling debts and some agreed to shave points in the team's games.

Although it is true anyone can fall victim to gambling, the majority of college gamblers have some common traits. First, college gamblers are almost always men. They share an obsession with sport, they live in a community to share their gambling tales, and generally they are aware of their actions. The typical college bettor will begin with relatively low bets always thinking they will win. These bets are often made in the form of football parlay cards. The outcome is enviable, small bets turn into larger ones regardless of whether the gambler wins or loses. This process known as "chasing" leads the college student to a dead-end street. Research on gambling seeks to provide answers to such problem.

While the rates of pathological gambling are high for college students, the rates for the subpopulation of college student athletes are posited to be even higher (Rockey et al., 1998). Weiss (1995) compared obsessive modalities between athletes and nonathletes and discovered athletes are more likely than non-athletes to exhibit maladaptive behaviors, which included gambling than non-athletes. Pathological gambling among students has been associated with low grades, skipping classes, and parental problems (Ladouceur \& Mireault, 1988; Lesieur \& Klein, 1987).

Gambling by college student athletes is of particular concern to college athletic administrators. College athletics is big money. The university or college loses enormously when a gambling scandal hits the campus. Negative publicity from gambling scandals could affect recruiting, ticket sales, alumni support, annual fund giving to the university, and television and post season play revenues. Moreover, a college student 
athlete risks his or her entire athletic career, both collegiate and professional, if he or she is caught gambling.

Negative Aspects of Gambling on the University

Recent, highly publicized incidents of gambling activity involving studentathletes from Arizona State University, Boston College, and Northwestern University have caught the attention of the National Collegiate Athletic Association (NCAA), officials of its member institutions, the press, and fans of intercollegiate athletics (Cross, Basten, Hendrick, Kristofic, \& Schaffer, 1998). Student-athletes are exposed to all types of gambling activities. The concern about gambling by college athletes stems from the substantial economic investment of colleges and universities and associated businesses in intercollegiate athletics (Cross et al., 1998). The integrity of college sports and the continuation of the associated economic rewards depend on the assurance the games are being played straight (Cross et al., 1998).

Colleges and universities face huge economic loss from scandals relating to gambling. College athletics is big business, and it takes substantial monetary capital to run a Division I athletic department. These monies come from such sources as national television appearances by athletic teams during the regular season, post season tournaments and bowl games, ticket sales, alumni donations, and corporate sales. Gambling scandals could result in the forfeit of some of these monies leading to possible budgetary problems for both the university's academic and athletic programs.

The issue of gambling, and especially sports wagering, has been of significant importance to the NCAA membership for the entire existence of the Association (NCAA, 2004). Even an isolated incident can undermine the integrity of a sport. Thus, there 
remains a strong commitment by NCAA institutions to educate those associated with college sports about the dangers of gambling (NCAA, 2004). The NCAA has a no tolerance policy, whereby the athlete is removed from competition as a result of gambling involvement. A student athlete risks being removed from the team, expelled from college, humiliated in news stories, an embarrassment to family and team, banished from professional sports, a victim of organized crime, ruined financially and perhaps even physically hurt, turned down for future employment, and even sent to jail (NCAA, 2001). Student-athletes who exhibit attitudes indicating willingness to engage in risky behavior, or who participate in actual risky behavior such as misdemeanor illegal activities may be more likely to engage in gambling activity (Cross et al., 1998). The National Association of Student Personnel Administrators (NASPA) urges colleges and universities to increase their awareness of the potential negative consequences of college gambling. Most students believe it is important that information about the negative outcome of gambling should be widely publicized through various sources, such as pamphlets, flyers, and public service announcements (Hira \& Monson, 2000). However, colleges and universities already struggle with underage drinking, drug usage, plagiarism, and other deviant activities that stretch the resources required to battle another problem as pathological or problem gambling. Therefore, targeted activities are important in order to curb problem gambling on campus.

\section{Need for the Study}

This research project will attempt to provide important information to researchers and may determine the extent to which possible programs are necessary to help college student athletes and other student gamblers cope with their problems. Researchers have 
estimated the number of pathological gamblers in the United States ranges from one to ten million people (Blume, 1989). Dunne (1985) estimates gambling impacts 30 million people directly or indirectly. Freiberg (1995) predicts gambling will become a nationwide addiction in the United States.

However, adolescent gamblers are particularly strong candidates for problem gambling (Jacobs, 1989a). Overall, research suggests gambling addiction is a problem on America's college campuses (Neighbors et al., 2002). The existing research on college students notes the majority participated in some sort of casino gambling, such as slot and video poker machines (Lesieur et al., 1991). However, little research has focused on why college students and athletes gamble, and college students have not been studied in depth.

As we strive to increase our understanding of the nature and extent of problem gambling on the college campus, it is important to consider the extent to which government policy, societal values, and gambling behaviors contribute to it. It is essential to seek strategies for reducing or minimizing the impact of gambling on college campuses. The current study is needed to provide possible answers to problems associated with student gambling and, in particular, student athlete gambling. Researchers suggest a comprehensive approach to the prevention of problem gambling is most effective (Kratzmann, 2002). The results of the current study will hopefully be useful in determining some of the aspects that would be important when developing a comprehensive approach. The development of an intervention strategy is key to the treatment of problem gambling on college campuses across America. 


\section{Conceptual Framework of the Study}

The Theory of Reasoned Action (TRA) (Ajzen \& Fishbein, 1980) is a widely accepted and tested behavioral model that examines the determinants of consciously intended behaviors (Davis, 1989). The ultimate goal of the TRA is to predict and understand an individual's behavior (Ajzen \& Fishbein, 1980). These predictions and understandings have been applied in different fields in order to intervene and promote positive behaviors (Ajzen \& Fishbein, 1980). The TRA defines three determinants of human behavior: behavioral intention, and its antecedents, attitudes and subjective norms (Ajzen \& Fishbein, 1980). The TRA views a person's intention to perform (or not perform) a given behavior as the immediate determinant of the action (Ajzen \& Fishbein, 1980). Ajzen and Fishbein (1980) define behavioral intention as a measure of the likelihood a person will engage in a given behavior.

According to the TRA, a person's intention is a function of two basic determinants, one personal in nature and the other reflecting social influence (Ajzen \& Fishbein, 1980). The personal factor is the individual's positive or negative evaluation of performing the behavior or attitude toward the behavior (Ajzen \& Fishbein, 1980). Attitudes refer to the degree to which a person has a favorable or unfavorable evaluation or appraisal of the behavior in question (Ajzen, 1991). The second, social, determinant of intention is the person's perception of the social pressures put on him to perform or not perform the behavior in question (Ajzen \& Fishbein, 1980).

The researcher in this study will examine gambling activities through attitudes, intentions and subjective norms, as well as motivations and locus of control. This strategy is a departure from the traditional approach, which focuses on the influence of 
demographics and selected personality variables of gambling behavior. The TRA suggests these variables could influence gambling behavior, but only to the extent they affect attitudes, subjective norms, or both.

\section{Purpose of the Study}

The purpose of this research study was to examine the gambling behavior of college student athletes and other college students. This study examined the relationships among subjective norms, gambling attitudes, gambling motivations, locus of control, and gambling intentions on the gambling behavior of college students. In addition, the study will examine the impact of gender and status as an athlete on the subjective norms and gambling attitudes. This study assessed gambling in a specific population with easy access to gambling, and to evaluate the adequacy of a theoretical model for predicting adolescent gambling frequency and problem gambling. The model is derived from the Theory of Reasoned Action (Ajzen \& Fishbein, 1980).

\section{Research Questions}

This study addresses the following research questions.

1. Do males report significantly more positive attitudes related to gambling than females? 2. Do student athletes report significantly more positive attitudes related to gambling than other students?

3. Do males report significantly higher levels of subjective norms than females?

4. Do student athletes report significantly higher levels of subjective norms compared to other students?

5. Will attitudes related to gambling significantly and positively predict gambling intentions? 
6. Will subjective norms significantly and positively predict gambling intentions?

7. Will gambling intentions significantly and positively predict gambling behavior?

8. Will gambling motivations significantly moderate the relationship between gambling attitudes and gambling intentions?

9. Will locus of control significantly moderate the relationship between gambling attitudes and intentions?

\section{Definitions}

The definitions that follow are intended to facilitate reader understanding of this study.

Amotivation - pertains to activities that people do not perceive contingencies between an outcome and their own actions (Chantal et al., 1994).

Casino - a location were games of chance with built-in probability favoring the host establishment is available (Shaffer \& Hall, 1997).

Casino state - a jurisdiction within the United States that legally permits games of chance at a particular location (Shaffer \& Hall, 1997).

Extrinsic motivation - pertains to viewing a given activity as a means to an end (Chantal et al., 1994).

Gambling - the betting or wagering of valuables on events of uncertain outcomes. Implicit in this definition are the following assumptions: (a) an element of risk is involved; (b) someone wins and someone loses; (c) at least two parties are involved; and (d) gambling is a conscious, deliberate, and voluntary activity (Devereux, 1979).

Gaming - a euphemism for gambling that is used by governments and the gambling 
industry to soften public perception of an activity that in the past may have "conjured up images of illegal activities being conducted by unsavory characters" (Pavalko, 2000).

Chasing - the act of returning to gamble to recover or win more (Shaffer \& Hall, 1997).

Intrinsic motivation - the act of participating in an activity for the pleasure and satisfaction afforded by the activity (Chantal et al., 1994).

Locus of control - the perception of the factors responsible for the outcome of an event (Lefcourt, 1991).

Low-risk gamblers - respondents who respond "never" to most of the indicators of behavioral problems but have one or more "sometimes" or "more often" responses (Shaffer \& Hall, 1997).

Moderate-risk gamblers - respondents who respond "never" to most of the indicators of behavioral problems, but will have one or more "most of the time" or "always" responses (Shaffer \& Hall, 1997).

Non-gamblers - are respondents who have not gambled at all in the last 12 months (Shaffer \& Hall, 1997).

Non-problem gamblers - are respondents who respond "never" to most of the behavioral problem indicators, although they may be a frequent gambler with heavy involvement in terms of money and time (Shaffer \& Hall, 1997).

Non-resident student - a college student who attends a university that is not in his/her home state (Shaffer \& Hall, 1997).

Pari-mutuel gambling - type of gambling held at animal racetracks. Developed by Frenchman, Pierre Oller, in the late $19^{\text {th }}$ century. Under this system, a fixed 
percentage of the total amount bet is taken out for track expenses, the remaining sum is divided by the number of wagers to determine the payoffs, or return on each bet (Renau, 1995).

Pathological / compulsive gambling - a psychological disorder in the American Psychiatric Association Diagnostic and Statistical Manual, ( $4^{\text {th }}$ edition $)$. It is diagnosed as a failure to control an impulse.

Prevalence - the proportion of a population having a condition at a given point in time or over a fixed period of time (Liljequist, 2000).

Problem gamblers - respondents who have experienced adverse consequences from their gambling, and may have lost control of their behavior (Shaffer \& Hall, 1997).

Problem gambling - gambling behavior that creates negative consequences for the gambler, others in his or her social network, or for the community (Measuring Problem Gambling in Canada, 2002).

Resident student - a college student who attends a university in his/her home state (Shaffer \& Hall, 1997).

\section{Delimitations}

Delimitating factors in the current study include: (a) the study included only undergraduate students and athletes enrolled in Health and Sport Sciences classes at the University of Louisville, (b) the study only examined a limited number of factors that have been shown to or are believed to have an impact on gambling behavior.

\section{Limitations}

As in any study, there are also limitations in the current study. First, this study was limited by individual student's truthfulness in answering the questions on the testing 
instrument. The survey pertained to sensitive material so the student might have been tempted to answer untruthfully. Given the strict NCAA rules on gambling, this may have been a particular problem with student athletes. The study was limited by the selection method (convenience sampling). Second, because the study asked about prior behavior, it was limited by the memory of the respondents. Third, the use of multiple survey instruments to measure the key variables may have resulted in common method bias. Method biases are a problem because they are one of the main sources of measurement error (Podsakoff, MacKenzie, Lee, \& Podsakoff, 2003). Some methods effects result from the fact that the respondent providing the measure of the predictor and criterion variable is the same person (Podsakoff et al., 2003), as was the case in the current study. People responding to self-reported surveys like the one in the current study may have the desire to be consistent with their responses. These situations could produce relationships that would not otherwise exist at the same level in real-life settings (Podsakoff et al., 2003). This is a common limitation in survey research. 


\section{CHAPTER II}

\section{LITERATURE REVIEW}

The purpose of this research study is to examine the gambling behavior of college student athletes and other college students. While gambling has existed for thousands of years, it has grown tremendously over the past 25 years (Shaffer \& Hall, 1997). Many people gamble in a responsible manner as entertainment and experience no personal or financial hardships. However, many Americans cannot control their urges to gamble and the results are sometimes catastrophic (Shaffer \& Hall, 1997). The increase in the availability of gambling opportunities has resulted in increased problem gambling for adults and adolescents. The current study was to examine a particular theoretical model (Theory of Reasoned Action) and explore possible predictors of gambling behavior. This model postulates relationships between engaging in a behavior and attitudes toward it, knowledge / beliefs about its likely outcomes, and intentions with respect to carrying out the behavior in question. In this model, intention to perform a behavior is the immediate antecedent of that behavior. Intention is predicted by two factors, the individual's attitude to the behavior and his or her subjective norms. With respect to gambling, this model would predict that intention to gamble would be a function of beliefs about the outcomes of gambling, perceived costs and benefits of gambling, beliefs about the acceptance of the behavior by significant others, and motivation to comply with those beliefs. 
This literature review is divided into sixteen sections. As a basis for this study, the researcher reviewed studies related to (a) identification and classification of gamblers; (b) theories and models of gambling behavior; (c) theory of reasoned action; (d) prevalence of gambling; (e) impact of proximity; (f) gambling motivations; (g) sensation seeking; (h) venturesomeness and impulsivity; (i) boredom; (j) gambling passion; (k) locus of control; (1) gambling attitudes; (m) gambling cognitions; (n) gambling among college student gambling; (o) gambling among college student athletes; and (p) conclusion.

Opportunities to gamble are increasing daily and these opportunities are quite varied but along with increased opportunity comes increased societal problems. The National Research Council (NRC) (1999) reports increases in bankruptcies, domestic violence cases, suicides, increased crime rates, youth aged gambling, child neglect, higher divorce rates, loss of employment, and involvement with other types of problem related to society. These societal costs are hard to evaluate. Comparing pre-societal costs to post-societal costs from gambling exposure is relatively impossible. Exploring possible treatment and prevention programs to deal with problem or pathological gambling is important to any gambling-related study.

This study is important to a wide variety of professionals, including health officials, athletic departments, student personnel departments, and local governmental officials. Research into the effects of expanded gambling has only recently begun and, so far, the research findings are inconclusive. Expanded gambling refers to the growth of gambling opportunities in a specific area. Most research has centered on the effects of expanding casinos, but not state lotteries, pari-mutuel wagering, and charitable gaming. 
This study will examine four distinct types of gambling: a) casino-style gambling including riverboat casinos, b) pari-mutuel wagering or horserace betting, c) lottery playing, and d) charitable gaming. However, the first step in understanding gambling behavior is to identify and classify gamblers.

Identifying and Classifying Gamblers

Pathological gambling was formally recognized as a mental disorder in 1980 (American Psychiatric Association, 1980). Custer (1980) treated pathological gamblers and wrote about their illness for several years. The inclusion of pathological gambling to the Diagnostic Statistical Manual-III, the publication of psychiatric medical disorders and treatment policies, was based on Custer's writings. The Diagnostic Statistical Manual-III criteria for pathological gambling started with a statement about progressive loss of control and then listed seven items. Three or more of the criteria had to be met for a diagnosis of pathological gambling. The emphasis was on damage and disruption to the individual's family, personal, or vocational pursuits and issues that had to do with money (five of the seven criteria fell into this latter category) (American Psychiatric Association, 1980). The American Psychiatric Association added another criterion as an exclusion criterion: "not caused by antisocial personality disorder" (American Psychiatric Association, 1980, p. 598).

Lesieur (1984) criticized the Diagnostic Statistical Manual-III criteria for its unidimensionality, emphasis on external consequences, and middle-class bias. The revision of the diagnostic manual in 1987 (Diagnostic Statistical Manual-III-R) emphasized the similarity to substance abuse by substituting "gambling" for "use of substance", this criterion created dissatisfaction among treatment professionals. In order 
to examine the usefulness of this approach, 222 self-identified compulsive gamblers and 104 substance-abusing controls that gambled at least socially $(N=326)$ participated in a study (Lesieur \& Rosenthal, 1991). The researcher analyzed results to determine which items discriminated between the two groups. A new set of nine criteria resulted from this study. Finally after a presentation of these findings, the American Psychiatric Association later added one additional item to the criteria.

In 1994, the American Psychiatric Association published in its Diagnostic Statistical Manual IV (DSM-IV) a set of criteria for evaluating excessive gambling habits. A person was diagnosed as a "compulsive gambler" with five "yes" responses. The following chart adapted from the Diagnostic Statistical Manual-IV contains the criteria for evaluating a compulsive gambler.

\section{DSM-IV Criteria}

A "yes" response to five or more of the following criteria attributes persistent and recurrent maladaptive behavior:

(a) Is preoccupied with gambling (e.g., is preoccupied with reliving past gambling experiences, handicapping or planning the next venture, or thinking of ways to get money with which to gamble),

(b) Needs to gamble with increasing amounts of money in order to achieve desired excitement,

(c) Has repeated unsuccessful efforts to control, cut back, or stop gambling,

(d) Is restless or irritable when attempting to control, cut back, or stop gambling, 
(e) Gambles as a way of escaping from problems or

of relieving feelings of anxiety, depression, guilt or helplessness,

(f) After losing money gambling, often returns another day to get even ("chasing" one's losses),

(g) Lies to family members, therapists, or others to conceal the extent of involvement in gambling,

(h) Have committed illegal acts, such as forgery, fraud, theft, or embezzlement to finance gambling,

(i) Has jeopardized or lost significant job, relationship, educational or career opportunity because of gambling,

(j) Relies on others to provide money to relieve a desperate

financial situation caused by gambling, or

The gambling behavior is not accounted for by a manic episode.

Source: Diagnostic Statistical Manual-IV (American Psychiatric Association, 1994, p. 671).

The Diagnostic Statistical Manual-IV (American Psychiatric Association, 1994) classifies gamblers into three groups: a) at risk gamblers, b) problem gamblers, and c) compulsive or pathological gamblers. Pathological gambling is a chronic and progressive failure to resist impulses to gamble, that compromise, disrupts, or endangers personal, family, or vocational pursuits (American Psychiatric Association, 1994). The American Psychiatric Association (1994) classifies "pathological gambling” as one of five different impulse disorders under a category called "Impulse-Control Disorders Not Elsewhere 
Classified." The other impulse disorders in this classification include intermittent explosive behavior, kleptomania, pyromania, and trichotillomania. This cluster of impulse disorders suggests there may be a relationship between pathological gambling and the other impulse-control disorders (American Psychiatric Association, 1994).

An impulse refers to 'incitement to action arising from a state of mind or some external stimulus; or a sudden inclination to act, without conscious thought, or a motive or tendency coming from within" (Oxford English Dictionary, 1989). The essential feature of an impulse-control disorder, as defined by the Diagnostic Statistical ManualIV, is "the failure to resist an impulse, drive, or temptation to perform an act that is harmful to the person or to others" (American Psychiatric Association, 1994, p.609).

Characteristics of pathological gambling include a continuous loss of control over gambling, a progression in gambling frequency and amounts wagered, and preoccupation with gambling and obtaining money to gamble (Westphal et al., 2000). Shaffer and Hall (1997) noted disordered gambling prevalence studies have used a wide array of criteria and labels to define the levels of disordered gambling. In their meta-analysis, they developed three levels for measuring disordered gambling. Level I included the proportion of the population that does not experience gambling problems (also known as non-gamblers and non-problematic gamblers). Level II includes gamblers with subclinical levels of gambling problems. These include at-risk gamblers, in-transition gamblers, and potential gamblers. Level III includes the most severe category of gamblers, including pathological or compulsive gamblers.

Rosenthal (1987) identified six predisposing factors for pathological gamblers: 
(a) A family history of compulsive gambling. As many as one-third of the compulsive gamblers have a biological relative with the disorder, and then extending through two or three generations.

(b) Growing up in a family with an extremely critical, or rejecting, or emotionally unavailable parent.

(c) An emphasis in the family on status or an overvaluing of money.

(d) Men, in particular, brought up to be extremely competitive.

(e) The existence of an early physical or development problem.

(f) Hyperactivity.

Custer and Milt (1985) reported three phases in the progression of compulsive gambling. These three phases include: early phase, losing phase, and desperation phase. The early phase uses such defensive mechanisms as minimization, rationalization, and denial. In the losing phase, the gambler is consumed with gambling and everything else is secondary. A gambler in the desperation phase is powerless over their compulsion, there is impaired thinking and moral/physical/emotional/ spiritual deterioration and the gambling problem is no longer a secret.

Gambling behavior ranges on a continuum of behavior (Appendix B) similar to the use of alcohol. With alcohol use there are "teetotalers" or abstainers, social drinkers, alcohol abusers, and alcoholics; likewise, there are abstainers, social gamblers, problem gamblers, and compulsive or pathological gamblers (Kentucky Legislative Research Report, 2003). Similarly, gamblers range from non-gamblers, to non-problematic gamblers, to problem gamblers, to pathological gamblers. 


\section{Summary}

Research about problem or pathological gambling was virtually nonexistent until the 1980s. The American Psychiatric Association recognized pathological gambling as a psychiatric mental disorder in 1980. Emphasis was placed on a progressive loss of control by the pathological gambler. The American Psychiatric Association revised the criteria for diagnosing pathological gamblers in 1994. This new set of criteria contained ten items for evaluating excessive gambling. Affirmative responses to five or more of the criteria led to a person being classified as a compulsive or pathological gambler.

Later researchers identified three levels for measuring disordered gambling (Shaffer \& Hall, 1997), phases in the progression of compulsive gambling (Custer \& Milt, 1985) and predisposing factors for becoming a pathological gambler (Rosenthal, 1987). In particular, the establishment of three distinct levels for identifying the different types of gamblers is vital to the success of the present study. By identifying the levels of problem and non-problem gamblers, administrators may develop programs to help college student athletes and others from falling into the same pitfalls as their adult counterparts. Moreover, it is important to understand not only levels of gambling, but why people gamble excessively. The next section will discuss various gambling theories that have been used to try to determine why people gamble.

\section{Theories of Gambling}

Shaffer and Gambino (1989) suggested three reasons why there was a conceptual crisis in the understanding of compulsive gambling: a) the absence of an accepted paradigm, b) the consequent paucity of facts, c) the lack of integration between research, theory, and practice. There are many competing models and theories of gambling 
behavior. Tabor (1987, p. 219) described the range of models available in this way, "Problem, excessive, and pathological gambling can be conceptualized in terms of addictionology, biology, genetics, disease process, values clarification, forensic responsibility, learning failure development disorder, anthropological matrix, social dynamic, impulse control, economic man, political theory, and yes, in terms of statistical learning theory and schedules of reinforcement."

Tabor (1987), Murray (1993), and Brown (1987), suggested it is difficult to fully describe or conceptualize gambling behavior or gambling problems using any one model. Brown (1987) has suggested using one model in exclusion of others acts as a perceptual filter, and leads to some aspects of behavior being ignored or relegated to the background. While there is some overlap in terms of theories and models described in the literature, the basic topology used is similar to that of Rosenthal (1987). Rosenthal (1987) uses three clusters of theoretical constructs. These include (a) psychodynamic or Freudian theory, (b) physiological or biological theory, and (c) behavioral theory.

\section{Psychodynamic Theories}

Psychodynamic models, also called psychoanalytical theories (Lesieur \& Rosenthal, 1991) of pathological gambling view the problem as within the gambler's psyche. These theorists suggested the pathological gambler uses gambling in an attempt to heal a psychic wound or as a means of coping with conflict. This concept is similar to Jacob's General Theory of Addiction (1986). This theory suggests two underlying and interacting conditions, which cause discomfort for an individual, leading to an attempt to self-medicate by engaging in an addictive behavior (Jacobs, 1986). The two factors are a 
uni-polar physiological resting state and a physiological problem such as rejection or insecurity that creates considerable physiological pain (Jacobs, 1986).

\section{Biological or Physiological Theories}

Theories classified as biological are those, which tend to view gambling problems as a result of some physiological predisposition or condition that results in a physiological response to gambling activity (Blume, 1987). Blume (1987) further states addictions tend to run in families. Lesieur and Rosenthal (1991) suggest there are three main models within the biological school of theories of problem gambling: (a) models which have looked at electroencephalogram (EEG) waves, (b) models based on plasma endorphin levels, and (c) models which are based on the incidence of other brain chemical imbalances.

Behavioral Theories

Trait Theory. Grahm and Lowenfeld (1986) examined different trait profiles for a group of men $(N=100)$ in a treatment for gambling problems. Their study showed very high scores on psychopathic deviate scale, indicating a tendency toward a sociopathic, sensation seeking lifestyle. Given the pivotal role of arousal in gambling, it is proposed that sensation seeking (Zuckerman, 1979) is a personality trait that warrants further investigation in regards to its relationship with gambling. Sensation seeking is the "need for varied, novel and complex sensations and experiences, and the willingness to take physical and social risks for the sake of such experience" (Zuckerman, 1979, p. 10). Zuckerman's theory predicts high sensation seekers will perceive gambling situations to be less risky and will enjoy the arousing experiences more than low sensation seekers (Zuckerman, 1979). 
Blaszczynski, McConaghy, and Frankova's (1991) study suggested three separate types or clusters of pathological gamblers: (a) those who were depressed, (b) those who were primarily just bored, and (c) those bored and depressed. Clinical support for this topology of gambling types is offered by Selzer (1992), who notes skilled gamblers are more likely to have personality disorders, while luck gamblers are most likely to have affective disorders. Gambling is a risk-taking experience that allows the gambler the opportunity to take chances for the sole purpose of winning and this tends to appeal to certain types of individuals.

Social Learning Theory. Social learning theory models view gambling as a learned behavior, learned through imitation, either of an admired figure or from one's peers (Bandura, 1977). Social learning models of gambling suggest gambling falls along a continuum of problem-free to problem-dominated behavior (Brown, 1987). Based on social learning theories, gambling behavior can be reduced, because the behavior is learned, it can also be unlearned (Lesieur \& Rosenthal, 1991). The major strength of the social learning theory is it includes the entire population of gamblers, and therefore has no artificial distinction between problematic and non-problematic gambling and can be used to examine all types of gamblers. However, the social learning theory seems to underestimate the power of individual motivation, emotions, and perceptions to influence outcomes, and overestimates the power of external social factors.

Cognitive-Behavioral Theory. Cognitive-behavioral theory builds on the social learning theory, but focuses on the role cognitive processes play in the acquisition and maintenance of gambling behavior (Ladouceur, Boisvert, \& Dumont, 1994). Gambling behavior is acquired through the traditional mechanisms of operant and classical 
conditioning (Dickerson, 1997; Sharpe \& Tarrier, 1993). Once the gambler experiences the thrill of winning, which acts as a positive reinforcement of the behavior, it increases the likelihood the gambler will return to gamble again. Gamblers learn winning will be intermittent, but it will occur, and so they learn to continue gambling despite repeated losses (Sharpe \& Tarrier, 1993; Walker, 1992).

Theory of Reasoned Action

In 1975, Fishbein and Ajzen published Belief, Attitude, Intention and Behavior: An Introduction to Theory and Research, laying out the theory of reasoned action, which they claimed improved our ability to predict behavior (Fishbein \& Ajzen, 1975). The theory of reasoned action focuses primarily on the prediction of intentions, as opposed to behavior itself. According to the theory, if behavior is under volitional control, then the intention to perform an action will correlate very highly with the action itself (Fishbein \& Ajzen, 1975). This supposition has been found to be correct, with correlations between intention and behavior averaging .55 (Fishbein \& Ajzen, 1975).

The full model is:

$B I=w p$ Attitude behavior $+w p$ Subjective Norm where Attitude behavior $=b i$ $e i$ and where Subjective Norm $=b i m i$ and the $w$ 's are subjective weightings for a particular participant.

Oh and Hsu (2001) examined the applicability of this model to gambling behavior by phoning 2,700 randomly selected potential participants and identifying "current gamblers" (i.e. individuals who reported gambling in the past 12 months). Using systematic probability sampling methods developed in previous research, Oh and Hsu (2001) identified and mailed questionnaires to 485 Iowan gamblers who agreed to 
participate in the study. The participants were enticed to participate by the possibility of winning a $\$ 100.00$ lottery prize. The study was a two-phase study.

The first phase of the study consisted of a self- administered questionnaire which assessed past gambling behavior, attitudes, social norms, perceived behavioral control (i.e., budgetary affordability, self-controllability, perceived gambling skills, time availability), and behavioral intentions. Three hundred fifty-two participants returned the questionnaire for a response rate of $73 \%$. In the second phase of the study, participants who returned the questionnaire were mailed a second questionnaire two months later so they could record changes in gambling behavior and attitudes. Two hundred twenty-six participants completed Phase II. This was a response rate of 64\%. Oh and Hsu (2001) conducted a path analysis to determine three things: (a) the ability of behavioral intentions, attitudes, and past behavior to independently predict behavior, (b) the ability of past behavior, attitudes, social norms, and perceived self-control to predict behavior intentions, and (c) the degree of inter-relatedness of the factors: past behavior, attitudes, social norms, and perceived self-control.

Past behavior and behavioral intentions had direct positive relationships with actual behavior. Past behavior, attitude, knowledge of social norms, and measures of behavioral self-control had direct positive relationships with behavioral intentions. The inter-relatedness among the factors was too low to moderate. This research fills an important void in our collective understanding of decision-making processes surrounding gambling behavior (Oh \& Hsu, 2001). It also moves towards an expansion of theoretically derived research agendas by integrating a social psychological theory of behavior and the applied assessment of gambling behavior. 


\section{Summary}

Theories of gambling behavior have largely focused on pathological, or problem gamblers. While there is some overlap in terms of the categories of theories and models described here, the basic typology used is similar to that of Rosenthal (1987) in that there are three major clusters of theoretical constructs. Variations in the motivations and characteristics of gamblers and in gambling activities themselves mean findings obtained in one context are unlikely to be relevant or valid in another (Dickerson, 1993, 1995). Therefore determining a theoretical approach to the study of gambling behavior that can be used in multiple settings is of major concern to the gambling research field. Gambling prevalence studies are examined in the next section of the literature review. In addition to determining which theoretical model is most useful when examining gamblers, many researchers have focused on the prevalence of gambling problems. It is important to know the nature of the problem, so examining the prevalence rates of college students will enable the researcher to determine the extent of gambling problem in the current study.

\section{Prevalence of Pathological Gambling}

\section{Prior Research}

Prevalence studies of pathological gambling began in the 1970s, as increasing numbers of states legalized gambling activities (Sullivan, 2001). Prevalence refers to the proportion of individuals in a population with a particular characteristic at a given time (Liljequist, 2000). Prevalence figures are usually reported as estimates as it is not possible to gather information from every member of a population (Liljequist, 2000). 
Estimating prevalence is a complex task with a variety of conceptual issues (Shaffer \& Hall, 1997). Scientists adopt strategic and tactical plans, based upon the principles of the scientific method, to generate a prevalence estimate (Shaffer \& Hall, 1997). Investigators usually report prevalence estimates of disordered gambling by providing a single number (Shaffer \& Hall, 1997). Single estimates are the simplest and often most attractive method of providing an index of prevalence (Shaffer \& Hall, 1997). Moreover, a range estimate of prevalence is more important than a single estimate. Range estimates provide a measure of confidence around the prevalence index. In the case of a prevalence estimate, a confidence interval identifies where a domain within a distribution of sample populations resides (Shaffer \& Hall, 1997).

Prevalence rates are calculated by dividing the number of respondents experiencing disordered gambling by the number of respondents in the study. Expressing the prevalence rate as a percentage of the population being studied, when answering a specific question is a standard practice in epidemiological research. Another method of calculating prevalence rates is to divide the number of respondents experiencing disordered gambling by the number of respondents who are at-risk for developing disordered gambling. This conceptualization of prevalence is based on the premise that if one never gambles, there is no active or practical risk of becoming a pathological gambler (Shaffer \& Hall, 1997).

Goodman (1995) estimated the prevalence of problem gamblers ranges from 1.5 to as high as $6.5 \%$ in the United States based on his research with the South Oaks Gambling Screen (SOGS). Goodman (1995) states higher prevalence rates are related to higher availability of gambling facilities. Shaffer and Hall's (1997) meta-analysis of 
pathological gambling youth in North America suggested prevalence rates to be between $4.4 \%$ and $7.4 \%$ of youth, age 13 to 20 . The National Research Council (NRC, 1999), designed to assist the U.S. National Gambling Impact, estimated the rate of pathological gambling among youth ranged from $1.2 \%$ to $11.2 \%$, within a median of $5.0 \%$.

Shaffer and Hall's (1997) study revisits the original effort to integrate the extant research on disordered gambling prevalence and examines two hypotheses regarding the extant of disordered gambling. First, prevalence estimates of gambling disorders among different population segments (e.g., adolescent and adult) will be significantly different. Secondly, the prevalence of gambling disorders will have increased since the first estimate was promulgated more than two decades ago; however, this increase will vary for different levels of disorder and different population segments.

Shaffer and Hall (1997) compared 180 distinct prevalence studies of disordered gambling. The prevalence estimates in this study identified four population groups: adult general population ( $n=66)$; adolescents $(n=32)$; college students $(n=19)$ and adults in prison or in treatment for psychiatric or substance use disorders $(n=22)$. These four categories include prevalence estimates for 139 studies. The remaining studies could not be classified into these categories. Of the 139 studies, $74.1 \%$ were conducted in the United States $(n=103)$ and $25.9 \%$ were conducted in Canada $(n=36)$. A comparison of the prevalence rates between Americans and Canadians revealed no significant differences.

Of the 139 prevalence estimates identified in this study, 65.8\% $(n=91)$ were unpublished. Methodologists have posited the findings of published research may differ significantly from those of unpublished research (Shaffer and Hall, 1997). Z-scores 
measured standardized prevalence rates of all the studies. T-tests revealed no significant differences between published studies and unpublished studies. To identify any significant trends in prevalence estimates over time, Shaffer and Hall (1997) investigated correlations between prevalence estimates and the year studies were conducted within each population segment. Analyses of adolescent, college, and treatment/prison studies revealed no significant patterns, however, there was a significant positive correlation between the year a study was conducted and past-year Level III gambling prevalence in adult studies $(r=.313, p<.05)$ (Shaffer \& Hall, 1997).

Shaffer and Hall (1997) examined the prevalence trends among adult studies in more detail by identifying states and provinces that met the following criteria: a) two or more state or province-wide prevalence studies had been conducted among the adult general population in the geographic area; b) studies conducted during different years; and c) the studies used the same instrument. Fifteen geographic areas met the criteria. Paired $t$-tests matching each earlier study to the corresponding later study in the same geographical area indicated later studies had significant higher prevalence estimates of past-year Level III gambling $(M=1.35)$ than earlier studies $(M=1.02) ;(t=-2.57, d f=$ $10, p<.05)$.

Kruskal-Wallis tests revealed significant differences in lifetime Level III and Level II prevalence estimates among population segments $(\chi 2=53.105, d f=3, p<.001)$ and $\left(\chi^{2}=29.151, d f=3, p<.001\right)$, respectively (Shaffer \& Hall, 1997). Dunnett's C tests for post-hoc analyses, assuming unequal variance, revealed for the following group differences: for lifetime Level III estimates, the estimate among adult general population studies was significantly lower $(p<.05)$ than estimates among adolescent studies, college 
students, and adult treatment/prison studies. The estimates of Level III lifetime gambling among adolescent studies were significantly lower $(p<.05)$ than the estimates among adult treatment/prison studies. College students also evidenced a significantly lower $(p<$ .05) Level III lifetime gambling estimate than adult treatment/prison studies. For Level II lifetime gambling estimates, adult studies evidenced significantly lower $(p<.05)$ prevalence than adolescent studies and adult treatment/prison studies. There was insufficient data to compare studies for past-year prevalence.

This new analysis supports previous findings: prevalence estimates among adolescents are significantly higher than estimates among adults for Level II and Level III gambling for both lifetime and past-year time frames. This study supports earlier estimates of disordered gambling suggesting that population segments vary and that an individual's likelihood of experiencing disordered gambling is dependent in part upon their personal attributes, including clinical circumstances (Shaffer \& Hall, 1997). Youthful age appears to increase the chance of experiencing gambling-related problems. Estimating prevalence is a dynamic process. According to Fisher (2000), prevalence rates are a function of several variable factors that make variation inevitable from study to study. These variable factors include location, date, age of respondents, and the measuring instrument. Researchers have little control over location, age of the respondents, and date. The source of funding determines the location and date. The age range is likely a reflection of the structure of the study. The researcher does, however determine the measuring instrument to be used to analyze the data. 


\section{Summary}

It is important to measure the prevalence rates of college student gamblers. This section of the literature review explored how prevalence rates of pathological gamblers are determined and how they differ across populations. Prevalence rates have been determined to be variable across age groups. In order to determine prevalence rates, researchers need accurate measures to classify gamblers. The next section in this literature review describes the existing measuring instruments for assessing problem gambling.

\section{Existing Measuring Instruments}

\section{South Oaks Gambling Scale}

Ten years ago a published critical review of existing literature indicated only two instruments for measuring problem or pathological gambling (Volberg \& Banks, 1990). Today there are more than 20 measuring instruments used to identify problem gambling. The South Oaks Gambling Screen (SOGS) has been the most widely used measure of gambling problems in the literature, both for the assessment of clinical populations and in the general population (Govoni, Frisch, \& Stinchfield, 2001). The South Oaks Gambling Screen is arguably the only gaming measure that has been validated and tested for reliability. The South Oaks Gambling Screen is based on the Diagnostic Statistical Manual-III criteria, but has been modified to avoid the Diagnostic Statistical Manual-III criteria's focus on late stage symptoms (Lesieur \& Blume, 1987).

Lesieur and Blume (1987) developed the South Oaks Gambling Screen in the mid-1980s. The South Oaks Gambling Screen is a 20-item paper-and-pencil instrument used to screen for pathological gambling. A cut score of five indicates the respondent is 
a probable pathological gambler. The content of the South Oaks Gambling Screen includes items that inquire about hiding evidence of gambling, spending more time or money gambling than intended, arguing with family members about gambling, and borrowing money from a variety of sources to gamble or pay gambling debts (Govoni et al., 2001).

The original developmental study of Lesieur \& Blume (1987) found the South Oaks Gambling Screen demonstrated satisfactory reliability and validity in four different samples, including Gamblers Anonymous members $(n=213)$, university students $(n=$ 384), psychiatric hospital patients $(n=867)$, and hospital employees $(n=152)$.

Reliability was estimated through combining the three samples and computing internal consistency $($ Cronbach's alpha $=.97)$. One-month test-retest reliability was computed on the South Oaks Gambling Screen dichotomous classification of probable pathological gambler versus non-probable gambler with 74 inpatients and 38 outpatients $(r=.71, n=$ 112).

Validity was examined by correlating the South Oaks Gambling Screen with counselor's and family members' independent assessments and Diagnostic Statistical Manual-III-R diagnosis for pathological gambling. The South Oaks Gambling Screen was correlated with counselor independent assessments $(r=.86)$, family member assessments $(r=.60)$, and Diagnostic Statistical Manual-III-R pathological gambling diagnosis $(r=.94)$. In terms of classification accuracy, the South Oaks Gambling Screen was compared to Diagnostic Statistical Manual-III-R diagnosis of pathological gambling and demonstrated satisfactory classification rates among Gamblers Anonymous members (98.1\%), university students (95.3\%), and hospital employees (99.3\%). 
Since its development, the South Oaks Gambling Screen has been used for a variety of purposes and populations, but beyond the original development, little systematic research has been conducted on the psychometric properties of the South Oaks Gambling Screen under these varying conditions of use (Govoni et al., 2001). The metaanalysis conducted by Shaffer and Hall (1997) contained 152 studies of which over half used the South Oaks Gambling Screen as the measuring instrument. Several changes and modifications have been made to the South Oaks Gambling Screen over the past ten years. The changes from the Diagnostic Statistical Manual-III to Diagnostic Statistical Manual-IV included significant revisions of the criteria, an increase from nine to ten criteria, and the cut score was raised from four to five (Govoni et al., 2001).

Lesieur and Blume (1993) reviewed the various modifications of the South Oaks Gambling Screen and provided suggestions as to their suitability. They suggested the initial questions, which ask about the type of gambling practices of the jurisdiction where the screen is being used should help the subjects define the concept of gambling before proceeding to the remainder of the measuring instrument. The original South Oaks Gambling Screen is based on lifetime gambling activity and does not differentiate pathological gamblers in remission from active pathological gamblers. Lesieur and Blume (1993) suggested the South Oaks Gambling Screen may be modified to cover a six-month or one-year time frame to identify active pathological gamblers.

The South Oaks Gambling Screen has recently been validated for a one-year time frame and was found to have satisfactory reliability and validity for this time frame (Stinchfield, 2001). In this study, the South Oaks Gambling Screen was administered to a general population sample $(N=803)$ and a gambling treatment sample $(N=1,589)$. 
The South Oaks Gambling Screen demonstrated satisfactory reliability with alpha $=.69$ in the general population and alpha $=.86$ in the gambling treatment sample. The South Oaks Gambling Screen demonstrated satisfactory validity in both samples with correlations between the South Oaks Gambling Screen and the Diagnostic Statistical Manual-IV criteria of .77 and .83 in the general population and treatment samples, respectively. Correlations with other gambling severity measures (e.g., Diagnostic Statistical Manual-IV diagnostic criteria, gambling frequency) in the gambling treatment sample were moderate to high ranging from .33 to .65 .

Using the Diagnostic Statistical Manual-IV criteria as the criterion, the South Oaks Gambling Screen showed satisfactory classification accuracy in the gambling treatment sample with a high hit rate $96 \%$, high sensitivity $99 \%$, modest specificity $75 \%$, and low false positive $4 \%$ and low false negative rates $10 \%$. The South Oaks Gambling Screen showed poorer classification accuracy in the general population with the modest sensitivity rate of $67 \%$ and a high false positive rate of $50 \%$ (Stinchfield, 2001). The South Oaks Gambling Screen overestimated the number of pathological gamblers in the general population, as compared to DSM-IV criteria (Govoni et al., 2001).

Ladouceur, Bouchard, Jacques, Ferland, Leblond, and Walker (2000) examined the accuracy of the South Oaks Gambling Screen in terms of how well children, adolescents, and adults understand the items and the effect of misunderstanding the scores. Ladouceur et al. (2000) found most participants misunderstood some South Oaks Gambling Screen items and which led the respondent to endorse the misunderstood items and resulted in higher South Oaks Gambling Screen scores. The clarification of 
misunderstood items had the effect of reducing the number of respondents classified as probable pathological gamblers (Govoni et al., 2001).

Gamblers Anonymous 20 Questions

Another widely used measuring screen is the Gamblers Anonymous 20 Questions (GA20). The GA20 use 20 questions for the purpose of identifying compulsive gamblers (Govoni et al., 2001). A score of seven or higher indicates the respondent is a compulsive gambler. The items address behaviors related to compulsive gambling, such as remorse over gambling, gambling to forget problems, borrowing money to gamble, difficulty sleeping, etc. Rosenthal (1987) found six out of twelve professionals used the GA20 in their assessment work. Although the GA20 is widely used, there is little psychometric and classification accuracy information available.

Ursa and Uribelarrea (1998) note that there is no published report describing the development of the GA20 and only two studies report any psychometric information. In terms of validity, Kuley and Jacobs (1998) reported that the GA20 yielded high correlations with frequency of gambling and with dissociate experiences. Derevensky and Gupta (2000) used the GA20 as one of three instruments to classify adolescents $(N=$ 980) in a study of comparative diagnosis. They reported the GA20 was significantly correlated with the South Oaks Gambling Screen-Revised Adolescents $(r=.61)$ and the Diagnostic Statistical Manual-IV-Juveniles $(r=.68)$. The Gamblers Anonymous 20 demonstrated satisfactory classification accuracy, using the Diagnostic Statistical Manual-IV-Juveniles as the standard, with the following rates: true positive (96\%), false negative $(0.6 \%)$, and false positive (3.3\%). 
Ursua and Uribelarrea (1998) conducted a study of the psychometric properties of the GA 20 in a sample of 127 problem gamblers who came for treatment at two self-help associations in Madrid, Spain and a normative sample of 142 non-problem social gamblers matched on age and gender with the problem gamblers. The internal consistency of the GA20, using Cronbach's coefficient alpha was .94, indicating high internal consistency. In terms of validity, the GA 20 was highly correlated with the SOGS $(r=.94)$, and the authors noted both instruments had a number of items that were virtually identical. A factor analysis revealed the GA 20 is a one-dimensional instrument with one factor accounting for over $50 \%$ of the variance.

The GA20 was found to clearly differentiate the problem gamblers from the nonproblem social gamblers and the classification accuracy indices were high, with a sensitivity of .98 , specificity of .99 , and hit rate of .99 . It should be noted that these classification accuracy indices are based upon a sample with a base rate of about $50 \%$ and this base rate tends to inflate classification accuracy indices.

\section{Diagnostic Statistic Manual IV Scale}

Fisher (2000) developed a new ten-item questionnaire to measure Diagnostic Statistical Manual-IV diagnostic criteria of pathological gambling in adults. There is one item for each criterion and the items are essentially paraphrased directly from the Diagnostic Statistical Manual-IV criteria. Most items have four response options: never, once or twice, sometimes, and often. Each yes response is scored as one point, and the scoring range is from zero to ten. A score of three to four, with at least one score being from items eight, nine, or ten, is classified as a problem gambler. A score of five or more with at least one score from items eight, nine, or ten, is classified a severe pathological 
gambler. The Diagnostic Statistical Manual-IV-MR was administered to 1,105 casino patrons in the United Kingdom. Internal consistency reliability was satisfactory with an alpha .79. In terms of validity, the Diagnostic Statistical Manual-IV-MR had significantly different mean scores between regular and non-regular gamblers and between selfidentified problem and social gamblers. Regular gamblers were those who visited casinos once a week or more often and non-regular gamblers visited casinos less often (Govoni et al., 2001).

Derevensky and Gupta (2000) compared the effectiveness of the Diagnostic Statistical Manual-IV-J, the Gamblers Anonymous 20, and the South Oaks Gambling Screen-RA. They found that the Diagnostic Statistical Manual-IV-J identified 3.4\% of the population studied as probable pathological gamblers, the South Oaks Gambling Screen-RA identified $5.3 \%$ of the population as probable pathological gamblers, and the GA20 identified $6 \%$ of the population as probable pathological gamblers.

Derevensky and Gupta (2000) found correlations to be in the moderate range (.61 - .68), with the correlations being higher for males (range: .75 - .84) than females (range: $.31-.50)$, an expected finding given the lower variability of severity in female gambling problems. The Diagnostic Statistical Manual-IV and the GA20 each contain unique criteria. Derevensky and Gupta (2000) found the two most endorsed items on the Diagnostic Statistical Manual-IV-J refer to preoccupation with gambling and lying about gambling activities, whereas the GA20 contained no similar items. A direct comparison of the Diagnostic Statistical Manual-IV-J, South Oaks Gambling Screen-RA, and the GA20 revealed a fairly high degree of agreement between the measures, with relatively small classification error (Derevensky \& Gupta, 2000). The South Oaks Gambling 
Screen-RA addresses the issues of relationships with parents and friends, while the GA20 places a greater emphasis on monetary issues.

Cox, Enns, and Michaud (2004) conducted a study to compare two forms of assessment for determining gambling problems in a community survey and to examine the characteristics of respondents who endorsed Diagnostic Statistical Manual-IV symptoms but scored below the formal Diagnostic Statistical Manual-IV diagnostic cutoff for pathological gambling. The researchers interviewed 1,489 Winnipeg adults by phone (response rate 70.5\%) using the South Oaks Gambling Screen (SOGS), a Diagnostic Statistical Manual-IV-based instrument, and several gambling related variables (Cox et al., 2004). The study included 715 men and 774 women with a mean age of 44.1 years $(S D=17.2)($ Cox et al., 2004).

Interviewers asked respondents whether they were involved in one or more types of gambling activities in their lifetime (Cox et al., 2004). When respondents answered yes to at least one of ten different types of gambling queried, interviewers asked a series of questions relating to gambling behavior (e.g., motivating factors and family history of gambling problems) similar to those used in previous gambling studies (Cox et al., 2004). Interviewers also administered the 20 -item South Oaks Gambling Screen and a Diagnostic Statistical Manual-IV interview previously developed in research. The interview assessed the ten Diagnostic Statistical Manual-IV symptoms for pathological gambling (Cox et al., 2004).

Of the total sample $(n=1,489), 1,320$ participants $(88.7 \%)$ reported at least one episode of gambling in their lifetime. According to South Oaks Gambling Screen-based scores, $6.1 \%$ of the participants were either probable or problem pathological gamblers. 
According to Diagnostic Statistical Manual-IV-based criteria of five or more symptoms for pathological gambling, lifetime prevalence in the total sample was $1.3 \%$ (Cox et al., 2004). A further $6.6 \%$ had symptomatic or sub-threshold pathological gambling (Diagnostic Statistical Manual-IV symptom scores of one to four) (Cox et al., 2004).

The correlation between SOGS items and Diagnostic Statistical Manual-IV symptoms was high, both for lifetime $(r=.81)$ and past-year $(r=.79)$ versions (Cox et al., 2004). At an individual level, most of the South Oaks Gambling Screen items were at least moderately correlated with the Diagnostic Statistical Manual-IV total scores (Cox et al., 2004). Over $91 \%(n=1202)$ of the participants scored a zero. This score represented recreational gambling.

As in previous studies, the researchers found no significant differences between problem and non-problem gamblers concerning forms of gambling that have been common to society. Most respondents did not report having a parent with a gambling problem. This finding is consistent with the likely increase in gambling-related problems in recent years that accompanied gambling expansion (Cox et al., 2004).

\section{National Opinion Research Center DMS Screen for Gambling Problems (NODS)}

The National Opinion Research Center DSM Screen for Gambling Problems, or NODS was developed in 1998. The purpose for the development of this measuring instrument was to be more restrictive in measuring problem gamblers than the South Oaks Gambling Screen. The NODS is asked of only individuals who report to gamble more than $\$ 100.00$ per day. The NODS has 17 items each answered dichotomously. A score of five or more represents pathological gambling characteristics. 
In developing the NODS, a field test examined its performance in a clinical sample prior to adopting it in a national study. Outpatients $(N=40)$ were surveyed by telephone. Thirty-eight of those individuals (95\%) scored five or more on the lifetime NODS. A diagnosis of a problem or pathological gambler requires a score of five or more. The other two cases scored four on the NODS. Scores on past-year NODS were lower with 30 of the 40 respondents scoring five or more, five respondents scored three to four, and the remaining five respondents scored zero to two. Both the lifetime and pastyear scores on the NODS were highly reliable. The lifetime test statistic $(r=.99)$ and the past-year statistic $(r=.98)$ were well above the .80 considered desirable for overall testretest agreement.

\section{Gambling Problem Index}

Neighbors, Lostutter, Larimer, and Takushi (2002) surveyed 560 undergraduate college students with three gambling outcome measures. One of these measures was the Gambling Problem Index (GPI). The GPI is a 20-item self-report survey measured on a five-point Likert-type scale with one anchor being "if things never happen" and the other end being "if it happens more than ten times".

The GPI was closely modeled after the Rutgers Alcohol Problem Index (RAPI) of White and Labouvie (1989). For each item respondents were asked to indicate, on a fivepoint scale (never, one to two, three to five, six to ten, and more than ten times), how many times during the previous six months they experienced a negative consequence while gambling or as a result of gambling (Neighbors et al., 2002).

The GPI was internally consistent $($ alpha $=.84)$ and demonstrated good convergent validity. The GPI was conceptualized as a general index of problems 
manifested as a result of gambling behavior (Neighbors et. al., 2002). The GPI displayed similar factor structure to the RAPI, with six factors having Eigenvalues above one. Convergent validity of the GPI was established through correlations with other gambling outcome measures including the GABS, which ranged from .39 to .61 . The researchers felt the GPI could be used as an excellent source for generating such feedback for gambling intervention (Neighbors et al., 2002).

\section{Summary}

It is important when choosing the correct measuring instrument to study all the possible options to determine the best fit for the present study. There were five scales discussed in the literature review. For the purposes of this study, the researchers chose to use the South Oaks Gambling Screen (Lesieur \& Blume, 1987). This measuring instrument has shown reliability and validity in many studies across the United States and Canada, including studies involving college students (Lesieur et al., 1991). By choosing this measuring instrument the researchers hope to gain insight to the behaviors of gamblers. The next section in the literature review pertains to proximity and its impact on gambling behavior.

\section{The Impact of Proximity}

Increasing the number of opportunities to gamble can be detrimental (Kassinove, 1998). Little research has been conducted about the connection between accessibility and problem gambling. Eadington (1989) and Lesieur (1992) suggest a casual link between U.S. problem gambling rates and increased accessibility however, others have doubted this notion. Whyte (1997) from the American Gaming Association notes: 
Contrary to the rhetoric of gaming opponents, increased availability of gaming does not lead automatically to an increase in problem gambling...the actual survey evidence is mixed, as some problem gambling rates have increased or stayed the same, and some have actually declined after the expansion of gambling. For example, a recent Connecticut survey showed a decrease in pathological gambling from $2.7 \%$ in 1991 to $1.2 \%$ in 1996, similar to a South Dakota survey, which found a decrease in prevalence from 1989 to 1991. In both cases there were major expansions in gambling availability between the survey dates (p. 5).

Two studies of problem gambling in Alberta, Canada, add a further twist (AADAC, 1998). The 1994 study found a prevalence rate of 5.4\% "problem gamblers" (based on SOGS 3+), which fell to 4.8\% in the replication study in 1998. However, the prevalence of what was termed "probable pathological gambling" (based on SOGS 5+) increased from $1.4 \%$ to $2 \%$.

In the U.S., much of the gambling centers in casinos, which are located along state borders to attract interstate visitors. A number of U.S. studies have attempted to examine accessibility and prevalence using bigger datasets or more novel methods. Volberg (1994) compared prevalence rates of problem gambling among five U.S. states with differing levels and histories of accessibility, and found those with a longer history of legally available gambling had higher levels of problem gambling. The National Research Council (1999, p. 249) examined replications studies in the United States and found:

There are very few studies that permit an assessment of whether the 
prevalence of problem and pathological gambling is associated with changes in the availability of legal gambling. The nature of the changes observed in those studies, however, was consistent with the view that increased opportunity to gamble results in more pathological and problem gambling. In states where gambling has been available for ten years, $0.5 \%$ of the population was found to be "probable pathological gamblers," whereas states in which gambling had been available for 20 years, $1.5 \%$ of the population were identified as "probable pathological gamblers." A meta-analysis of 34 studies of gambling problems among adults in North America from 1977 to 1997 (Shaffer \& Hall, 1997) suggested problem gambling has increased over time as gambling opportunities have multiplied in the U.S. This trend suggests a link between accessibility and gambling problems, but other factors may also play a part.

The final report of the U.S. National Gambling Impact Study Commission (Gerstein et al. 1999) used a large micro dataset to examine the link between location and the prevalence of problem gambling. They found the availability of a casino within 50 miles (versus 50 to 250 miles) is associated with approximately double the prevalence rate of problem and "pathological gamblers." While this pattern was apparent for the combined dataset, a contrary pattern was obtained for the telephone survey for the key "pathological" gambling measure. Overall, this data provides a tentative finding about the link between proximity to casinos and gambling problems. Campbell and Lester (1999) found a positive and significant link between a measure of the prevalence of problem gambling in parishes in Louisiana and the density of video poker machines. However, their simple method explained only about $17 \%$ of the variation in problem gambling. 
Finally, a unique natural experiment into the effect of gambling machines on gambling problems was provided by the experience of South Dakota. The South Dakota Supreme Court ordered all of the state's video gambling machines shut down in August 1994. Other forms of gambling were not affected by the Court's order. A three-month lull in playing video gambling machines occurred. A referendum in November 1994 legalized the games again. Inquiries to four problem gambling treatment centers in South Dakota fell dramatically from 68.1 per month to 9.7 per month during the ban, before rising to 24 per month after the ban was lifted (Carr et al., 1996). This result also suggests a link between availability of certain forms of gambling and the incidence of gambling problems.

The potential link between accessibility and problem gambling is a key policy issue. The evidence as a whole points to a positive link between the availability of gambling opportunities and problem gambling. Accessibility is not just about proximity, but it is also about the mass appeal and ease of use of gambling venues. The research suggests problem gambling tends to be highest in areas where accessibility is highest. Accessibility has a number of dimensions, which may affect problem gambling. These dimensions include: (a) total number of gambling opportunities; (b) how gambling opportunities are arranged spatially is very important to accessibility; (c) conditions of entry into the gambling opportunity; (d) location of the gambling opportunities; (e) hours of operation of gambling venues; (f) social accessibility; (g) ease of use; and (h) initial outlay of the gambling participant.

In a recent study by Engwall, Hunter, and Steinberg (2003) the interaction of gambling and problem gambling with other risk taking behaviors in students attending 
college in a pro-gambling culture with many gambling opportunities was examined. In Connecticut, the lottery is available in approximately 2,900 locations, pari-mutuel wagering is available at various sites across the state, and two major tribal casinos are located in the southeastern part of the state. Starting in 1988, the Connecticut State University (CSU) survey project was used to assess student health behaviors at four campuses. To reflect differing enrollments at each campus, 500 students were targeted at Central Connecticut State University (CCSU), 500 students at Southern Connecticut State University (SCSU), 300 students at Western Connecticut State University (WCSU), and 200 students at Eastern Connecticut State University (ECSU). Of the 1,500 surveys, 1,348 were used in the data analysis. This study reported a $90 \%$ response rate. The participants were $64 \%$ female, $50 \%$ aged $18-20$ and $35 \%$ aged $21-25$.

The survey contained 120 items dealing with demographics, drug usage, binge eating, and gambling. A shortened version of the SOGS was used, because of the length of the survey. The revamped SOGS was labeled SOGS-CT and contained ten items. When the scores were calculated, $53 \%$ of the students $(n=1,301)$ had a score of zero. Scores from zero to one were considered social gamblers. As in the previous literature, the rate of problem gambling and pathological gambling was higher for men than women. Ten gambling options were included in the survey. Overall, men and women played the lottery more than any other form of gambling. Social gamblers showed preferences for lottery (62\%), casino games (46\%), slot/poker machines (42\%), and playing card games (38\%). Social gamblers used significantly fewer venues $(M=3.2)$ than the pathological gamblers $(M=6.1)$. Paired comparisons using the Scheffe Test confirmed this significant difference but showed no significant difference between the problem and 
pathological gamblers (Engwall et al., 2003). Social gamblers were not frequent gamblers in any venue. Pathological gamblers were about twice as likely as problem gamblers to frequent all the venues.

\section{Summary}

Research has suggested the relationship between proximity of gambling opportunities and gambling participation. Within the setting of this study, four distinct types of gambling exist, (pari-mutuel wagering, casino-style gambling, lottery play, and charitable gaming). Although not a priority for this study it is possible that the proximity of these existing gambling opportunities will impact the behaviors of college students. Further research is needed to establish the link between these opportunities and behaviors of college students, in particular college student-athletes. The next section of the literature review deals with gambling motivations.

\section{Gambling Motivations}

\section{Possible Motives}

In addition to trying to assess problem gambling, researchers have been interested in identifying gambling motives. Neighbors et al. (2002) surveyed 184 undergraduate college student gamblers, enrolled in first-year psychology classes at a large northwestern university in the United States. This survey was designed to assess motivation for gambling among college students without imposing a predefined set of motives (Neighbors et al., 2003). The mean age of the participants was 19.4 years. The sample was ethnically representative of the campus. The participants completed the questionnaire in mass testing format. The questionnaire included items measuring demographics, gambling motivations, and the SOGS. 
Seventy-nine (45.6\%) participants were non-problem gamblers, $72(41.6 \%)$ had minimal problems, 16 (9.3\%) were level II sub clinical gamblers, and six (3.5\%) were level III probable gamblers (Neighbors et al., 2003). Participants were asked to "think about what motivates you to gamble and briefly list the five top reasons in rank order (e.g., 1: the most important reason, 2: the second most important reason)." Participants varied in the number of reasons $(M=4.11, S D=1.13)$. Responses were qualitatively analyzed to categorize the 766 reasons given by participants (Neighbors et al., 2003). An initial qualitative analysis of responses yielded 16 distinct motives that captured the majority of the reasons listed by respondents (Neighbors et al., 2003). The following motives were identified:

(a) Money: Gambling to make or obtain money (e.g., "make money," "win money," and "get rich").

(b) Enjoyment/Fun: Gambling for enjoyment or just to have fun (e.g., "to have a good time", "its enjoyable", and "it's fun").

(c) Excitement: Gambling for arousal, thrill, or excitement. (e.g., "for the rush "excitement", and "it's exciting").

(d) Social: Gambling as a means of interacting with friends or family, or to meet new people (e.g., "social interaction", "to be with friends", and "to socialize").

(e) Occupy time/Boredom: Gambling to occupy time, to have something to do, or to alleviate boredom (e.g., "something to do", "past time", and "bored"). 
(f) Winning: Gambling to experience winning (e.g., "victory", "winning", and "just to win").

(g) Competition: Gambling to compete with others (e.g., "to bet someone else", "competition", and "compete with friends").

(h) Conformity: Gambling because others are doing it, just to go along with the crowd, or because of peer pressure (e.g., "peer pressure", "because friends are doing it", and "friends decide to go gamble, so I just go along").

(i) Risk: Gambling in order to take risks or experience uncertainty (e.g., "feel like doing something risky", "risk taking", and "the risk of losing”).

(j) Skill: Gambling to develop or practice one's skills or to learn (e.g., "show skills", "learn games", and "practice strategies").

(k) Interest: Gambling because it is interesting or adds interest (e.g., "it's interesting", "friendly bets make a game/event more interesting", and "makes playing cards interesting").

(1) Coping: Gambling in order to escape or to cope with problems, depression, or anxiety (e.g., "release from stress", “avoid responsibility", and "to shut the world out").

(m)Challenge: Gambling to experience a challenge (e.g., "it is challenging", "I enjoy a challenge" and "challenge").

(n) Drinking: Gambling motivated by alcohol (e.g., "free drinks", "something to do when drinking", and "drink liquor"). 
(o) Luck: Gambling to test one's luck or because one feels lucky (e.g., "luck", "test your luck", and "feel lucky").

(p) Chasing: Gambling to win back previous losses (e.g., "to get my money back", "to pay back what I lost", and "chance of getting your money back").

Source: Neighbors et al., 2003 p. 365.

Five coders were provided descriptions for each of the 16 motives and each participant was instructed to classify each of the 766 responses as a single motive where possible but could select more than one category if clear determination for a single category could not be made (Neighbors et al., 2003). In examining all reasons for gambling, money, enjoyment, social, excitement, and boredom motives constituted slightly more than $70 \%$ of the respondents' reasons for gambling (Neighbors et al., 2003). After applying Bonferroni corrections for multiple comparisons, there were no significant relationships between motives and SOGS scores (Neighbors et al., 2003).

Results from this study indicated most college students gamble to win money, for fun, for social reasons, for excitement, or just to have something to do (Neighbors et al., 2003). This study suggests motivations for gambling are not necessarily unique to specific segments of the population (Neighbors et al., 2003). The scope of motives reported in this study supports the notion that comprehensive etiological approaches to gambling must be integrative and accommodate multiple perspectives (Brown, 1987). Reasons for gambling in this study were relatively consistent with other studies that used checklists to determine motivations for gambling.

\section{Gambling Motivation Scale}


Chantal, Vallerand, and Vallieres (1994) created and tested the Gambling Motivation Scale (GMS) in Quebec, Canada, as a way to quantify the gamblers' motivations to participate in various games of chance. They based their development of the GMS on Deci and Ryan's (1985) self-determination theory. Chantal and Vallerand (1996) used the GMS to contrast levels of motivation for participants in games of skill (horse racing) and games of luck (lottery). Players of games of skill scored significantly higher on measures of self-determined motivations than players of games of luck.

The self-determination theory identifies three general motivational orientations: a controlled orientation, an autonomy orientation, and an impersonal orientation (Deci \& Ryan, 1985a). Impersonal orientation is associated with amotivation and learned helplessness. Controlled and autonomy orientations measure independent aspects of selfdetermination (Deci \& Ryan, 1985a). The controlled orientation involves basing behaviors on contingencies, pressures, and characteristics of the environment and is a negative indicator of self-determination (Deci \& Ryan, 1985a). Autonomy orientation is a positive indicator of self-determination and is associated with experiencing choice and basing behaviors on personal interests and integrated values (Deci \& Ryan, 1985a). Controlled orientation is associated with basing self-worth on external determinants, such as wealth (McHoskey, 1999) and responding to challenges and negative feedback from the environment in an ego-defensive manner (Koestner \& Zuckerman, 1994; Neighbors, Vietor, \& Knee, 2002). Autonomous individuals tend to view feedback as useful information and are thus likely to become ego-involved based on outcomes (Deci \& Ryan, 1987, 1991; Koestner \& Zuckerman, 1994). 
Chantal et al. (1994) conducted a study to test if participants who exhibited a high self-determined motivational profile would report a higher degree of gambling involvement. The study involved gamblers $(N=245)$ who bet on horse racing. The study viewed gambling as a motivational consequence, positing that motivation leads people to become involved in gambling and to invest considerable amounts of time and money in betting (Chantal et al., 1994). The researchers reasoned if motivation was defined as the internal and/or external force that triggers, directs, intensifies, or leads to the persistence of a behavior, a theory that adequately addresses gambling motivation would help delineate gamblers' motivational orientation and thus clarify how gamblers interact with their environment (Chantal et al., 1994).

Three types of gambling motivation have been identified from the development of the GMS (Chantal et al., 1994): intrinsic motivation (IM), extrinsic motivation (EM), and amotivation (AM). IM consists of three facets (a) towards knowledge via learning, exploring or trying to understand something new, (b) towards accomplishment of things such as improving one's skills in a betting activity, and (c) towards stimulation or excitement (Clarke, 2004). EM involves receiving or avoiding something on termination of an activity, it also consists of three facets: (a) gambling for rewards (external regulation), (b) gambling for release of tension and guilt (introjected regulation), and (c) gambling for certain internal values such as wanting to be dynamic and important in the eyes of others (identified regulation) (Clarke, 2004). AM occurs when one does not perceive relations between one's own actions and gambling outcomes, and pertains to activities that are neither intrinsically nor extrinsically motivated, and is a characteristic 
of gamblers who have lost their sense of choice and control over their betting habits (Chantal \& Vallerand, 1996).

Chantal et al.'s (1994) study predicted the self-determination theory could be used as a conceptual framework. Intrinsic motivation stems from the satisfaction of two needs, a need to feel self-determined and a need to be competent in one's environment. Intrinsic motivation to experience stimulation is exemplified by gamblers who bet for fun and excitement (Chantal et al., 1994). Gamblers find pleasure and satisfaction in surpassing themselves in the course of their betting activities (Chantal et al., 1994). This reasoning suggests people who have a high self-determined motivational profile gamble because the inherent characteristics of gambling offer excitement, an opportunity to acquire knowledge, and a sense of accomplishment (Chantal et al., 1994).

All the participants in their study completed two measures: the GMS and a measure of gambling involvement (Chantal et al., 1994). The GMS contained 28 items representing potential answers to the question: "Why do you gamble?" The items were scored on a seven-point Likert-type scale anchored by the endpoints "does not correspond at all" at one and "corresponds exactly" at seven. The internal consistency values (Cronbach's alpha) of the seven subscales were as follows: .81 for intrinsic motivation to know, .78 for intrinsic motivation to accomplish, .73 for intrinsic motivation to experience stimulation, .64 for identified regulation, .80 for introjected regulation, .77 for external regulation, and .78 for amotivation (Chantal et al., 1994).

The study participants computed two numerical indexes, the Self-Determination Index (SDI) and the Gambling Involvement Index (GII). The SDI was calculated using the score of six GMS subscales and the following formula: 
$\{[2 x(I M$ to know $+I M$ to experience stimulation $/ 3]\}+($ identified regulation) [(external regulation $+(2 x$ amotivation $)]$

The Introjected Regulation Scale (IRS) was omitted because the distribution of the scores indicated there was a floor effect $(M d n=1.25)$, which would have artificially inflated the SDI scores (Chantal et al., 1994).

Gambling involvement was computed through the GII and summing $z$ scores of the five involvement items (numbers of years spent gambling, weekly gambling expenses, weekly visits to a racecourse, self-perception as occasional gambler/heavy gambler, and intent to continue gambling) (Chantal et al., 1994). An analysis of variance was performed on the GII scores. It was a 2 x 2 ANOVA comparing motivational profile by gender. The results of the ANOVA indicated that motivational profile had a significant main effect, $(F(1,237)=4.57, p<.05)$. There was a significant main effect for gender, $(F(1,237)=12.27, p<.001)$ with men reporting more involvement in gambling than the women $(M s=.37$ and 1.30, respectively) (Chantal et al., 1994). The motivational profile by gender interaction was not significant.

The results of this study indicated high self-determined motivational profile participants were more involved in gambling than low self-determined motivational profile participants (Chantal et al., 1994). This finding supports the hypothesis that motivation is a key determinant of gambling involvement. The results of this study are consistent with previous research suggesting that men gamble more than women (Chantal et al., 1994). 


\section{Sensation Seeking Scale}

Gambling is a risk-taking activity associated with subjective excitement, physiological arousal, and withdrawal symptoms (Blaszczynski, Wilson, \& McConaghy, 1986). The central feature of all gambling has been observed to be the subjective excitement or arousal it appears to engender (Boyd, 1976). Zuckerman (1979) developed the Sensation Seeking Scale based on the theory individual differences existed in need for optimal levels of stimulation or arousal. The relationship between arousal and chasing suggests arousal is a re-enforcer that may be an important determinant of loss of control (Blaszczynski, Wilson, \& McConaghy, 1986; Dickerson, Hinchy, \& Fabre, 1987). Zuckerman's Scale (1979) of Sensation Seeking makes explicit predictions concerning a person's preference for gambling.

Blaszczynski et al. (1986) tested the hypothesis that pathological gamblers seeking treatment have elevated scores on the Zuckerman's Sensation Seeking Scale and to investigate the relationship between their scores on that scale and the Eysenck Personality Questionnaire and Spielberger's State-Trait Anxiety Inventory. The respondents were 51 male pathological gamblers seeking therapy to reduce their gambling urge and behavior. The mean age was 34.55 years ( $S D=9.22$ years) ranging between 18 years and 61 years of age. There was a significant negative correlation between age and the Sensation Seeking Scale total score.

Dickerson, Hinchy and Fabre (1987) found lower than average Sensation Seeking Scale scores in a sample of non-treatment seeking off-course bettors. They suggested off-course betting is favored by low sensation seekers as high sensation seekers "might well prefer to choose from a wide range of sporting and social activities rather than bet in 
an off-course betting agency commonly set in a shopping center or playing poker machines in their local social club" (Dickerson, Hinchy, \& Fabre, 1987, p. 674). Kuley and Jacobs (1987) found problem gamblers scored significantly higher than social gamblers on the Sensation Seeking Scale total score and on the Disinhibition, Experience Seeking, and Boredom Susceptibility subscales.

Coventry and Brown (1993) studied two groups of subjects: a group of gamblers $(n=79)$ from off-course betting offices and a sample of the general population of the city of Glasgow, Scotland $(n=96)$. Participants completed a battery of questionnaires consisting of (a) Sensation Seeking Scale Form V, (b) demographic questions, (c) a fouritem subscale of the State-Trait Anxiety Inventory, (d) a version of the Awareness of Automatic Activity, (e) a question concerning chasing, (f) questions concerning betting behaviors, and (g) questions relating to cash involvement in betting, including size and amount of the bet. The sample came from eight off-course betting agencies in the Glasgow area, each selected to cover different types of location, to ensure a wide selection of bettors from different areas that included large and private offices. All the respondents were males.

The mean age of the respondents was 40.7 years $(S D=17.3)$ with ages ranging from 19 years to 74 years. Ninety-four percent reported gambling at least once a week. Of the betting samples, $34 \%$ reported themselves as never chasing; $26 \%$ as occasionally; $17 \%$ as usually; and nearly $23 \%$ as nearly always. All the respondents who returned the questionnaires completed the Sensation Seeking Scale. The mean total SSS score was $17.5(S D=7.96$, range 2-37), with mean subscale scores of 5.23 for the Trait Anxiety Scale $(S D=7.96$, range 0-10), 4.26 for Experience Scale $(S D=1.96$, range 0-9), 4.64 for 
Disinhibition Scale $(S D=2.73$, range 0-10), and 3.48 for Boredom Scale $(S D=2.24$, range 0-10). In accordance with previous research, a greater decline in age was observed for TAS and DIS than for ES and BS.

The study also found a preference among high sensation seekers for casino and racetrack gambling, which fits the general picture of the high sensation seeker (Coventry $\&$ Brown, 1993). The only statistical difference between off-course bettors and the general population was on the TAS subscale, which might suggest that low sensation seekers, especially, would shun the more dramatic and extravert form of sensation seeking and be more likely to choose off-course betting in a safe, well-controlled environment close to home (Coventry \& Brown, 1993).

\section{Venturesomeness and Impulsivity}

Similar to sensation seeking, some have suggested venturesomness and impulsivity are related to gambling behavior. While some may believe the venturesomeness and impulsiveness are the same thing, they are actually distinct. Moore and Ohtsuka (1997), noted venturesomeness, the desire to try some new, exciting activities was associated with risk-taking in sexual, smoking, driver, and passenger behaviors, whereas impulsiveness was not. In contrast, prior research found problem gambling was predicted by high impulsiveness and low venturesomeness (Moore \& Ohtuska, 1997). Eysenck and Eysenck (1991) described impulsiveness as the pathological aspect of risk-taking behavior, related to psychoticism and by implication to antisocial attitudes, with venturesomeness being true risk-taking and related to extroversion. Impulsive individuals do not look ahead at the consequences of their actions, while venturesomeness people show understand fully there is risk involved with 
their actions (Clarke, 2004). Thus, the personality traits of impulsiveness and venturesomeness should be considered separately when looking at sensation-seeking in terms of problem gambling behavior (Clarke, 2004).

On the basis of the relationships between impulsiveness, venturesomeness, motivations, and locus of control it would be expected that problem gamblers would have higher impulsiveness and extrenal locus of control (Clarke, 2004). Problem gamblers would also have greater motivation towards stimulation and amotivation than nongamblers (Clarke, 2004). Moore and Ohtsuka (1997) found in contrast, venturesomeness, internal locus of control, and internal motivation towards knowledge and accomplishment would be expected to be lower for problem gamblers than for non-problem gamblers.

Clarke (2004) proposed to compare non-problem gamblers and problem gamblers on psychological variables. He administered a gambling questionnaire to a class of introductory psychology students $(N=147)$ at the Albany campus of Massey University. The sample consisted predominately of young, female, Caucasian adults with moderate to high socioeconomic status. Ladouceur et al (1997) stated despite not having a representative sample, it was possible to examine the relationships among the psychological variables that are relevant to problem gambling. The questionnaire consisted of seven sections: demographics, gambling behavior, problem gambling and parents' gambling, depression, impulsiveness and venturesomeness, locus of control, and gambling motivation.

Gamblers were divided into three groups according to their scores on the South Oaks Gambling Screen. Problem gamblers were compared to non-problem gamblers on gambling frequency, number of gambling activities, the psychological variables of 
depression, impulsiveness, venturesomeness, three locus of control factors, and the seven aspects of motivation. To test the hypothesis about differences between problem gamblers and non-problem gamblers, a one-way MANOVA revealed significant differences, $(F(15,131)=4.34, p<0.001)($ Clarke, 2004). Problem gambles had significant higher mean scores on gambling frequency, number of activities, depression, and impulsiveness, but venturesomeness scores were not significantly lower as predicted (Clarke, 2004).

Lightsey and Hulsey (2002) said impulsive persons may behave with a lack of restraint or reflectiveness and may be less likely to use planning and other forms of adaptive coping. They further state, use of coping mechanisms such as social diversion, anger, or blame often leads to stress exacerbation and, in theory, to gambling or other addictive behavior. In this regard, attention deficit/hyperactivity disorder (ADHD), in which hyperactivity-impulsivity is one major symptom (APA, 1994), has been found to be related to gambling (Carlton \& Manowitz, 1992). Furthermore, the fact that impulse control disorders occur at a much higher rate among individuals with gambling pathology (35\%) than controls (3\%) suggests that impulsivity may predispose some persons to pathological gambling (Specker, Carlson, Christenson, \& Marcotte, 1995). While the manner in which impulsivity leads to gambling has not been thoroughly examined, Lightey and Hulsey's findings suggest higher impulsivity levels is related to the use of more ineffective coping strategies, which leads to a greater probability of gambling. 


\section{Boredom}

Wolfgang (1988) found gambling among undergraduates was related to disinhibition and boredom susceptibility. These emotions are affective factors in gambling behaviors. Researchers argue these negative emotional states induce gambling behavior, however there is evidence pathological gambling contributes to these negative emotions (Brown, 1996 ; Firestone, 1993; Hendricks, Meerkerk, Van Oers, \& Garretsen, 1997). Some studies report boredom proneness, rather than sensation seeking, characteristics the pathological gambler (Carruthers, 1999). Boredom can be defined as "a state of mental weariness and dissatisfaction produced by lack of interest or activity" (Blaszczynski, McConaghy, \& Frankova, 1990, p. 36). While sensation seeking suggests an active seeking of novel experiences, boredom proneness is characterized as being dissatisfied, underaroused, apathetic, and easily bored (Blaszczynski et al., 1990). While boredom proneness and depression share similarities, boredom proneness is characterized by a lack of interest and connectedness to one's environment, as well as intolerance of boredom, rather than sadness (Farmer \& Sundberg, 1986).

\section{Summary}

There are many psychological variables available for testing in gambling research. The researchers chose not to include impulsiveness and venturesomeness, in this study. However future research into the study of college student athletes and other students should consider adding these variables. The addition of these variables may greatly argument the explanation and prediction of gambling behavior.

\section{Gambling Passion Scale}


Rousseau, Vallerand, Rotelle, Mageau, and Provencher (2002) examined the impact of passion on gambling. Rousseau et al. (2002) developed the Gambling Passion Scale (GPS) for measuring harmonious and obsessive passion. Obsessive passion refers to an internal pressure that forces individuals to perform an activity (Rousseau et al, 2002). A person with an obsessive passion experiences an urge to do an activity that is difficult to resist. Rousseau et al. (2002) state individuals for whom gambling is an obsessive passion may feel guilty for spending too much time at a gambling establishment instead of spending time with their family. Harmonious passion refers to a motivational tendency that leads an individual to choose freely to engage in an activity (Rousseau et al., 2002). Individuals with a harmonious passion feel in control of their activity and can decide when to engage in it. Harmonious passion is expected to result in positive consequences (Rousseau et al., 2002).

Gambling differs from other passionate activities in two aspects. First, the consequences associated with gambling can be extremely detrimental (Ladouceur et al., 1994). Second, gambling takes place in locations where testing might be difficult to control (Rousseau et al., 2002). The scale contained ten items measuring passion on a seven-point Likert-type scale. The scale was anchored on one end by "not agree at all" and on the other end by "very agreeable". A Pearson correlation between the two subscales was conducted. A correlation between obsessive passion and harmonious passion was $(r=.28),(n=312)$, thus underscoring that both scales were independent of each other (Rousseau et al., 2002). This study was the first attempt to determine if passion influences a gambler's reasons for participating in such a risking activity. Research into 
the affects of passion on gambling behavior is relatively new and further research is needed to verify its relationship to problem gambling.

\section{Summary}

Determining the significance of motivations in gambling research is vital to the present study. Motivations are used as a moderating variable to better understand the relationship between gambler attitudes and intention to gamble. College students are at the age when many of these motivations would appear to be higher (e.g., risk taking, sensation seeking). The current research study seeks to fill a void in the research of gambling behavior. While prior research has not explored the possible moderating impact of gambling motivations, it appears worthy of examination in the current study.

\section{Locus of Control}

In the addition to the importance of understanding motivations when examining gambling behaviors, some researchers have also been interested in how an individual's locus of control impacts their gambling. There are few recent studies of the relationship of locus of control to problem gambling. Locus of control is an individual's belief system regarding the causes of his or her experiences and the factors to which that person attributes success of failure. It has traditionally been assessed with the 13-item Rotter Internal-External Locus of Control Scale (Rotter, 1966). The scale measures generalized expectancies for internal versus external control of reinforcement (Rotter, 1966). People with an internal locus of control believe that their own actions determine the rewards they obtain, while those with an external locus of control believe their own behavior does not matter much and rewards in life are generally outside of their control (Rotter, 1966). 
Scores range from zero to 13 on the scale, with lower scores indicating an internal control and higher scores indicating an external control.

Some research (McCombs, 1991, p. 6) suggests what underlies the internal locus of control is the concept of "self as agent." McCombs (1991) states:

Our thoughts control our actions and when we realize this executive function of thinking we can positively affect our beliefs, motivations, and academic performance. The self as agent can consciously or unconsciously direct, select, and regulate the use of all knowledge structures and intellectual process in support of personal goals, intentions, and choice (p. 6).

Prior research suggests one of the key determinants of gambling behavior is one's locus of control (Miyazaki, Brumbaugh, \& Sprott, 2001). People with internal locus will be gamblers who will, upon winning, attribute the victory to skill rather than a favorable draw or roll of the die, and are attracted to games with an element of skill, strategy, or personal involvement (Miyazaki et al., 2001). Griffiths (1990) found blackjack players who are allowed to choose their own cards (still without knowing what cards there were), rather than have a dealer hand them the cards, were willing to wager more. On the other hand, those with an external locus of control, who views events as beyond their control, are subject to a different impetus, luck (Griffiths, 1990). Miyazaki et al. (2001) state these people do not regard their skill as affecting the outcome of these games, convincing them that they were lucky and can win regardless of their inexperience or lack of skill can incite a greater desire to engage in gambling.

Browne and Brown (2001) conducted a study of 288 American college students on lottery gambling behavior. The purpose of their study was to: (a) describe lottery play 
among college students; (b) examine the relationship among student gambling, parental gambling, and peer gambling; and (c) determine the relationship of locus of control to these factors. They focused on lottery gambling for two reasons. First, lottery gambling is the most common form of gambling of college students. Second, while use of state lotteries for educational funding is increasing, they could produce negative effects on special groups.

The sample consisted of 288 students enrolled in introductory marketing classes at a state university in the Northwest (Browne \& Brown, 2001). The sample contained 111 women and $177 \mathrm{men}$. The age level ranged from 18 to 38 years of age. The majority of the participants $(89 \%)$ were college juniors and seniors. The sample was restricted to American-born students. Participation in the study was voluntary, but the participants received a small amount of course credit for their cooperation.

The participants completed a self-reported questionnaire asking about their gambling practices and the gambling practices of parents and friends. The return rate was approximately $95 \%$. Responses to the items were rated on a five-point Likert-type scale ranging from "never" (1) to "very frequently" (5). The students also estimated how much money they spent and whether they played more, less, or about the same since being in college.

Participants completed the 40-item Nowicki-Strickland Internal-External Locus of Control Scale for Adults (ANS-IE; Lefcourt, 1991, Norwicki \& Duke, 1974). Persons scoring high on the scale see life as a game of chance (external control) whereas persons scoring low see life as a game of skill. The scale showed discriminant validity and scores were not related to either intelligence or social desirability scores. Construct validity was 
demonstrated by moderate relationships to the Rotter IE Scale (Browne \& Brown, 2001). The scale also showed reliability (split-half reliabilities range from .74 to .86 ; test-retest reliability is about .83 over a six-week period) (Browne \& Brown, 2001).

The students in Browne and Brown's study (2001) tended to score in the direction of internal locus of control, $(M=9.53)$. This was consistent with the research of Lefcourt (1976) linking education and youth to greater belief in personal efficiency. Browne and Brown (2001) conducted a median split on locus of control to examine the relationship between locus of control and lottery play. Analysis of variance showed lower locus of control was only marginally related to more frequent lottery play among college students, $(F(1,285)=2.74, p<.10)$ (Browne \& Brown, 2001). However, students with an external locus of control were significantly more likely to have parents who were gamblers $(F(1,285)=8.60, p<.004)$ (Browne \& Brown, 2001). The participant's, locus of control scores were not related to having friends who were more frequent lottery gamblers (Browne \& Brown, 2001).

Browne and Brown (2001) found when game playing was examined external locus of control was related to betting on sports, $(F(1,285)=4.21, p<.05)$. These results indicate external locus of control has a significant effect on lottery play of college students. College students felt betting on sports was determined by an external locus of control whereby they had no control over the outcome of the bet. The outcome of the bet was the result of luck and not skill. Men were more involved in sports betting than were women $(F(1,285)=35.52, p<.0001)$ (Browne \& Brown, 2001). These results indicate college students are consistent with the social learning interpretation of gambling behavior, having parents and peers who gambled does predict student gambling (Browne 
\& Brown, 2001). This external control does effect why students choose to gamble on sports.

\section{Summary}

It is important in explaining behavior of a gambler to examine the inner beliefs of the individual involved in the activity. Locus of control is examined in the present study as a moderating variable between attitudes and intention to gamble. Vogt (2005) explains a moderating variable is a variable that influences or moderates the relation between two other variables and produces an interaction effect. Students with internal locus of control will be gamblers who will, upon winning, attribute the victory to skill rather than a favorable draw or roll of the die, and are attracted to games with an element of skill, strategy, or personal involvement such as pari-mutuel wagering. On the other hand, students with external locus of control will be gamblers who will, upon winning, attribute the victory to something beyond their control, such as a scratch-off lottery ticket.

\section{Gambling Attitudes}

\section{Gambling Attitude Scale}

While locus of control does appear to be important, it is also important to understand first attitudes towards gambling, because they typically represent a readiness to act (Kassinove, 1998). Kassinove (1998) developed a Gambling Attitude Scale (GAS) to measure general attitudes, attitudes towards gambling in casinos, attitudes towards gambling on horse races, and attitudes towards gambling on the lottery. Kassinove's Gambling Attitude Scale is designed to uncover attitudes that may underscore the development of pathological gambling. The Gambling Attitude Scale had four sub-scales to assess gambling attitudes. A tri-componental model of attitudes (Oskamp, 1991) was 
used to generate items that reflected affective, cognitive, and behavioral aspects of attitudes. Initial findings showed the scale possessed adequate internal consistency and construct validity when tested on a group of college students (Kassinove, 1998).

Kassinove (1998) examined 71 men and 98 women ranging in age from 17 to 35. Ninety-eight percent of the participants were single. A pool of 116 items was generated to develop four gambling attitude scales. Twenty-nine items measured each of the four hypothesized scales. These 116 items were examined for appropriateness by two judges and five items were removed from each of the four scales. Twenty-four items remained in each of the scales. Three other scales were included in the survey: a liberalconservative scale, a risk taking scale, and the Marlowe-Crowne Social Desirability Scale. The Marlowe-Crowne Scale was used in hopes of removing false answers of the participants. The liberal-conservative scale measured the respondent's reactions to specific questions concerning liberal and conservative viewpoints of issues relating to political, social, and economical issues. The risk taking scale measured the respondent's views on taking certain risks when performing specific risk-taking activities such as gambling.

A six-point Likert-type scale measured the first 119 items. Researchers divided the items into five-item units, each containing one question about the four gambling areas and one question regarding liberal-conservative attitudes or thrill seeking (Kassinove, 1998). Participants answered the Marlowe-Crowne Scale in a true-false format. Researchers computed alpha coefficients for the 24 items in each of the four gambling scales to assess their relationship to the total score. The sample of 127 students, the 12 best items on each of the four scales remained based on the following criteria. Items with 
the highest correlation with the total score on their respective scales remained except when the item was above five or below two, or when items were judged to be superior in representing the construct (Kassinove, 1998). In every case the best cognitive, affective, and behavioral items remained. Three items with low temporal consistency were removed from the questionnaire.

A test-retest was conducted on the same sample. Each of the four gambling scales showed adequate internal consistency, with alpha coefficients ranging from .86 to .90. The Gambling Attitude Scale appears to be a reliable tool to assess attitudes towards various gambling activities. Internal consistency and temporal stability data indicate each scale is consistently measuring a unitary construct (Kassinove, 1998). The mean scores on the Gambling Attitude Scale-Lottery scale were the highest, indicating positive attitudes towards lotteries. Each of the Gambling Attitude Scales showed significant associations with the risk-taking thrill seeking items, ranging from .27 to .47 . The Gambling Attitude Scale may have potential to predict the development of excessive gambling behavior among young adults (Kassinove, 1998).

\section{Gambling Attitudes and Belief Survey}

Breen and Zuckerman (1999) developed another scale focusing on measuring the gambling attitudes and beliefs (GABS) of respondents. Breen and Zuckerman (1999) selected subjects $(N=248)$ on the basis of self-reported frequency of gambling involvement, ranging from those who reported gambling at least weekly to those who reported gambling less than monthly. The vast majority of the respondents were freshmen and sophomores about 18-19 years of age. Fifty-one percent of the sample placed a bet on a sporting event at least on a monthly basis (Breen \& Zuckerman, 1999). 
Thirty-seven percent bet money on card games at least monthly. Thirty-three percent bought a lottery ticket at least once per month.

The expected positive correlations were observed between GABS and SOGS scores $(r=.38, p<.001)$. Subjects could: (a) decline to gamble; (b) gamble and quit while they still had some money left; or (c) gamble until all money was lost (Breen \& Zuckerman, 1999). Those who did not gamble were described as "Non-players", those who gambled and quit with money left were called "Non-chasers", and those who gambled all their money away were called "Chasers".

The number of trials played differed significantly between chasers $(M=51.09)$ and non-chasers $(M=21.55)$. The average wager was not significantly different between groups. The comparison of trials and betting is important in support of internal validity. Chasers almost always persisted in gambling beyond the optimal point in the sequence (Breen \& Zuckerman, 1999). The frequency of gambling per respondent did not show any relationship with the mean numbers of trials played. Frequency of gambling showed no association with either the decision to gamble or with chasing.

The hypothesis that chasers would be higher in sensation seeking received no support (Breen \& Zuckerman, 1999). However, the GABS did prove to be a significant predictor of gambling participation. Despite the opportunity to take the money and not risk it in a game of chance, those with significantly stronger gambling beliefs decided to play (Breen \& Zuckerman, 1999). This research supports the description of the GABS scores as measures of gambling "affinity” (Breen \& Zuckerman, 1999). 


\section{Summary}

Kassinove (1998) and Breen and Zuckerman (1999) examined attitudes of gamblers and developed scales to measure these attitudes. Their studies were designed to uncover specific attitudes towards gambling. These attitudes were significantly related to risk-taking behavior. The impact of chasing gambling wins or losses was also examined and the researchers found pathological or problem gamblers chased both wins and losses in gambling (Shaffer \& Hall, 1997; Zuckerman, 1979). The researchers in the current study chose to further the research in this area by using Moore and Ohtsuka's (1999) instrument to determine the attitudes of college student gamblers. Attitudes are a key variable in the theory of reasoned action, which the current study is using to try to predict gambling behavior.

\section{Gambling Cognitions}

\section{Gambling Related Cognitions Scale}

The Gambling Related Cognitions Scale was developed to provide a brief scale to screen for gambling cognitions among a population (Raylu \& Oei, 2003). An original 59-item questionnaire was developed to reflect a range of gambling related cognitions. Items were constructed by the authors using the examples and/or description of the various categories of gambling related cognitions described in previous research (Gaboury \& Ladouceur, 1989; Griffiths, 1994; Toneatto, 1999).

Raylu and Oei (2003) recruited 968 volunteers from a community-based population. They were divided randomly into two groups. The researchers performed principal axis factoring with varimax rotation on one group and confirmatory factor analysis on the other group to decide the best-fitted scenario. Before the questionnaire 
was distributed to the respondents, two authors and two independent evaluators reviewed the items. Six items were removed and a 53-item scale was developed. The questionnaires were distributed and the overall response rate was 90\%. All the responses were confidential. The following process was used to reduce the original 53-item questionnaire to the final 23-item scale. All loadings less than .4 were suppressed based on Stevens' (1992) suggestion this cut-off point was appropriate for interpretative reasons. The inter-item correlations and item-total correlations for all 53 items were calculated. Any items with double factor loading were deleted. This included ten items. Each item correlated significantly higher with the lower item total correlation was deleted. This deleted five items. Eight items were deleted based on the fact they duplicated information. Communalities were calculated for the remaining items. All items with communalities of less than .3 were deleted. This resulted in a 23 -item scale.

Principal confirmatory factor analysis on the 23 items using group B data was performed. Kaiser's Meyer Olkin measure of sampling adequacy was .93 showing that the patterns of correlation are relatively compact, and so factor analysis should produce distinct and reliable factors (Field, 2000). Bartlett's Test of Sphericity was significant ( $p$ $<.001$ ), showing that there were some relationships between the variables. Factor analysis and scree test showed that a five-factor was appropriate. All 23 items had factor loadings of greater than .4, communalities of greater than .5 , no hyperplane items and no items with substantial cross-loadings on other factors. The five-factor accounted for $70 \%$ of the variance in scores. A significant gender difference was found in four of the five factors as well as the total score, where males tended to have significantly higher GRCS scores than females (Raylu \& Oei, 2003). 
The five-factor model reflected dimensions of interpretative bias/control, illusion of control, predictive control, perceived inability to stop gambling and expectations of gambling, and provided a good fit for the data. Significant positive correlations were demonstrated with other instruments assessing gambling-related variables including gambling-related thoughts, motivations towards gambling, and gambling problems. Although the study of Raylu and Oei (2003) provided important support for the GRCS as a measure of gambling behavior, future studies may need to access the psychometric properties with other samples including clinical samples.

\section{Summary}

The study of cognitive relationships with gambling is relatively new. The researchers in the present study chose not to include the Gambling Related Cognitions Scale in this study because it did not fit into the current model. However, further research on gambling cognitions is warranted.

\section{Gambling Among College Students}

\section{Reasons for Concern}

Gamblers in both urban and rural areas have easy access to a wide variety of games (Alberta Alcohol and Drug Abuse Commission, 1998). The gambling industry is profitable because it attracts low-income levels, which includes college students. College students use the availability of gambling venues to gamble in hopes of winning money that might improve their financial situation. Problem gambling among college students may result in family problems, poor class attendance, poor school performance, poor health conditions, and early withdrawal from school (Alberta Alcohol and Drug Abuse Commission, 1998). While a number of studies have identified addictive behaviors such 
dearth of information on the extent of problem gambling among college students (Alberta Alcohol and Drug Abuse Commission, 1998).

\section{Results from Research on College Students}

Lesieur et al. (1991) conducted a comprehensive study of the extent of pathological and problem gambling among university and college students. The sample consisted of 1,771 students from six colleges and universities in the United States. The states represented were New York, New Jersey, Oklahoma, Texas, and Nevada. The study found rates of pathological and problematic gambling among college and university students are four to six times higher than those reported for the general population, with about $15 \%$ of their respondents experiencing some gambling-related problems.

In 1995, supported by funds from the Minnesota Department of Human Services, Winters et al. (1998) surveyed two Minnesota Universities located a short distance from high-stakes gambling. The primary goal of this research was to describe the extent of general problem gambling among the college and university students and to identify psychosocial factors that could mediate problem gambling. Nearly 1,400 students were surveyed in the study. The participants were mainly Caucasian (95\%) and 19-23 years of age (73\%). Fifty-two percent of the participants were female. The participants were given the SOGS to complete.

Gambling at some level was the norm among participants in this study. Ninetyone percent of the males in the study reported gambling at least once during the past twelve months. Eighty-four percent of the women reported gambling at least once in the past twelve months. The most popular type of gambling reported by the students was casino-style gambling, followed by the lottery. The results of this study show the typical 
problem gambler was a male, a weekly or daily user of alcohol or illicit drugs, and someone with a relatively high disposable income whom had been raised by a parent with a gambling problem (Winters et al., 1998).

Although pathological and problem gambling may not manifest any physical symptoms, its social and economic impact on college students has been documented in two recent studies (Lesieur et al., 1991). For example, Ladouceur et al. (1994) evaluated the prevalence of pathological gambling among college students in the region of Quebec City, and found that gambling practices are widespread. Surprisingly, the study also revealed the incidence of problem gambling among college students is twice as high as that of the general population in the province of Quebec.

A total of 521 students participated in the Quebec study during the fall of 1994. The study was conducted from a college-wide (in-class) survey of students enrolled at the Alberta Vocational College-Lac La Biche. The study explored the extent and social correlates of gambling among college students. The data analyses confirmed some of the background variables in the study, such as gender, age, martial status, and ethnicity of the respondents had a significant influence on gambling participation. Respondents were asked, "Have you ever bet or spent money on gambling activities?" (e.g., bingo, card games, horse racing, lottery tickets, etc.). Eighty-eight percent reported they had played a game for money or spent money on gambling. This finding is consistent with previously reported results (Lesieur et al., 1991) indicating that $85 \%$ of the college students surveyed have gambled.

Respondents who gambled varied noticeably by gender. Research on the link between gambling participation and gender has consistently indicated men are more 
likely to gamble than women (Abbott \& Cramer, 1993; Lorenz, 1990). This study by the Alberta Alcohol and Drug Abuse Commission (1998) revealed the contrary as six of ten gamblers (59\%) were female. The gender difference in gambling participation was statistically significant $(p=.000)$. The significant gender difference in gambling participation of male and female sample members could be a manifestation of changes in gender role socialization or the increasing number of economically disadvantaged women participating in adult learning (Alberta Alcohol and Drug Abuse Commission, 1998). There were also age differences in this study. Forty-five percent of the youngest respondents (under the age of 25) gambled, compared to $27 \%$ aged $25-31,16 \%$ aged 32 39, and 12\% aged 40 and over (Alberta Alcohol and Drug Abuse Commission, 1998).

Opinions and beliefs about gambling varied among respondents in the Alberta Alcohol and Drug Abuse Commission study. To gauge respondents' views on gambling they were presented with ten general statements on a four-point Likert-type scale anchored on one end by "strongly agree" and on the other end by "strongly disagree." Forty-eight percent of respondents agreed gambling provided a quick source of tax-free income. The high proportion of gamblers who agreed gambling provides a quick source of tax-free income clearly establishes attitudes and believes as a risk factor in gambling problems (Alberta Alcohol and Drug Abuse Commission, 1998).

When opinions about gambling were analyzed separately among respondents $(n=$ 461) some significant differences were observed across gender, age, martial status, and ethnic background (Alberta Alcohol and Drug Abuse Commission, 1998). A higher proportion of males (10\%) agreed that gambling makes them better off financially, compared to only $4 \%$ of female respondents in the study. Female respondents were 
significantly more likely to either strongly agree or agree that: (a) most people feel in control of their lives when they gamble; (b) most people gamble when they are sad, lonely, or depressed; (c) gambling is a form of entertainment; and (d) gambling is a social activity (Alberta Alcohol and Drug Abuse Commission, 1998). Respondents $(n=461)$ in the Alberta study (1998) who gambled were asked to indicate their favorite types of gambling activities. Bingo was the most preferred gambling activity (35\%), followed by the lotto (34\%), and instant/scratch offs (33\%).

In a later study, Hira and Monson (2000) examined the proportion of college students who gamble to determine the level of their gambling involvement. The purpose of their study was to find factors in family and social settings that explain particular gambling behavior in college students. Their study sought a better understanding of what motivates college students to gamble and what factors influence their choices. Data was collected from 797 undergraduates at Iowa State University. The dependent variables were students' gambling status, scope, frequency, and expenditure. The independent variables included age, gender, employment status, grade point average, and gambling expenditure of mother, father and best friend of the student.

A three-page questionnaire was used to collect the data. Frequency and crosstabulation analyses were used to develop the student's demographic profile and to describe differences between characteristics of gamblers. Gamma-statistics were used to test the strength of the relationship between the dependent and independent variables. This study used the framework of the social learning theory. This theory proposes the behavior of a specific participant is impacted by the behavior of significant others. 
Fifty-one percent of the participants in this study were males. Ninety-one percent of the participants were white. Sophomores and juniors were seventy-four percent of the sample. The mean grade point average was 2.93 on a four-point scale. Respondents were presented with six distinct gambling types. These included: (a) lottery sales, (b) betting on a sporting event or game, (c) playing poker or other non-casino games, (d) playing video poker, (e) casinos, and (f) betting on horse or dog races. The students were asked to indicate how many times in the past year they had played one of these games.

The results of this study indicated fifty-six percent of the students gambled in the past year. Lottery playing was identified as the number one gambling activity of the students. Several reasons were given for gambling including: (a) form of entertainment, (b) to win money, and (c) to meet people. College students were found to exhibit significantly different gambling behavior in terms of frequency, scope, and expenditure than the general population. Male students were found to gamble more frequently and to spend more money. Student gambling also was positively related to parental gambling and peer gambling.

A longitudinal study of college students in Missouri by Sluske, Jackson, and Sher (2003) was conducted on 468 first-year college students. The sample was $94 \%$ Caucasian and 54\% female. The participants were surveyed in person or over-thetelephone over the course of eleven years. Participant retention was high: 97\%, 94\%, and $84 \%$ for years 4,7 , and 11 , respectively. In the first year the participants were given a truncated version of the gambling section of the Diagnostic Interview Schedule (DIS) based on the DSM-III. Throughout the study only four individuals (three men and one 
woman) met the DSM-III criteria for pathological gambling. Sluske et al. (2003) defined problem gambling as an endorsement of one or more of the problem gambling symptoms. In the three years it was measured, the past-year rate of gambling problems was lowest in year $11(1.8 \%)$, while the years $7-11$ showed the greatest increase in lifetime prevalence, from $3.7 \%$ to $5.3 \%$. This inconsistency could result from either unusually large increases in new gambling problems, or incongruities in self-reports of lifetime and past-year gambling problems (Sluske et al., 2003). Despite many limitations, this study by Sluske et al. (2003) indicates lifetime prevalence rates of problem gambling by college students may be lower than previously suggested by the literature.

Knapp, Rasmussen, and Niaghi (2003) conducted a study of 359 college students at the University of Nevada, Las Vegas. This study asked participants how often they wagered on athletic events. Participants were volunteers from psychology classes at the University of Nevada, Las Vegas. The convenience sample was 35.7\% male and 64.3\% female. Residents of Nevada comprised $79 \%$ of the sample. The questionnaire consisted of 15 items pertaining to aspects of sports betting with demographic questions limited to gender, age range, residency status, and history of employment in the hotel/casino industry (Knapp et al., 2003). The questionnaire was answered during class time.

Of the 359 participants, $43 \%$ said they "never" gambled in a casino, while $6 \%$ said they did so often as "once or several times a week" (Knapp et al., 2003). There was a significant gender difference in the study. Over ten percent (10.3\%) of the males reported gambling in a casino "once or several times a week" compared to only $3.4 \%$ of the females, $(F(1,359)=7.21, p<.05)$. Slightly over half of the participants stated they never placed bets on sporting events at a casino (53.5\%), while $46.4 \%$ said they did so 
"once in a while or more frequently" (Knapp et al., 2003). Since betting on local teams became legal, $15 \%$ reported they had placed a bet on a UNLV team. The difference between males and females was significant $(F(1,359)=17.08, p<.05)$ (Knapp et al., 2003), with nearly one quarter (23.2\%) of the males placing a bet on a UNLV team compared to only $7.5 \%$ of the females (Knapp et al., 2003). Although the UNLV student body may not represent the nation's college student body as a whole, they do provide a baseline representing the only state where bets on college teams is legal, against which to assess reports from other campuses (Knapp et al., 2003).

Platz and Miller (2001) conducted a study to determine the motivations for gambling of recreational and pathological student gamblers compared to motivations of other leisure activities. Students $(N=996)$ at the University of Nevada, Las Vegas completed a self-report questionnaire including the SOGS and the Recreation Experience Preference Scale (REPS). The sample was restricted to students who had indicated a gambling preference. The sample was $53.8 \%$ female and $46.2 \%$ male, with a mean age of 21 .

Participants answered questions in a self-report questionnaire describing their recreation participation, motives for recreation, gambling participation, and motives for gambling (Platz \& Miller, 2001). A demographic section included questions dealing with age, gender, major, class standing, grade point average, Nevada residency, length of residency, location of residency (on or off-campus), and ethnic or racial background. Participants completed the questionnaires in small groups of three or four in an experimental room in the psychology department at the University of Nevada, Las Vegas. 
The SOGS was used to differentiate levels of gamblers for description and comparison $($ Cronbach's alpha $=.80)$. Items on the SOGS were summed to produce a composite score. Individuals were assigned to groups according to the traditional classification scheme recommended by Lesieur and Blume (1991). Students who scored zero were classified as recreational gamblers. Those scoring one to four were classified as problem gamblers. Students scoring five or more were classified as pathological gamblers. Pearson correlations provided additional support for SOGS classification as higher SOGS scores were associated with higher levels of other gambling indicators. A significant positive association was found between student's scores on the SOGS and the largest amount of money they had gambled in one day.

Moore and Ohtsuka (1999) conducted a study to characterize gambling attitudes and social norms among gamblers in Australia and to evaluate whether gambling behavior (frequency) and problem gambling could be predicted by a theory or model combining attitudes and social influences. The sample contained 215 participants. The study used Ajzen \& Fishbein's (1980) Theory of Reasoned Action (TRA) to try to predict gambling frequency and problem gambling.

The TRA postulates relationships between engaging in a behavior and attitudes toward it, knowledge/beliefs about its likely outcomes, and intentions with respect to carrying out the behavior in question (Moore \& Ohtsuka, 1999). In this model, intention to perform a behavior is the immediate antecedent of that behavior (Moore \& Ohtsuka, 1999). Intention is predicted by two factors, attitude of the individual and his or her subjective norms. The TRA has been successful in predicting behaviors for voting choice 
(Bowman \& Fishbein, 1978) and wearing safety helmets (Allegrante et al., 1980), as well as with adult gambling (Oh \& Hsu, 2001).

The participants $(n=215)$ ranged in age from 17 to $55,(M=22.0, S D=7.1)$. Fifty-eight males and 157 females were included in the sample. First-year students in psychology classes completed the survey. The survey consisted of four sub-sections designed to measure; (a) gambling attitudes, (b) subjective norms with respect to gambling (beliefs about the attitudes and behaviors of significant others) plus motivation to comply with these norms, (c) gambling intentions, and (d) gambling behavior. In addition the participants completed a modified version of the SOGS. Demographic information pertaining to age and sex were also collected.

The sub-section dealing with gambling attitudes consisted of 12 statements rated on a five-point Likert-type scale anchored on one end by "strongly agree" and on the other end by "strongly disagree." With appropriate reversals, items were summed to produce a scale for which scores could range from 12 to 60 , with the higher scores an indication of positive attitudes towards gambling. The Cronbach's alpha for the scale was .79 (Moore \& Ohtsuka, 1999). A five-point Likert-type scale was used to measure subjective norms. Twelve items were contained in this sub-section. To provide a measure of subjective norms, the normative beliefs' items and the motivation to comply items were combined in the manner suggested by Ajzen and Madden (1986), that is, by multiplying the beliefs of each specific referent group (family, friends) by the motivation to comply with these referents (Moore \& Ohtsuka, 1999). The two measures were added together to create a single measure of subjective norms, with a Cronbach's alpha of .69. 
High scores on the measure reflected a perception of positive social norms toward gambling and the desire to fit in with these norms. Scores ranged from 12 to 300 .

Seven items on the intention to gamble in the future scale were developed (Moore $\&$ Ohtsuka, 1999). Scores ranged from seven to 35 , with the high scores reflecting a strong intention to gamble. Cronbach's alpha for this scale was .80. Gambling behavior was assessed by two measures, frequencies of ten types of gambling and largest amount of money ever gambled. The frequency measure was rated on a five-point Likert-type scale ranging from zero - "never participated", one - "once-a-year", two - "more than once-a-year", three - "more than once-a-month", and four - "once-a-week". Scores ranged from 0 to 40 . The Cronbach's alpha reliability coefficient for the scale was .71 .

While most of the respondents approved of moderate gambling and believed at least some gambling should be legal, negative attitudes were also heavily endorsed (Moore \& Ohtsuka, 1999). The mean score on the attitude scale was $36.5(M=36.5)$, with a standard deviation of $6.5(S D=6.5)$. Respondents believed their families and friends approved of gambling, and that gambling occurs among most of the families and friends (Moore \& Ohtsuka, 1999). The mean score for this approval rating was 36.4 ( $M$ $=36.4$ ). The gambling intentions scale had a mean score of 14.3 with a standard deviation of $4.7(M=14.3, S D=4.7)$ (Moore \& Ohtsuka, 1999). Few respondents engaged in any type of gambling on a regular basis, although lotteries did receive the most play. More than half of the respondents played cards for money, bet on horses or dogs, bought lottery tickets, or went to casinos, representing widespread involvement in gambling activities (Moore \& Ohtsuka, 1999). 
Intention to gamble was significantly predicted by attitudes and subjective norms in this study. The TRA was moderately supported by this study. Regression analysis indicated more positive attitudes and stronger social norms significantly predicted a stronger intention to gamble in the future (Moore \& Ohtsuka, 1999). Intentions and gender predicted actual gambling behavior, both frequency and acknowledgement, with men more likely to gamble and worry about it than women (Moore \& Ohtsuka, 1999). The data from this study indicates a moderately strong correlation between problem gambling and gambling frequency (Moore \& Ohtsuka, 1999). One difference between prediction of gambling frequency and problem gambling was the social norms were influential in the former but not the latter (Moore \& Ohtsuka, 1999). The study indicated the TRA was a useful tool in the explanation of gambling (Moore \& Ohtsuka, 1999).

\section{Summary}

While pathological gambling can infiltrate all segments of society, research suggests college students are particularly susceptible to the risks and effects of pathological gambling (Rockey et al., 1997). The rate of pathological gambling among college students is four to eight times higher than the rate of adults not currently enrolled in college (Lesieur et al., 1991). Similarly, Frank (1990) reported prevalence rates of pathological gambling among college students attending school in New Jersey to be $6 \%$. Ladouceur et al. (1994) found the prevalence rates of pathological gambling among college students in Quebec City to be $2.8 \%$. Due to the higher prevalence of problem gambling among college students, it is important to researchers to determine the attitudes, motivations, intentions, and behaviors of college students. The results of this research 
will enable administrators to help better understand problem gambling among college students and possibly prevent others from becoming addicted to this illness.

\section{Gambling Among College Athletes}

\section{Reason for Concerns}

While there is concern over general student gambling, gambling by athletes is a particular concern. Participating in sporting events is very competitive and involves risktaking, which is similar to gambling. Sports wagering, beginning in high school and increasing in college is done by $50 \%$ of student-athletes (Engwall, Hunter, \& Steinberg, 2003). Lesieur (1991) reported $85 \%$ of college athletes as having participated in betting and 23\% surveyed showed evidence of pathological gambling behavior. Gambling activities in sport include playing cards for money, wagering on sporting events, playing the lottery, and casino betting (Miller, Adams, Kraus, Clayton, Miller, Anderson, \& Ogilvie, 2001). Collegiate student-athletes are unique and face different challenges than their non-athlete peers (Engwall, Hunter, \& Steinberg, 2003; Weiss, 1999). The sport environment is complex with student-athletes having to negotiate a unique set of challenges: including trying to succeed at both academics and athletics, dealing with issues related to time management, handling stress related to the pressures of their sport, handling peer pressure regarding recreational activities including drug and alcohol use, and having to cope with the traditional developmental tasks typical of their peer group (Etzel, Ferrante, \& Pinkney, 1991). Athletic department staff and counseling center practitioners are faced with developing and implementing appropriate and successful intervention strategies to address the special needs of this population. 


\section{Results from Research on College Athletes}

Rockey et al. (1997) conducted a study to compare the prevalence rates of pathological and problem gambling between college athletes and the general student body (non-athletes) using the SOGS. The data for this study was obtained from students who attended universities in the Southeastern Athletic Conference. The sample was drawn from first aid and safety classes because a diversity of students participated in these classes and enrollment in these classes was usually large. The sample $(n=954)$ volunteered to complete the survey. The surveys were mailed to contact persons at each university and the study was administered during class time and returned to the proctor. Frequency rates and cross-tabulations were calculated to allow researchers to establish prevalence rates of gambling for the different sub-categories of participants (Rockey et al., 1997). Pearson chi-square tests were performed to determine if relationships existed between the variables. Any Pearson chi-square tests found significant $(p<.05)$ had Cramer's V tests calculated to measure the strength of the relationships. Cramer's V tests enable the researcher to measure the degree of association between variables.

Eighty-one percent of the athletes $(n=104)$ and $81.3 \%$ of the non-athletes $(n=$ $670)$ reported gambling. Four percent of the 954 participants $(n=36)$ showed signs of being pathological gamblers. Almost four percent of the participants $(n=35)$ showed signs of being problem gamblers. Male athletes showed higher prevalence rates than females. In addition the mean score for non-athletes was only .60 (95\% CI: .50 -.70), while the mean for male athletes was 1.01 (95\% CI: .63 - 1.39) (Rockey et al., 1997). Slot machines, poker machines, and lotteries were the most common forms of gambling 
in the study. The majority of the participants gambled relatively small amounts of money (Rockey et al., 1997).

The results of this research study suggest there is a significant association between pathological gambling and college athletes. While statistically significant associations were not found between pathological gambling and athletes, in general male athletes were found to have a very high prevalence rate of pathological gambling (Rockey et al., 1997). These results support the findings of Weiss (1995) that college student athletes have a higher rate of problem gambling. According to Curry and Jiobu (1995), the socialization of athletes includes a continuous emphasis on competition. Gambling in its' many forms allows athletes outlets in which to compete.

Previous studies have attempted to quantify wagering behavior among select groups of student athletes. For example, Cullen and Latessa (1996) found 25\% of Division I football and basketball players indicated they wagered on college sports. A few years later, Cross and Vollano (1999) conducted a study designed to determine (a) the types of gambling activities in which student athletes engage and (b) the extent to which student athletes participate in these gambling activities. A self-administered, written questionnaire was used to gather responses to close-ended questions. The participants $(N=3,000)$ included 1,500 football players, 750 basketball players and 750 women's basketball players.

A total of 182 institutions were represented in the sample. All of the institutions participated in men and women's basketball, but only 148 of the schools competed in football. All National Collegiate Athletic Association (NCAA) Division I football playing schools were included in the study. The questionnaire was developed using 
concepts and items taken from three previously published studies (Cullen \& Latessa, 1996; Kallick, Suits, Dielman, \& Hybels, 1979; Lesieur \& Blume, 1987).

The questionnaire was divided into four sections: (a) general gambling activities; (b) sports related gambling with friends; (c) gambling with bookmakers and other organized gambling activities; and (d) demographic and other general information about the participant (Cross \& Vollano, 1999). The questionnaire was pilot-tested four times prior to the national distribution to assure an easily understood survey instrument (Cross \& Vollano, 1999). The questionnaires were mailed to each participant. Participants' names and addresses were obtained from team rosters and information available through various public sources. A randomization process resulted in approximately $10 \%$ of each institution's football team and $27 \%$ of each men and women's basketball teams being included in the sample (Cross \& Vollano, 1999).

The primary purpose of this research was to provide descriptive information regarding student athlete gambling at the Division I level. Analysis of variance was used to determine significant differences between male and female student athlete responses. The final sample consisted of 758 student athletes, a 25.3\% response rate. Sixty percent of the sample was male and $40 \%$ female. The sample age ranged from 18 to 28 years of age with the average of 20.5 years. Forty-five percent of male athletes reported gambling on sporting events while attending college. This increase after the $25 \%$ found by Cullen and Latessa (1996) may be from the new survey instrument, which was more accurate in measuring gambling. The research suggests gambling on sports by student athletes is a prevalent activity (Cross \& Vollano, 1999).

Other findings related to the issue of sports gambling include: 
(a) Over 4\% of male student athletes admitted to directly betting with bookies since attending college.

(b) Student athlete's involvement with bookmakers poses a serious threat to the integrity of intercollegiate sports with $7.1 \%$ of male student athletes having either bet with a bookie or through the use of a parlay card. Assuming 100 football student athletes on each collegiate team, it is possible that seven individuals per team are engaged in illegal sports wagering. Assuming 15 athletes on each basketball team, it is possible that one individual from each team is engaged in illegal sports gambling.

(c) Over $5 \%$ of male student athletes have wagered on a game in which they participated, provided inside information for gambling purposes or fixed a game in which they participated. All of these activities are cause for concern because they directly compromise the integrity of intercollegiate sports and are illegal. These findings suggest it is increasingly likely some intercollegiate contests are not being legitimately contested.

The involvement of female athletes in gambling activities should not be discounted. Although the findings indicate a lesser involvement by females than their male peers, this should not provide false comfort for administrators (Cross \& Vollano, 1999). The increase in the amount of money spent on women's athletic programs is increasing yearly. Female athletes may become involved in risky behaviors as their male counterparts and it is vital to the success of the total athletic program at the university to determine this involvement. 
In 2003, the NCAA began conducting a survey in an attempt to collect information on gambling and associated behaviors of student athletes. The major goal of this study was to quantify the levels of various wagering activities among the population of student athletes at NCAA member institutions. This report focused on descriptive statistics that outlined the extent and nature of gambling behavior. The issue of gambling, and especially sports wagering, has been of significant importance to the NCAA membership for the entire existence of the association (NCAA, 2004). The NCAA conducted this study with the hope of providing baseline information related to the level of gambling behavior within the student athlete population (NCAA, 2004).

The study asked 2,003 individual sports teams at 1,032 member institutions to participate in the study. A total of 20,739 surveys were received from the institutions that responded. Sixty-one percent of the respondents were male, $37 \%$ female, and $2 \%$ failed to indicate their gender. Seventy-four percent were Caucasian, 15\% African American, and the rest were from other ethnicities or chose not to be classified. Forty-four percent of the schools were Division I, 23\% were Division II, and 32\% were Division III.

Male athletes consistently reported engaging in gambling or sports wagering activities in much higher proportions than female athletes (NCAA, 2004). Division III student athletes were more likely to engage in gambling or sports wagering behavior, while Division I student athletes were least likely to engage in such activities (NCAA, 2004). The proportions of males reporting participation in gambling were $63.4 \%$ for Division I, 66.5\% for Division II, and 73.6\% for Division III (NCAA, 2004). Females reported rates of $41.7 \%, 51 \%$ and $51.2 \%$ respectively (NCAA, 2004). These findings 
correlate with previous studies where males showed a higher proportion rate than females in student athlete gambling (NCAA, 2004).

\section{Summary}

The focus on addictions among athletes has gained considerable attention among sports experts across the country. Schaef (1987) defines addiction as an insidious process that we are powerless to control, propelling us to act in ways contrary to our values and beliefs and may progress to obsession and maladaptive action. Persons with addictive behaviors are at high risk for affective disorders, criminal behavior, ethical misconduct, absenteeism, and problematic relationships (American Psychiatric Association, 2000; Weiss, 1999). Collegiate student-athletes are thought to be at an even higher risk for academic and socially problematic behaviors than their non-athletic peer cohort (National Collegiate Association Drug Education Committee, 2001).

Big money attracts organized crime and illegal sports wagering is big money. Money skimmed from sports betting schemes is used to fund a host of illegal activities including the sale of narcotics and loan sharking. Student-athletes are viewed by organized crime as easy marks. When student-athletes place bets with a bookie, they have jeopardized their eligibility and have broken the law. The bookie now is in control. If a student-athlete is sufficiently indebted or addicted, point shaving often is introduced as a way out.

Therefore, the research in this study is important for determining the affects of gambling on college student athletes. Developing a plan to cope with the possible outcomes of gambling by college student athletes is vital to college administrators. The purpose of this research study is to examine the gambling behavior of college athletes and 
other college students. This study will examine the relationships among subjective norms, gambling attitudes, gambling motivations, locus of control, and gambling intentions on the gambling behavior of college students. In addition, the study will examine the impact of gender and status as an athlete on the subjective norms and gambling attitudes. A particular segment, college student athletes is examined to answer the question, "Do college student athletes gamble more than other college students?"

\section{Conclusion}

Some researchers estimate Americans spend more money gambling than they do on books, movies, recorded music, and amusement parks (Shaffer \& Hall, 1997). While some may gamble without experiencing any negative results, empirical reports on the prevalence of gambling indicate a problem exists. For some, the consequences of engaging in games of luck or chance can be devastating.

Based on a thorough review of the literature, a theoretical framework was chosen for this study. This study seeks to determine if this theoretical framework (the Theory of Reasoned Action) can be used to better predict the intentions and behaviors of college student gamblers. The Theory of Reasoned Action (TRA) suggests behavior is rational and dependent on the individual's analysis of available information. The TRA defines three determinants of human behavior: intention, attitudes, and subjective norms. Ajzen and Fishbein (1980) proposed a person's behavior is determined by his intention to perform the behavior, and this intention is a function of his attitude toward the behavior and his subjective norms. Prior research by Moore and Ohtsuka (1999) found the TRA can be used effectively in gambling research. However, the current study seeks to go beyond the study of Moore and Ohtsuka by exploring possible moderating variables and 
to discover if the TRA can be useful in better explaining differences in gambling behaviors based on gender and athletic participation.

The two moderating variables that were added to the theoretical framework were gambling motivations and locus of control. Motivation is defined as an internal or external force that triggers, directs, intensifies, or leads to the persistence of a behavior. Prior research has indicated certain motivations can lead a person to become more involved in gambling (e.g., Chantal et al., 1994). The current study will examine whether these motives may moderate the relationship between gambling attitudes and intentions to gamble. While attitudes are generally important, it seems logical that stronger motives would enhance the impact of these attitudes on subsequent behavior.

Likewise, the current study will examine locus of control. Locus of control can be either internal or external. Those with an internal locus of control believe their own actions determine the awards they obtain. Those with an external locus of control believe their own behavior does not matter much and rewards in life are generally outside of their control. Prior research has suggested that an individual's locus of control may impact their gambling activities (e.g., Clarke, 2004). The current model suggests locus of control may also moderate the relationship between attitudes and intentions. By adding these two variables, the researcher hopes to gain valuable insight into researching gambling behavior of college students.

The researcher for this study chose to examine these two factors as moderating variable instead of either a mediating or antecedent variable. Vogt (2004, p. 178) defines a moderating variable as a variable that influences ("moderates") the relationship between two other variables and thus produces an interaction effect. In contrast a 
mediating variable is a variable that transmits the effects of the variable onto another variable, while an antecedent variable is a variable that comes earlier in an explanation, or in a chain of causal links as in a path analysis (Vogt, 2004). Therefore, the researchers were looking for a variable that influences the relationship between two variables in this case motivation influences the relationship between attitude and intention, while likewise locus of control influences the relationship between attitude and intention.

In addition, prior research has suggested there are differences in gambling behavior based on gender (Hira \& Monson, 2000) and athletic participation (NCAA, 2004). However, much of the prior research has not explored why these differences exist. Based on the Theory of Reasoned Action, it seems logical that if differences exist in attitudes toward gambling or subjective norms based on gender or athletic participation, this would logically lead to differences in gambling intentions and ultimately gambling behavior. Therefore, the current study will examine whether there are differences in these two variables based on gender or athletic participation.

The model used in the current study extends and expands the Theory of Reasoned Action. Two moderating variables were added between attitudes and intentions. Also gender and athletic participation were added as predictors of gambling attitudes and subjective norms. The current study will statistically examine all relationships in this model to determine if the model will be useful in helping us to better understand gambling behavior by college students. 
Figure 1: Conceptual Framework of Study

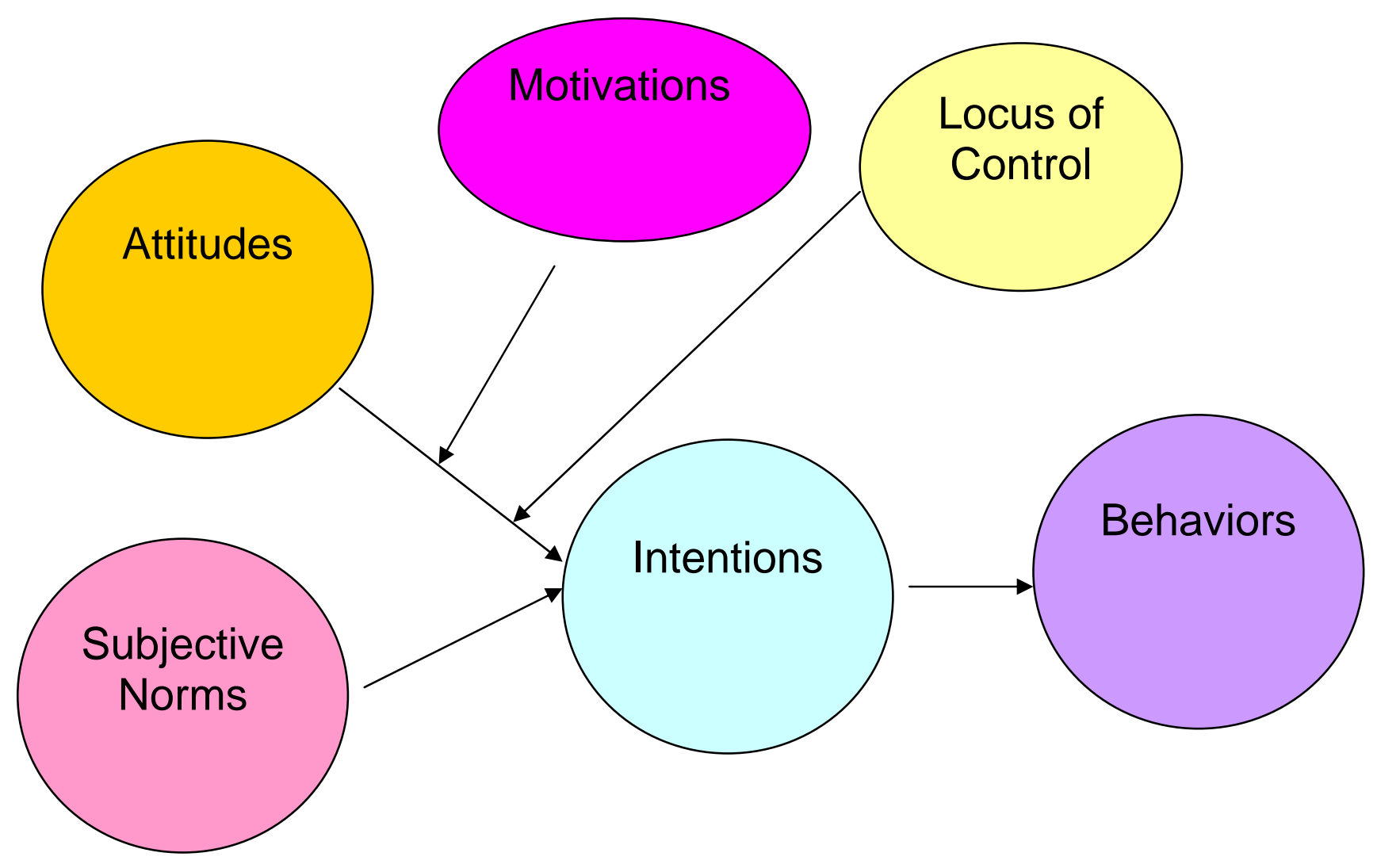

Figure 1. Adapted from Theory of Reasoned Action (Ajzen \& Fishbein, 1980). 


\section{CHAPTER III \\ METHODOLOGY}

\section{Study Purpose}

The general purpose of this study was to examine the gambling behavior of college students and, in particular, college student athletes. Specifically, this study examined the relationships among subjective norms, gambling attitudes, gambling motivations, locus of control, and gambling intentions on the gambling behavior of college students. The goal of this study was to assess gambling in a specific population with easy access to gambling and to evaluate the adequacy of the Theory of Reasoned Action (Ajzen \& Fishbein, 1980) for predicting adolescent gambling frequency and problem gambling. The following research questions were proposed:

1. Do males report significantly more positive attitudes related to gambling than females?

2. Do student athletes report significantly more positive attitudes related to gambling than other students?

3. Do males report significantly higher levels of subjective norms than females?

4. Do student athletes report significantly higher levels of subjective norms compared to other students?

5. Will attitudes related to gambling significantly and positively predict gambling intentions?

6. Will subjective norms significantly and positively predict gambling intentions?

7. Will gambling intentions significantly and positively predict gambling behavior? 
8. Will gambling motivations significantly moderate the relationship between gambling attitudes and gambling intentions?

9. Will locus of control significantly moderate the relationship between gambling attitudes and intentions?

The following sections describe the research hypotheses, survey procedures, sampling, the proposed instruments, and the statistical methods for analysis of the survey responses.

\section{Research Hypotheses}

Past research has failed to examine differences in gambling attitudes and subjective norms between either males or females or athletes or other students. Therefore, the following null hypotheses were proposed: H1: Males will not report significantly more positive attitudes related to gambling compared to females.

$\mathrm{H} 2$ : Student athletes will not report significantly more positive attitudes related to gambling compared to other students.

H3: Males will not report significantly higher levels of subjective norms compared to females.

H4: Student athletes will not report significantly higher levels of subjective norms compared to other students.

Moore and Ohtsuka (1999) found intention to gamble was significantly predicted by attitudes and subjective norms. Based on these findings, the following research hypothesis was proposed: 
H5: Attitudes related to gambling will significantly and positively predict gambling intentions.

Hira and Monson (2000) found student gambling was positively related to parental gambling and peer gambling. Moore and Ohtsuka (1999) stated respondents believed their families and friends approved of gambling, and gambling occurs the most in the families and friends of students who gambled. Based on prior research, the following hypothesis was proposed:

H6: Subjective norms will significantly and positively predict gambling intentions.

The TRA has been successful in predicting behaviors of voting choice (Bowman \& Fishbein, 1978) and wearing safety helmets (Allegrante et al., 1980), as well as with adult gambling (Oh \& Hsu, 2001). Based on prior research linking intentions to behavior, the following hypothesis was proposed:

H7: Gambling intentions will significantly and positively predict gambling behavior.

Past research has failed to examine research concerning the potential moderating impact of gambling motivations and locus of control on the relationship between attitudes and intentions. Therefore, the following null hypotheses were proposed: H8: Gambling motivations will not significantly moderate the relationship between gambling attitudes and gambling intentions.

H9: Locus of control will not significantly moderate the relationship between gambling attitudes and gambling intentions.

A graphical representation of the study hypotheses is found in Figure 2. 
Figure 2

Graphic Representation of Hypotheses

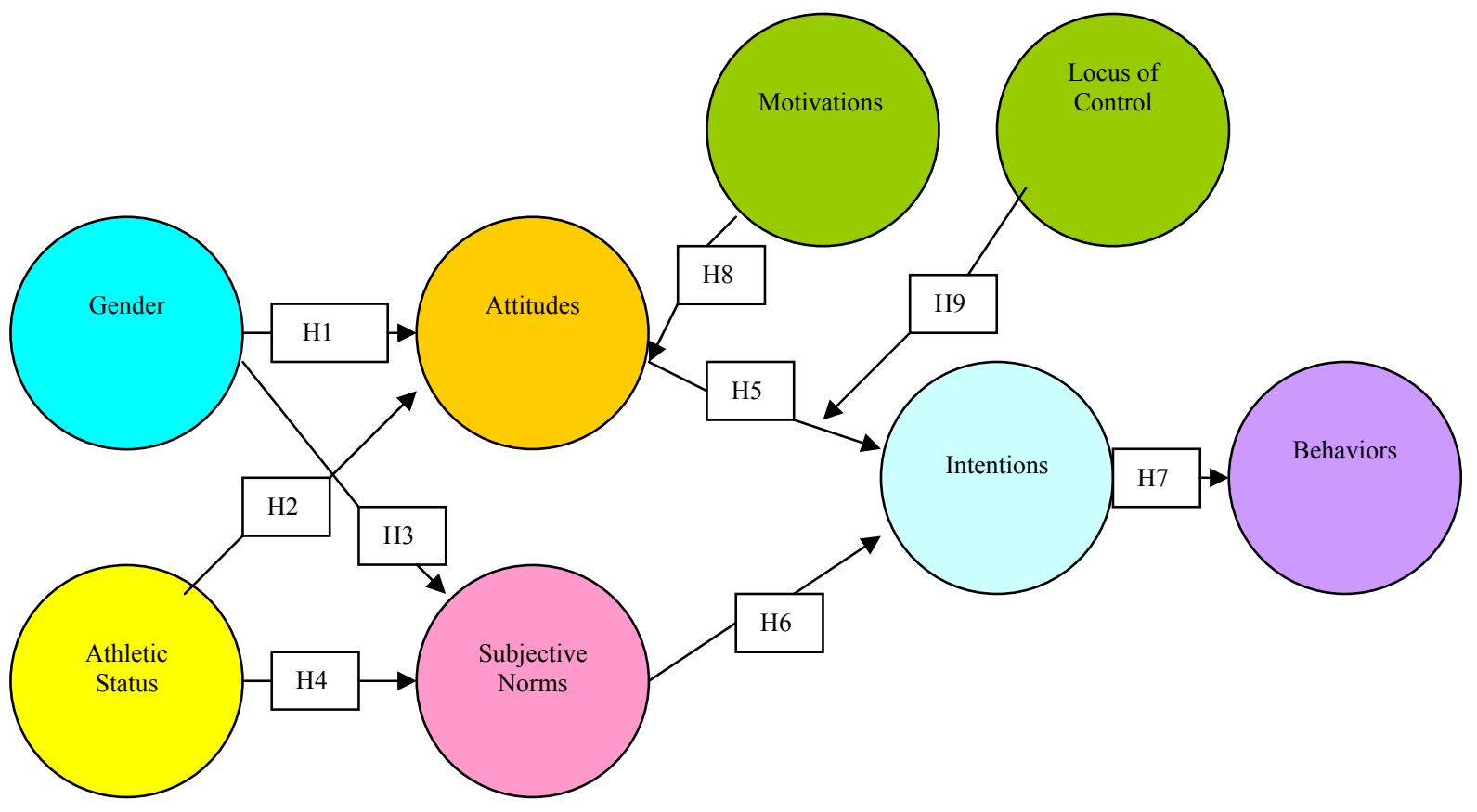

(Adapted from Ajzen and Fishbein's Theory of Reasoned Action, 1980).

The Theory of Reasoned Action (TRA) (Ajzen \& Fishbein, 1980) is a widely accepted and tested behavioral model that examines the determinants of consciously 
intended behaviors (Davis, 1989). The ultimate goal of the TRA is to predict and understand an individual's behavior (Ajzen \& Fishbein, 1980). These predictions and understandings have been applied in different fields in order to intervene and promote positive behaviors (Ajzen \& Fishbein, 1980). The TRA defines three determinants of human behavior: behavioral intention, and its antecedents, attitudes and subjective norms (Ajzen \& Fishbein, 1980). The TRA views a person's intention to perform (or not perform) a given behavior as the immediate determinant of the action (Ajzen \& Fishbein, 1980). Ajzen and Fishbein (1980) define behavioral intention as a measure of the likelihood a person will engage in a given behavior.

According to the TRA, a person's intention is a function of two basic determinants, one personal in nature and the other reflecting social influence (Ajzen \& Fishbein, 1980). The personal factor is the individual's positive or negative evaluation of performing the behavior or attitude toward the behavior (Ajzen \& Fishbein, 1980). Attitudes refer to the degree to which a person has a favorable or unfavorable evaluation or appraisal of the behavior in question (Ajzen, 1991). The second, social, determinant of intention is the person's perception of the social pressures put on him to perform or not perform the behavior in question (Ajzen \& Fishbein, 1980).

\section{Research Design}

This study incorporated a survey design, and the research variables were not manipulated. The purpose of the survey design was to generalize from a sample to a population so that inferences can be made about some characteristic, attitude, or behavior of the population (Babbie, 2001). Surveys have several advantages and disadvantages. The advantages include the following: a) surveys are particularly useful in describing the 
characteristics of a large population; b) surveys make large samples feasible; c) surveys are flexible, and d) standardized questionnaires ask exactly the same questions of all subjects and must impute the same intent to all respondents giving a particular response, thus strengthening the measurement quality (Babbie, 2001).

According to Babbie (2001), the disadvantages of survey research include (a) the requirement of standardization forces standardized questionnaire items to often represent the least common denominator in assessing people's attitudes, orientations, circumstances, and experiences; (b) surveys can be inflexible in the respect that initial survey designs typically must remain unchanged through the research study; and (c) surveys are subject to artificiality in the respect that the topic of study may not be amenable to measurement through questionnaires or the act of studying that topic (i.e., an attitude) may actually affect it. Furthermore, it is also important to note that the survey design selected for this study was cross-sectional and reflected the attitudes of the participants at one point in time. The survey questions were also superficial in the respect that they assessed attitude levels such as motivation and commitment (Andrew, 2004).

Participants were asked to answer questions in a self-report questionnaire about their level of gambling, locus of control, motivations to gamble, attitudes about gambling, subjective norms, gambling intentions and gambling behavior. The questionnaire included demographic questions, an abbreviated South Oaks Gambling Screen (Lesieur \& Blume, 1987), Levenson's Brief Locus of Control Scale (adapted by Sapp \& Harrod, 1993), the Intention to Gamble Scale (Moore \& Ohtsuka, 1999), the Subjective Norms Scale (Moore \& Ohtsuka, 1999), the Gambling Motivation Scale (Chantal et al., 1994) 
and the Gambling Attitude Scale (Moore \& Ohtsuka, 1999). All scales were adapted to a seven-point Likert-type scale for the purposes of this study. The scales were anchored on one end with the response "strongly agree" and on the other end by "strongly disagree".

\section{Participants}

Participants $(N=345)$ were recruited from the student population at the University of Louisville, a Midwestern university located with ample gambling opportunities surrounding the campus. These opportunities include pari mutuel gambling, lottery gambling, charitable gambling, and casino-style gambling. The respondents were enrolled in classes in the fall semester of 2005. Because the number of pathological gamblers is only a small percentage of the population, a large sample is desirable to examine effects between groups (Platz, 1999). While, Salant and Dillman (1994) suggested that in order to achieve a 95\% confidence level with a 50/50 split, the sample size should have been between 370 - 378, the sample size in the current study was close to that and was considered acceptable.

Students were sampled from courses in the Department of Health and Sport Sciences. Theses classes were also chosen because the researcher felt they would provide a more than adequate sample of student athletes. The researcher also felt by choosing these classes the sample would contain approximately equal cell sizes of men and women and athletes and non-athletes. They would also include students from the freshman through senior level. In order to obtain this sample, the researcher focused on three types of classes. First, a large number of 100-level health classes were chosen. These classes are taken primarily by freshman and sophomores from a variety of majors across the campus. There were also specific sections of these courses which included all 
student athletes. Second, a few sections of a 200-level course that is part of the general education program were chosen. These classes also included students from across the university. Finally, a number of upper division courses in the department were chosen. These courses included mostly juniors and seniors. Also, the majors in the department are popular among student athletes. Subjects were asked to volunteer for the study after they have been briefed on the study by the researcher. There was no penalty for nonparticipation in the study.

\section{Instrumentation}

A variety of methodological questions have been raised in recent years about research on gambling and problem gambling in the general population (Dickerson, 1993; Lesieur, 1994; Walker, 1992). The majority of gambling prevalence surveys carried out in the United States used the South Oaks Gambling Screen to assess problem and pathological gambling (Shaffer et al., 1997). Demographic questions included age, gender, ethnicity, class standing, athlete or non-athlete, scholarship or non-scholarship, and zip code of residence.

The researcher utilized existing surveys with demonstrated reliability and validity in prior studies. A panel of Sport Administration experts reviewed the preamble for this study and evaluated the content validity of the surveys to ensure these measures are adequate for this study's context.

\section{Gambling Attitude Scale}

This measure consists of 12 items used to predict positive gambling attitudes. All items were arranged with a seven-point Likert-type scale with anchors of "strongly agree" on one end and "strongly disagree" on the other end. With appropriate reversals, 
items were summed to produce a scale for which scores will range from 12 and 84, with high scores representing positive attitudes towards gambling. The Cronbach's alpha reliability measured in Moore and Ohtsuka (1999) measured .79. The attitude measure for the present study incorporated both the beliefs and the cost/benefit elements of the TRA model through the use of evaluative belief statements.

\section{Subjective Norms Scale}

This measure consists of 12 items about perceived family and peer norms with respect to gambling. All items were arranged with a seven-point Likert-type scale with anchors of "strongly agree" and "strongly disagree". The family normative beliefs scale and the peer normative scale consists of seven and five items, respectively. In Moore and Ohtsuka's (1999) study, the Cronbach's alpha were .78 for the family normative beliefs scale and .75 for the peer normative scale. To provide a measure of subjective norms, the normative beliefs items and the motivation to comply items were

combined in the manner suggested by Ajzen and Madden (1986), that is, by multiplying the beliefs of each specific referent group (family, friends) by the motivation to comply with those referents. The two measures were added together to form a single measure of subjective norms, with a reported Cronbach's alpha reliability of .69 (Moore \& Ohtsuka, 1999). High scores on the measure reflect a perception of positive social norms towards gambling and the desire to fit in with these norms (Moore \&Ohtsuka, 1999). Scores can range between 12 and 300 .

\section{Gambling Motivation Scale}

Chantal et al. (1994) developed the Gambling Motivation Scale (GMS) to measure gambling involvement. The GMS was derived from the tenets of self- 
determination theory (Deci \& Ryan, 1985; 1991). The GMS contains 28 items representing potential answers to the question: "Why do you gamble?" The items are scored on a seven-point Likert-type scale from one "strongly agree" to seven "strongly disagree". The GMS measures seven types of motivation incliuding intrinsic motivation to accomplish, intrinsic motivation to experience stimulation, identified regulation, introjected regulation, external regulation, and amotivation (Chantal et al., 1994). This scale has been validated in a sample of college students (Chantal et al., 1994).

\section{Locus of Control Scale}

The Levenson scale provides a reliable and valid scale for convenient use in studies where locus of control was not the focus of the study and when time and space are set at a premium (Sapp \& Harrod, 1993). A nine-item locus of control scale was chosen for this study. This scale was chosen because other scales (e.g., Nowiki-Strickland, 1974; Palenzuela, 1988; and Rotter, 1996). were determined to be too lengthy for the present study. Sapp and Harrod (1993) tested an abbreviated version of Levenson's locus of control scale on 137 undergraduates enrolled in an introductory sociology class. All items used a seven-point Likert-type response scale with the endpoints "strongly agree" and "strongly disagree".

Listwise deletion of missing cases (Joreskog \& Sorbom, 1989) reduced the data set to 129 cases. The abbreviated Levenson Locus of Control scale demonstrated adequate reliability and construct validity in past research. Sapp and Harrod (1993) found the abbreviated Levenson Locus of Control scale had reliability coefficients of .58 for the Internal scale, .65 for the Chance scale, and .72 for the Powerful Others scale. A path model specifying the theoretical dimensions of the scale and its effect on perceived 
risk provided a satisfactory fit for the data used (Sapp \& Harrod, 1993). All of the $t$ ratios for the loadings of the items on the three factors and for the paths between the factors and locus of control and between locus of control and perceived risk were significant at $p<$ .01 (Sapp \& Harrod, 1993).

\section{Intentions Scale}

Moore and Ohtsuka's (1999) study provided seven intentions to gamble in the future. For the purposes of the present study, the researcher added eight additional items to measure intentions for the week, the month, and the year. Items were arranged on a seven-point Likert-type scale with anchor points of "strongly agree" and "strongly disagree". In Moore and Ohtsuka's (1999) study, intentions and gender predicted actual gambling behavior. The Gambling Intentions scale had a mean score of $14.3(S D=4.7)$ representing, on average, disagreements with statements about intention to gamble. Intention to gamble was significantly predicted by attitudes and subjective norms. The more positive the attitudes toward gambling, and the more positively the subjective norms to gambling were perceived, the greater resulting intention to gamble. However, the percent of variance accounted for was not high, suggesting that other factors not assessed by Moore and Ohtsuka in their study must be contributing to gambling intention.

\section{South Oaks Gambling Screen}

The South Oaks Gambling Screen (SOGS) is a reliable, valid indicator of gambling problems (Lesieur \& Blume, 1987; Volberg \& Banks, 1990). The SOGS is scored on a 20-point scale as follows: zero $=$ no problem, one to four $=$ some problems, five or more $=$ probable pathological gambler (Lesieur \& Blume, 1987). The SOGS was initially developed and intended for diagnostic use with adults in a clinical setting 
(Rossen, 2001). The SOGS correlates highly with the Diagnostic Statistical Manual-III$\mathrm{R}$ and the Diagnostic Statistical Manual-IV with demonstrated validity and reliability among university students (Beaudoin \& Cox, 1999; Ladouceur et al., 1994; Lesieur et al., 1991).

The SOGS was used to measure respondent gambling behavior. The original SOGS was modified from a 20 -item scale to a 2 -item scale to fit the needs of this study. This corresponds with the approach taken by Moore and Ohtsuka (1999). Research on the performance of the SOGS has shown the lifetime screen is very effective at detecting pathological gambling among those who currently experience the disorder.

The SOGS accomplishes three purposes. First, it provides information on the extent to which the respondents have participated in specific types of gambling activities. Secondly, it gauges the probability the respondent may be a problem or pathological gambler. Finally, the screen provides insights into the respondent's association with gambling. Reliability of the instrument was verified with an internal consistency check showing the SOGS to be highly reliable (Cronbach's alpha $=.97, p<.001$ ) and a testretest correlation coefficient yielded a positive correlation of .71 $(p<.001$ Lesieur et al., 1991).

\section{Data Collection}

Once permission was received from the University's Institutional Review Board (Appendix C), the investigators distributed the questionnaires in the classroom setting. The 90-item questionnaire and a cover letter explaining the study is contained in Appendix D. The questionnaires were distributed during class time. Professors were contacted prior to the distribution of the questionnaires to determine the appropriate time 
for handing out the questionnaires. All respondents were undergraduates, because very few student athletes are in graduate programs. The respondents were advised to read a cover letter and remove it from the questionnaire so he/she was able to contact the investigator if needed. The respondents were given instructions on how to complete the survey instrument. The respondents were not compensated for their time. All questionnaires were held in utmost confidentiality. To ensure truthful responses, respondent anonymity was assured by requiring no respondent names on the questionnaires. The completed surveys were collected by the investigator. The completed questionnaires were manually coded by the investigator.

\section{Moderating Variables}

A moderating variable alters the effects of an independent or predictor variable on a dependent or criterion variable (Markland, 2000). Moderation is perhaps more familiar to researchers in the guise of interactive effects among independent variables and is frequently analyzed within a two (or more) factor analysis of variance (ANOVA) framework (Markland, 2000). In this study, two moderating variables were used to test the effects of one independent variable upon the levels of a dependent variable. In this study, motivations to gamble were chosen as the first moderating variable and tested the effects of the interaction between attitudes towards gambling and gambling intentions to see if an alteration will occur: 
Figure 3. Moderating Variable: Motivation to Gamble

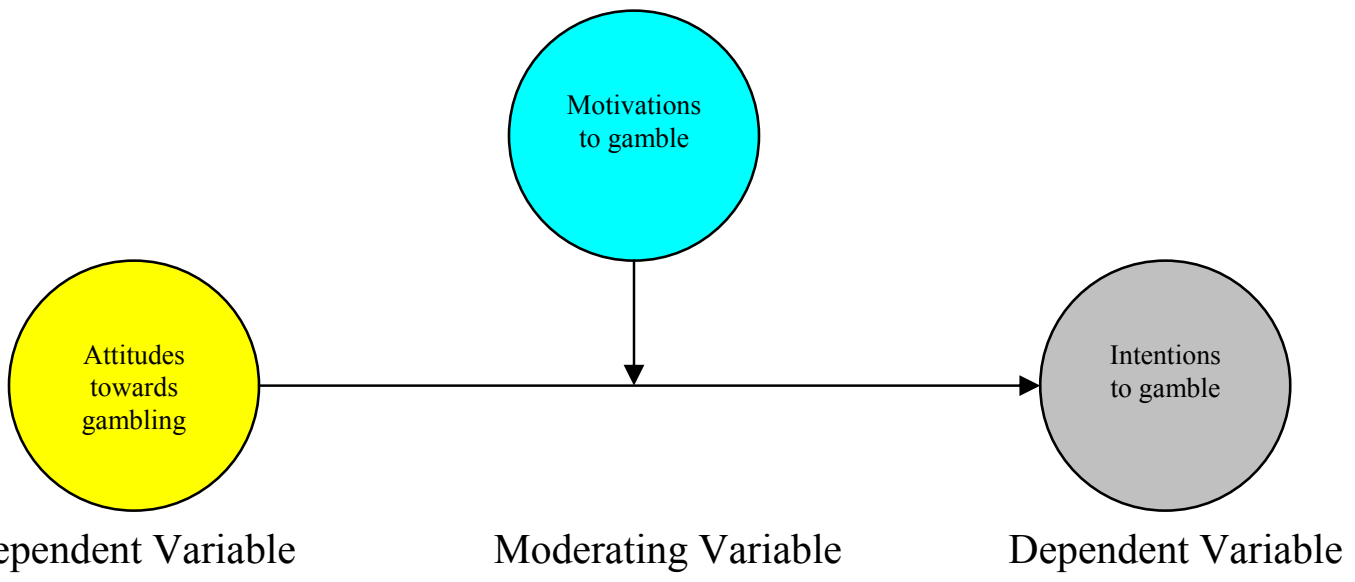

The second moderating variable was locus of control and tested the effects of the interaction between attitudes towards gambling and intentions to gamble to see if an alteration will occur:

Figure 4. Moderating Variable: Locus of Control

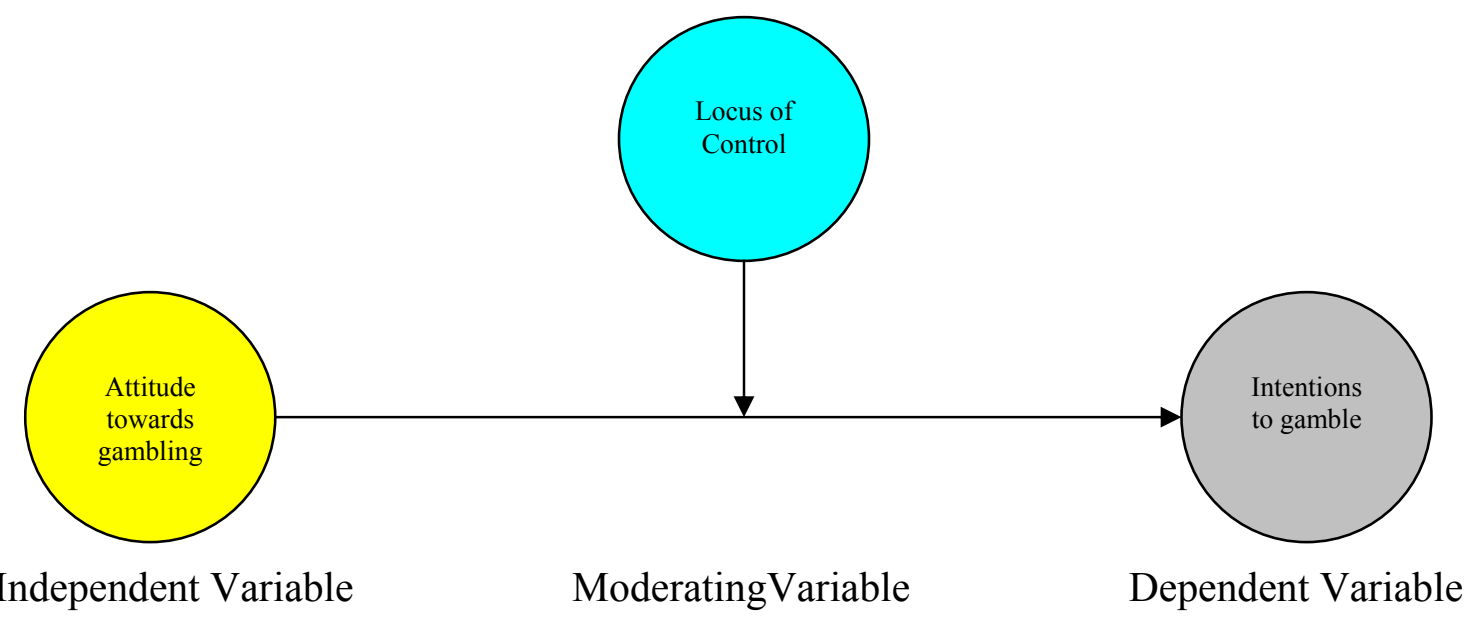

In different circumstances, the moderating influence may result in an enhancement of the effects of the independent or criterion variable, a reduction in the effects, or a change in the direction of the effects (Markland, 2000). In other words, a moderating relationship can be thought of as an interaction, it occurs when the relationship between 
two variables (A and B) depends on the level of another variable, the moderating variable (C). In this study, the moderating variables; locus of control and motivations to gamble might moderate the effects of a relationship between attitude to gamble and intention to gamble by college student athletes and other students. Depending on the nature of the interaction and the performance task, locus of control or motivations to gamble, college student athletes or other students might conceivably show greater attitudes to gamble, lesser attitudes to gamble, or no improvement. While the possible moderating effect of these variables has not been examined in prior research, the researcher believed that it was possible that such an effect may exist. Both motivations to gamble and locus of control have internal and external effects that could moderate the relationship of attitude to gamble and intention to gamble.

For the purposes of this study the researcher chose to use gambling motivations and locus of control as moderating variables instead of as mediating variables or antecedent variables. Moderator variables always function as independent variables, whereas mediating events shift roles from effects to causes, depending on the focus of the analysis (Baron \& Kenny, 1986). A mediating variable is concerned with the transmission of effects or the mechanism by which an independent or predictor variable exerts its influence on a dependent or criterion variable (Markland, 2000). The mediating variable does not alter or modify the effects of the independent variable in any way; it is simply the mechanism by which the independent variable influences the dependent variable. Mediators explain how external physical events take on internal psychological significance (Baron \& Kenny, 1986). To demonstrate mediation one must establish strong relations between (a) the predictor and the mediating variable and (b) the 
mediating variable and some distal endogenous or criterion variable (Baron \& Kenny, 1986).

The researcher examined gambling motivations and locus of control as moderating variables in this study, because it was believed the relationship between gambling attitude and gambling intentions was present before and these moderator variables might affect the relationship between attitudes and intentions. However, it was not believed high levels of these variables were necessary for attitudes to impact interactions (i.e., a high internal locus of control is not necessary for positive gambling attitudes to impact gambling intentions), so it would not be appropriate to examine them as mediators. In addition, they were examined as antecedent variables, because it was believed the relationship of gambling attitude to gambling intention was not determined by earlier motivations to gamble or locus of control prior to the explanation, or in a chain of casual links as in a path analysis.

To address the role of motivation to gamble as a moderator, the presumed moderator was entered into the regression equation. Then, the moderator terms formed by multiplying the moderators (motivation to gamble) by the independent variables were entered into the regression model. If the change in $\mathrm{R}^{2}$ is significant, the identification was deemed to moderate the relationship between gambling attitude and intention to gamble. To address the role of locus of control as a moderator, the presumed moderator was entered into the regression equation. Then, moderator terms formed by multiplying the moderator (locus of control) by the independent variables were entered into the regression model. If the change in $\mathrm{R}^{2}$ is significant, then locus of control was deemed to moderate the relationship between gambling attitude and gambling intention. 


\section{Behavior Intention-Behavior Relation}

Because Fishbein and Ajzen's (1975; Ajzen \& Fishbein, 1980) attitude Theory of Reasoned Action is in general, highly sophisticated at both the conceptual and quantitative levels, it provides a good example of the extent of confusion regarding mediators and moderators (Baron \& Kenny, 1986). Moreover, this model, as Bentler and Speckart (1979) have demonstrated, readily lends itself to a causal modeling approach. Specifically, behavior intention (BI) is a clear-cut example of a mediator concept in social psychology. Fishbein and Ajzen (1980) assumed the impact of both attitudes and normative factor on behavior (B) are mediated through behavioral intentions. Although one can disagree with Fishbein and Ajzen's assertion that attitudes and norms can influence behavior only indirectly through behavioral intention (Bentler \& Speckart, 1979; Songer-Nocks, 1976), their formulation represents a correct statement of a strong mediator position.

Surprisingly, however, given the elegance of their general model, similar care was not taken regarding the nature of the BI-B link (Baron \& Kenny, 1986). For example, Fishbein and Ajzen's treatment of this reaction failed to distinguish between variables that are likely to moderate this relation. Such diverse variables as gender, time delay, perceived likelihood of co-workers complying, skill, and resources were all treated as mediating factors (Fishbein \& Ajzen 1975).

From the present perspective, such an approach ignores the possibility that some of these factors are best conceptualized and treated statistically as moderators whereas others are best viewed as mediators (Baron \& Kenny, 1986). For example, gender of subjects is best viewed as a moderator of the BI-B relation (Baron \& Kenny, 1986). 
Given this distinction, different analysis strategies are entailed at the statistical level, specifically, Fishbein and Ajzen (1980) tested the importance of given factors by looking at the impact on the multiple correlation of dropping or adding a variable. This type of strategy, which is analogous to treating a covariate as a potential mediator, is best used to infer mediation as opposed to moderation (Baron \& Kenny, 1986). For testing a moderator interpretation, what is required is a term involving the product of $\mathrm{BI}$ and the hypothesized moderator; for example, one would construct a Gender x BI interaction term to test for gender as a moderating variable (Baron \& Kenny, 1986).

\section{Data Analysis}

Data analysis was calculated for each of the demographic variables. Cronbach's Alpha coefficients were calculated for the components of each measurement scale to verify internal consistency. Nunnally and Burnstein's (1994) recommended alpha value of .70 was utilized to evaluate the internal consistency of each subscale. Descriptive statistics were calculated for each of the demographic variables.

MANOVA

A series of factorial multivariate analyses of variance were utilized to determine predictive relationships between group means. Factorial multivariate analysis of variance is a test of statistical significance allowing for the simultaneous study of two more related dependent variables while controlling for the correlations among them (Vogt, 2004).

Assumptions for factorial multivariate analyses of variance are (a) independence: the score for any particular subject is independent of the scores of all other subjects (i.e. it provides a unique piece of information about the effect), (b) normality - the scores 
within each cell of design are drawn from a population in which scores are normally distributed, and (c) homogeneity of variances - the variances of scores in the populations underlying all the cell of the design are equal (Shavelson, 1996).

Factorial multivariate analyses of variance were used to analyze the following hypotheses:

H1: Males will not report statistically more positive attitudes related to gambling than females.

H2: Student athletes will not report significantly more positive attitudes related to gambling than other students.

H3: Males will not report statistically higher levels of subjective norms than females. H4: Student athletes will not report significantly higher levels of subjective norms compared to other students.

Simple Linear Regression

A series of simple linear regressions were utilized to determine the additive predictive relationships of a selected independent variable on selected dependent variables. Simple linear regression was utilized in the following hypotheses: H5: Attitudes related to gambling will significantly and positively predict gambling intentions.

H6: Subjective norms will significantly and positively predict gambling intentions. H7: Gambling intentions will significantly and positively predict gambling behavior.

Hierarchical Linear Regression

A series of hierarchical linear regressions were utilized to determine the addictive 
predictive relationships of selected moderating variables on the relationship between selected variables. Hierarchical linear regression is a form of multiple regression. Multiple linear regression is a method of regression analysis that uses more than one independent variable to predict a single dependent variable (Vogt, 2005). Hierarchical linear regression allows the researcher to input the independent variables one at a time and see the additional variance predicted as each variable is input.

Assumptions for multiple regression are (a) the variables have normal distributions, (b) the relationships between the independent and dependent variables are linear in nature, (c) the measurement instruments are reliable, and (d) the variance errors are the same across all levels of the independent variable (Thomas et al., 2005).

Hierarchical linear regression was utilized in the following hypotheses: H8: Gambling motivations will not significantly moderate the relationship between gambling attitudes and gambling intentions.

H9: Locus of control will not significantly moderate the relationship between gambling attitudes and intentions.

In each case, the moderating variable was entered in the analysis after entering gambling attitudes and the change in $R^{2}$ was interpreted to determine if the factor was a significant moderator.

Groupwise Error and the Bonferroni Procedure

Whenever researchers use multiple tests of significance the probability of getting a Type I error increases. This potential problem is dealt with by recognizing the distinction between the error rate of a single statistical test and the groupwise error rate of a set of tests (Morrison, 2002). When there is a series of tests being performed, each 
separate test has its own individual error rate, but researchers are also interested in the cumulative probability associated with the series of tests as a whole, which is the groupwise error rate (Morrison 2002). The simplest and best-known procedure for controlling the groupwise error rate is to use the Bonferroni correction. In this procedure, the researcher choose the groupwise error rate, $p^{l}$, and then calculated the individual error rate as $P=p^{1} / j$, where $j$ is equal to the number of analyses performed (Morrison, 2002). In the current study, the conventional significance level of .05 was used, to determine the Bonferroni correction, the researcher divided the significance level of .05 by the number of analyses performed, in this case five. The Bonferroni correction significance level would be .01 , which was used to determine the significance of the tests for each of the analyses associated with Hypothesis 8 ad Hypothesis 9.

\section{Summary}

In conclusion, this chapter described the methodology for obtaining outcome information about attitudes and motivations of college students and the effects on gambling behavior at the University of Louisville. This chapter contains a detailed description of the instruments used in the data analysis. The statistical analysis used in answering each research question was described. 


\section{CHAPTER IV}

\section{RESULTS}

The general purpose of this study was to examine the gambling behavior of college students and, in particular, college student athletes. Specifically, this study examined the relationships among subjective norms, gambling attitudes, gambling motivations, locus of control, and gambling intentions on the gambling behavior of college students. The goal of this study was to assess gambling in a specific population with easy access to gambling and to evaluate the adequacy of a modified Theory of Reasoned Action (Ajzen \& Fishbein, 1980) for predicting gambling frequency and problem gambling. The following research questions were examined:

1. Do males report significantly more positive attitudes related to gambling than females?

2. Do student athletes report significantly more positive attitudes related to gambling than other students?

3. Do males report significantly higher levels of subjective norms than females?

4. Do student athletes report significantly higher levels of subjective norms compared to other students?

5. Will attitudes related to gambling significantly and positively predict gambling intentions?

6. Will subjective norms significantly and positively predict gambling intentions? 
7. Will gambling intentions significantly and positively predict gambling behavior?

8. Will gambling motivations significantly moderate the relationship between gambling attitudes and gambling intentions?

9. Will locus of control significantly moderate the relationship between gambling attitudes and intentions?

This chapter will detail the results of the questionnaire by examining the demographic characteristics of the respondents, reliability of the survey instrument, and the general results of the nine hypotheses, along with relevant tables of the findings.

Data Analysis

The data were analyzed using SPSS, Version 13.0 (SPSS Inc., Chicago, IL). Descriptive statistics were calculated for each of the demographic variables. A factorial analysis of variance was utilized to determine relationships between group means. A series of simple and multiple linear regressions were utilized to determine the predictive relationships of selected independent variables, dependent variables, and moderating variables, when appropriate.

Demographic Variables

The convenience sampling resulted in a total of 345 student participants registered in classes offered in the Health and Sport Sciences at the University of Louisville. The sample was $57.7 \%$ male (199) and $42.3 \%$ female (146). There were 164 athletes in the sample, representing $47.5 \%$ of the total population. Age of the subjects ranged from 18 to 59 with a mean age of $21.01(S D=3.895$ years). The majority of the sample was White American (78\%), with the remainder of the sample reporting as follows: African 
American (13\%), Hispanic American (2\%), Native American (2\%), Asian American (1\%), and Others (4\%). The ethnicity of the sample was representative of the 2005 university student population as a whole $($ White American $=78.1 \%$; African American $=$ $11.5 \%$; All other minorities $=10.4 \%$ ). Approximately $55 \%$ of the sample resided in dormitories, $19.1 \%$ in apartments, $18.6 \%$ in their parent's home, $7 \%$ in their own homes, and less than $1 \%$ in fraternity or sorority houses. The sample was divided into four class groups with $29.9 \%$ freshmen, $14.5 \%$ sophomores, $21.5 \%$ juniors, and $34.5 \%$ seniors. Six percent of the sample were members of revenue producing athletic teams (football and men's basketball), while $41.5 \%$ were members of other varsity sports teams. Ninetythree percent of the sample were single, $5.8 \%$ married, $.3 \%$ divorced, and $.9 \%$ widowed.

\section{Reliability of the Survey Instrument}

The instrument used in this study was composed of subscales validated by previous researchers. Alpha (Cronbach) coefficients were calculated for the components of each measurement survey instrument to verify internal consistency. The internal consistency estimates for every component of each of the scales are featured in Table 1. Two of the scales contained unreliable information. The gambling attitude scale was only reliable after the deletion of items 3 and 8 , and the gambling motivation scale for intrinsic motivation to experience stimulation was found to be unreliable $(\alpha=.468)$. Items 3 and 8 of the gambling attitude scale contained statements concerning a respondent's perceptions of whether others need professional help to control their gambling behavior. Since these items are highly situation-specific compared to the other scale items, their inclusion adversely affected overall scale reliability. 
Table 1

Reliability Estimates of Instrument

Scale

Alpha Level

Gambling Attitude Scale

$.810^{*}$

Subjective Norms Scale

.834

Gambling Intentions Scale

.900

South Oaks Gambling Screen 1-2

Gambling Motivation Scale: Intrinsic Motivation to Know

.903

Gambling Motivation Scale: Intrinsic Motivation to Accomplish

Gambling Motivation Scale: Intr. Motivation to Experience Stimulation

$.468 * *$

Levenson's Brief Internal Locus of Control Scale

Levenson's Brief Chance Locus of Control Scale

Levenson's Brief Powerful Others Locus of Control Scale

.879

*Resulting reliability when Items 3 and 8 deleted

** Scale dropped; scale too unreliable for statistical analysis.

$\mathrm{H} 1-\mathrm{H} 4$

Hypotheses Testing

A $2 \times 2$ between-subjects multivariate analysis of variance was performed on two dependent variables: gambling attitudes and subjective norms. Independent variables were gender and athletic status. The overall main effect for gender was significant ( $p=$ $.000)$. However, the overall main effect for athlete $(p=.538)$ and the gender/athlete interaction ( $p=.872$ ) was not significant. With the use of Wilks' criterion, the combined dependent variables (attitudes and subjective norms) were significantly affected by gender, $F(2,343)=11.29, p=.000$, but was not by athlete, $F(3,342)=.622, p=.538$ or 
the gender/athlete interaction $F(2,343)=.137, p=.000$. The results reflected a association between gender and gambling attitudes (partial $\eta^{2}=.062$ ) but not subjective norms. There was no association between athlete and athlete/gender interaction. Male Attitude and Female Attitude towards Gambling Hypothesis 1 proposed males would not report significantly more positive attitudes to gambling than females. Hypothesis 1 was rejected because males $(4.6176+/-$ 1.07569) did report statistically $(p=.008)$ more positive attitudes toward gambling than females $(4.2870+/-1.08553)$. These means are included in Table 2.

Student Athlete Attitude and Other Student Attitude towards Gambling

Hypothesis 2 proposed student athletes would not report significantly more positive attitudes related to gambling than other students. Hypothesis 2 was accepted because athletes $(4.4098+/-1.01934)$ did not report significantly $(p=.451)$ more positive attitudes toward gambling than non-athletes $(4.5392+/-1.15078)$. These means are included in Table 2 .

Male Subjective Norms and Female Subjective Norms

Hypothesis 3 proposed males would not report statistically higher levels of subjective norms than females. Hypothesis 3 was accepted because males $(4.8320+/-$ 1.17758) did not report significantly $(p=.851)$ higher levels of subjective norms than females $(5.0235+/-.99075)$. These means are included in Table 2 .

Student Athlete Subjective Norms and Other Student Subjective Norms

Hypothesis 4 proposed student athletes would not report significantly higher levels of subjective norms compared to other students. Hypothesis 4 was accepted because athletes $(4.8548+/-1.03280)$ did not statistically $(p=.270)$ differ from non- 
athletes $(4.9658+/-1.16680)$ in regards to reported subjective norms. These means are included in Table 2.

Table 2

Means and Standard Deviations of Gambling Attitudes and Subjective Norms by Gender and Athlete Status

Mean $\mathrm{SD} \quad \mathrm{N}$

Total Gambling Attitude Scale

Male Athletes

4.57

$.93 \quad 83$

Male Non-Athletes

4.64

4.61

$1.16 \quad 116$

All Males

4.23

$1.07 \quad 199$

Female Athletes

4.34

$1.07 \quad 81$

Female Non-Athletes

All Females

4.28

$1.10 \quad 65$

All Athletes

4.40

All Non-Athletes

4.53

4.47

$1.08 \quad 146$

All Students

Male Athletes

4.73

4.90

4.83

$\begin{array}{ll}1.01 & 164\end{array}$

Male Non-Athletes

All Males

4.83

$1.15 \quad 181$

$1.09 \quad 345$

Female Athletes

4.97

$1.12 \quad 83$

Female Non-Athletes 5.07

$1.21 \quad 116$

All Females

5.02

$1.17 \quad 199$

All Athletes

4.85

$.92 \quad 81$

All Other Students

4.96

$1.07 \quad 65$

All Students

4.91

$.99 \quad 146$

$\begin{array}{ll}1.03 & 164\end{array}$

$1.16 \quad 181$

$1.10 \quad 345$


$\mathrm{H} 5-\mathrm{H} 7$

Simple linear regression was used to analyze the data in hypotheses five, six and seven. The main objectives of these three hypotheses were to determine if gambling attitudes would predict gambling intentions (Hypothesis 5), if subjective norms would predict gambling intentions (Hypothesis 6), and if gambling intentions would predict gambling behavior (Hypothesis 7).

Gambling Attitudes and Gambling Intentions

Hypothesis 5 proposed attitudes related to gambling would significantly and positively predict gambling intentions. Hypothesis 5 was accepted because attitudes related to gambling significantly $(p=.000)$ and positively $(\beta=.223)$ (Table 3$)$ predict gambling intentions. The $R^{2}$ was .05 which meant that $5 \%$ of the variance in intention to gamble was accounted for by gambling attitude.

Table 3

Summary of Regression Analysis for Variables predicting Gambling Intentions

$\underline{\text { Variable }}$

Attitude

Note. $R^{2}=.05$

$* p<.05$

Subjective Norms and Gambling Intentions

Hypothesis 6 proposed subjective norms would significantly and positively predict gambling intentions. Hypothesis 6 is accepted because subjective norms significantly $(p=.005)$ and positively $(\beta=.151)$ (Table 4$)$ predicted gambling intentions. 
Table 4

Summary of Regression Analysis for Variables predicting Gambling Intentions

Variable

Subjective Norms

Note. $R^{2}=.02$

$* p<.05$
B .187
SE B .066
$.151 *$

Intention to gamble was significantly predicted by attitudes and subjective norms. The more positive the attitudes toward gambling, and the more positive the reported subjective norms, the greater the intention to gamble. However, the percent of variance accounted for by each independent variable was low (5\% and 2\% respectively), suggesting that other factors may contribute to gambling intentions. However, the effect sizes were in the medium and small-medium range (Cohen 1988), so the relationships are still important to interpret.

Gambling Intentions and Gambling Behaviors (SOGS 1A-K Total)

Hypothesis 7 proposed gambling intentions would significantly and positively predict gambling behavior in terms of specific types of gambling. Hypothesis 7 is supported because gambling intentions significantly $(p=.009)$ and positively $(\beta=.140)$ (Table 5) predicted gambling behavior. 
Table 5

Summary of Regression Analysis for Variables predicting Gambling Behavior

$\underline{\text { Variable }}$

Intention

Note. $R^{2}=.02$

$* p<.05$

Specific types of gambling behaviors were significantly predicted by intention to gamble. Moreover, the percent of variance accounted for by gambling intentions was only $2 \%$, suggesting that other factors may contribute to gambling behavior, it would be classified $\mathrm{n}$ the range of a small-medium effect size (Cohen, 1988).

H8 - H9

The Influence of Intrinsic Motivation to Know on Gambling Attitudes and Gambling Intentions

A series of five hierarchical regression analyses were used for Hypothesis 8 and 9 in order to control for a Type I error, a Bonferroni correction was used which resulted in a significance level of.01. Hypothesis 8a proposed intrinsic motivation to know would not significantly moderate the relationship between gambling attitudes and gambling intentions.

Total gambling intention scale, total gambling attitude scale, intrinsic motivation to know, and the total gambling attitude scale/ intrinsic motivation to know interaction were significantly correlated. Hypothesis $8 \mathrm{a}$ is rejected because intrinsic motivation to know significantly $(p=.041)$ (Table 6 ) moderated the relationship between gambling attitudes and gambling intentions. The results of the regression analysis were significant, 
$F(3,341)=14.435, p=.000$. However, the moderating variable must be interpreted with caution for two reasons. First, while the $\Delta R^{2}$ was significant at the .05 level, it was not significant at the .01 level suggested by the Bonferroni correction. Second, the $\Delta R^{2}$ was on $1 \%$ indicating the effect size is small (Cohen, 1988).

Table 6

Hierarchical Regression Analysis for the Interaction Effect Intrinsic Motivation to Know and Gambling Attitudes on Gambling Intentions

Variable

Step 1

Gambling Attitude

Intrinsic Motivation to Know
.222

.179
SE B

.065

.040

.129
$.177 *$

$.232 *$

Step 2

Gambling Attitude

Intrinsic Motivation to Know

Attitude X Motivation to Know -.067
.449

.470
.147 $-.067 \quad .033$

Note. $R^{2}=.102$ for Step $1 ; \Delta R^{2}=.011$ for Step $2(p<.041)$ $* p<.05$

Influence of Intrinsic Motivation to Accomplish on Gambling Attitudes and Gambling Intentions

Hypothesis $8 \mathrm{~b}$ proposed intrinsic motivation to accomplish would not significantly moderate the relationship between gambling attitudes and gambling intentions. Hypothesis $8 \mathrm{~b}$ is rejected because intrinsic motivation to accomplish significantly $(p=.002)$ moderated the relationship between gambling attitudes and 
gambling intentions. The results of the regression analysis were significant, $F(3,341)=$ $20.009, p=.000$.

Table 7

Hierarchical Regression Analysis for the Interaction Effect of Intrinsic Motivation to Accomplish and Gambling Attitudes on Gambling Intentions

Variable

$\mathrm{B}$

SE B

$\beta$

Step 1

Gambling Attitudes

Intrinsic Motivation to Accomplish
.255

.242

Step 2

Gambling Attitudes

Intrinsic Motivation to Accomplish

Attitudes X Intrinsic Motivation-Accomplish -.107

Note. $\mathrm{R}^{2}=.125$ for Step $1 ; \Delta \mathrm{R}^{2}=.024$ for Step $2(p<.002)$.

$* p<.05$

Total gambling intention scale, total gambling attitude scale, intrinsic motivation to accomplish, and the gambling attitudes/intrinsic motivation to accomplish were significantly correlated. Since the change in R-square was significant $(p=.002)$ (Table 7), intrinsic motivation to accomplish was deemed to moderate the relationship between gambling attitudes and gambling intentions. The variable predicted $2.4 \%$ of the variance indicating the effect size was in the small to medium range (Cohen, 1988). 
Influence of Intrinsic Motivation to Experience Stimulation and Gambling Attitudes, on Gambling Intentions

Hypothesis 8c proposed intrinsic motivation to experience stimulation would not significantly moderate the relationship between gambling attitudes and gambling intentions. Due to the unreliability of the scale this hypothesis was not evaluated. Influence of Internal Locus of Control on Gambling Attitudes, and Gambling Intentions Hypothesis 9a proposed internal locus of control would not significantly moderate the relationship between gambling attitudes and gambling intentions. Hypothesis 9a is rejected because internal locus of control significantly $(p=.000)$ moderated the relationship between gambling attitudes and gambling intentions. The results of the regression analysis were significant, $F(3,341)=18.011, p=.000$.

Table 8

Hierarchical Regression Analysis for the Interaction Effect Internal Locus of Control and Gambling Attitudes on Gambling Intentions

Variable B

SE B

$\beta$

Step 1

Gambling Attitudes .350

.067 $.279 *$

Internal Locus of Control $-.206$

.054

$-.205 *$

Step 2

Gambling Attitudes

$$
-.511
$$

.209

$-.408 *$

Internal Locus of Control $-.813$

Attitudes X Internal Locus of Control

Note. $R^{2}=.089$ for Step $1 ; \Delta R^{2}=048$ for Step $2(p<.001)$ $* p<.05$ 
Gambling intentions, gambling attitudes, internal locus of control, and the gambling attitudes/internal locus of control interaction were significantly correlated. There was a negative correlation between internal locus of control and total gambling intention. This small correlation of $r=-.129$ indicated a negative relationship between internal locus of control and total gambling intention. Since the change in R-square was significant $(p=.000)$ (Table 8$)$, internal locus of control was deemed to moderate the relationship between gambling attitude and gambling intentions. The percent of variance predicted (4.8\%) was lose to the range for a medium effect size (Cohen, 1988). Influence of Chance Locus of Control on Gambling Attitudes, and Gambling Intentions

Hypothesis $9 \mathrm{~b}$ proposed chance locus of control would not significantly moderate the relationship between gambling attitudes and gambling intentions. Hypothesis $9 \mathrm{~b}$ is rejected because chance locus of control significantly $(p=.000)$ moderated the relationship between gambling attitudes and gambling intentions. The results of the regression analysis were significant, $F(3,341)=30.877, p=.000$. 
Table 9

Hierarchical Regression Analysis for the Interaction Effect Chance Locus of Control and Gambling Attitudes on Gambling Intentions

Variable

Step 1

Gambling Attitudes

Chance Locus of Control

Step 2

Gambling Attitudes .938

Chance Locus of Control

Attitudes X Chance Locus of Control
B SE B

$$
.253
$$

.063

.050

Note. $R^{2}=.136$ for Step $1 ; \Delta R^{2}=.078$ for Step $2(p<.001)$. $* p<.05$

Gambling intentions, gambling attitudes, chance locus of control, and the attitudes/chance locus of control interaction were significantly correlated. Since the change in R-square was significant $(p=.000)$ (Table 9), chance locus of control was deemed to moderate the relationship between gambling attitudes and gambling intentions. The percent of variance predicted was $7.8 \%$, indicating an effect size in the medium to large range (Cohen, 1988).

Influence of Powerful Others Locus of Control, Gambling Attitudes, and Gambling Intentions

Hypothesis 9c proposed powerful others locus of control would not significantly moderate the relationship between gambling attitudes and gambling intentions. Hypothesis $9 \mathrm{c}$ is rejected because powerful others locus of control significantly $(p=.000)$ 
moderated the relationship between gambling attitudes and gambling intentions. The results of the regression analysis were significant, $F(3,341)=31.470, p=.000$.

Table 10

Summary of Hierarchical Regression Analysis for Powerful Others Locus of Control and Gambling Attitudes on Gambling Intentions

Variable

$\mathrm{B}$

SE B

$\beta$

Step 1

Gambling Attitudes

.299

.064

$.239 *$

Powerful Others Locus of Control

.235

.046

$.258 *$

Step 2

Gambling Attitudes .871 .105 $.696 *$

Powerful Others Locus of Control

Attitudes X Powerful Others Locus of Control

$-.211$

.032 $-1.106 *$

Note. $R^{2}=.116$ for Step $1 ; \Delta R^{2}=.101$ for Step $2(p<.001)$ $* p<.05$

Gambling intentions, gambling attitudes, powerful others locus of control, and the attitudes/powerful others locus of control interaction were significantly correlated. There was a negative correlation between powerful others total and total gambling attitude scale. A trivial negative correlation of $r=-.060$ was found between powerful others total and total gambling attitude scale, suggesting as the influence of powerful others decreases gambling attitude increases. However, it is important to note that the magnitude of this negative correlation is relatively small. Since the change in R-square was significant $(p=.000)$ (Table 10), powerful others locus of control was deemed to moderate the relationship between gambling attitudes and gambling intentions. The 
percent of variance predicted by powerful others locus of control as over $10 \%$, which indicates the effect size is in the medium to large range (Cohen, 1988).

\section{Summary}

This chapter presented the results of the study. It began with the purpose of the study as well as an explanation of the techniques used to run the data analysis. The overall sample was described in the demographic variables section. The instrument used in this study was composed of subscales validated by previous researchers. The nine hypotheses were reviewed and analyzed based on the data obtained. Hypothesis 1 was rejected because males did report statistically different attitudes towards gambling than females. Hypothesis 2 was accepted because student athletes did not report significantly less positive attitudes toward gambling than non-athletes. Hypothesis 3 was accepted because males did not report significantly higher levels of subjective norms than females. Hypothesis 4 was accepted because athletes did not statistically differ from non-athletes in regards to reported subjective norms. The overall main effect for gender was statistically significant, but the athlete and the gender/athlete interaction were not statistically significant.

Hypothesis 5 was accepted because attitudes related to gambling significantly and positively predicted gambling intentions. Hypothesis 6 was accepted because subjective norms significantly and positively predicted gambling intentions. Hypothesis 7 was supported because gambling intentions significantly and positively predicted the type of gambling students took part in.

Hypotheses $8 \mathrm{a}$ and $8 \mathrm{~b}$ examined potential moderating variables chosen by the researcher. Hypothesis 8 a was rejected because the moderator, intrinsic motivation to 
know, significantly moderated the relationship between gambling attitudes and gambling intentions. However, the change in R-square was not significant when using the Bonferroni correction, so this result should be interpreted with caution. Hypothesis $8 \mathrm{~b}$ was rejected because intrinsic motivation to accomplish significantly moderated the relationship between gambling attitudes and gambling intentions. Because the change in R-square was statistically significant, intrinsic motivation to accomplish was deemed to moderate the relationship between gambling attitudes and gambling intentions.

Hypotheses 9a, 9b, and 9c examined potential moderating variables chosen by the researcher. Hypothesis 9a was rejected because internal locus of control significantly moderated the relationship between gambling attitudes and gambling intentions. There was a negative correlation between internal locus of control and total gambling intention. Because the change in R-square was significant, internal locus of control was deemed to moderate the relationship between gambling attitude and gambling intention. Hypothesis $9 \mathrm{~b}$ was rejected because chance locus of control significantly moderated the relationship between gambling attitudes and gambling intentions. Because the change in R-square was significant, chance locus of control was deemed to moderate the relationship between gambling attitude and gambling intention. Hypothesis $9 \mathrm{c}$ was rejected because powerful others locus of control significantly moderated the relationship between gambling attitude and gambling intention. A trivial negative correlation was found between powerful others total and total gambling attitude scale, suggesting as the influence of powerful others decreases, gambling attitude increases. Because the change in R-square was significant, powerful others locus of control was deemed to moderate the relationship between gambling attitude and gambling intention. 
In the next chapter, the relationship between the findings and prior research will be examined. Implications and suggestions for further research will also be discussed. 


\section{CHAPTER V}

\section{DISCUSSION}

The general purpose of this study was to examine the gambling behavior of college students and, in particular, college student athletes. Specifically, this study examined the relationships among subjective norms, gambling attitudes, gambling motivations, locus of control, and gambling intentions on the gambling behavior of college students. The goal of this study was to assess gambling in a specific population with easy access to gambling and to evaluate the adequacy of a modified Theory of Reasoned Action (Ajzen \& Fishbein, 1980) for predicting gambling frequency and problem gambling. The following research questions were examined:

1. Do males report significantly more positive attitudes related to gambling than females?

2. Do student athletes report significantly more positive attitudes related to gambling than other students?

3. Do males report significantly higher levels of subjective norms than females?

4. Do student athletes report significantly higher levels of subjective norms compared to other students?

5. Will attitudes related to gambling significantly and positively predict gambling intentions?

6. Will subjective norms significantly and positively predict gambling intentions? 
7. Will gambling intentions significantly and positively predict gambling behavior?

8. Will gambling motivations significantly moderate the relationship between gambling attitudes and gambling intentions?

9. Will locus of control significantly moderate the relationship between gambling attitudes and intentions?

The following sections discuss the findings of the study, implications and recommendations, and conclusion.

\section{Findings}

In the present study $85.5 \%$ of the respondents indicated they gambled in some form. This finding is similar to previous studies (Browne \& Brown, 1994; Ladouceur et al., 1994; Lesieur et al., 1991; Moore \& Ohtsuka, 1997, 1999; Rockey et al., 1997), which all found gambling rates between $80-90 \%$ (see Table 22).

Table 11

Comparison to Other Studies of College Students

\begin{tabular}{lccc} 
Study & Year & $\mathrm{N}$ & \% Gambled \\
\hline Moore \& Ohtsuka & 1999 & 215 & 89.0 \\
Rockey et al. & 1998 & 954 & 81.2 \\
Devlin \& Peppard & 1996 & 238 & 72.7 \\
Ladouceur et al. & 1994 & 1471 & 86.9 \\
Browne \& Brown & 1994 & 288 & 80.0 \\
Lesieur et al. & 1991 & 1771 & 85.0 \\
\hline
\end{tabular}


The high percentage of students who gamble is consistent with the belief of the National Association of Student Personnel Administrators (NASPA) that problem gambling is a concern for university and college students (McClellan, Caswell, Beck, Hollady, Mitchell, \& O'Connor, 2002). NASPA recommends college officials increase their awareness of the potential health risks associated with gambling. They further recommend materials related to problem gambling be integrated into student prevention and treatment programs. It is important to the well-being of the student that campus counseling services operate with awareness that excessive gambling exists on the campus and needs to be addressed like any other addictive behavior. It is also important that research continue to study the gambling habits of college students. After examining gambling rates, the current study further explored gambling behavior by college students using statistical analyses to answer the nine research questions.

Attitudes Towards Gambling

Males versus Females. The results indicated males reported statistically more positive gambling attitudes than females. This finding is not surprising based on previous studies. Prior research has consistently indicated men are more likely to gamble than women (Abbott \& Cramer, 1993; Lorenz, 1990). In fact, men outnumber women among pathological gamblers at a ratio of two to one (Volberg, 1994; Volberg \& Steadman, 1998, 1989). However, prior to the current study, researchers had not examined differences in attitudes towards gambling based on gender.

The results of the current study suggest that previously observed differences in gambling based on gender may be related, at least in part, to more positive attitudes toward gambling by men. When faced with gambling opportunities, more positive attitudes toward gambling may lead men to be more willing to participate in gambling 
activities. While positive attitudes toward gambling are not necessarily a problem, it may be a problem if the positive attitudes among men lead them to be less likely to see the potential problems associated with gambling. This could make them more likely to be pathological gamblers. While it is interesting to speculate about the potential problems of these positive attitudes, what is still unclear based on the current study is why men have more positive attitudes toward gambling. Future research should examine the development of gambling attitudes to determine how attitudes may develop differently based on gender.

Student Athletes versus Other Students. The results from this study indicated student athletes did not report significantly different attitudes towards gambling than other students. This finding was consistent with previous research of Rockey et al. (1997), who found no statistically significant associations between pathological gambling and one's role as a student-athlete. In contrast, other research studies at colleges and universities have identified higher rates of problem gambling among students who engage in intercollegiate sports than non-athletes (Engwall et al., 2003).

While the findings of the current study are more consistent with the findings of Rockey et al. (1997), they may not be representative of all college athletic programs. First, this finding could be the result of the athletic department's program to combat illegal gambling by its athletes. It is possible the athletic program at the university examined is more successful at educating athletes about the dangers of gambling than other institutions. Second, the current study contained very few members of the intercollegiate football team, while many of the prior studies on college athletes focused primarily on the football players (Rockey et al., 1997). It is possible that the gambling 
attitudes may vary across sport teams and the under-representation among some teams may have impacted the results. While programs at the university and issues related to the sample could explain why the athletes in this study reported no significant differences in attitudes towards gambling than other students in the study, further research is needed to examine the possibility at other universities with more football players included in the sample.

\section{Subjective Norms}

Males versus Females. The results indicated males did not report significantly different levels of subjective norms than females. Prior research had found that student gambling was positively related to parental gambling and peer gambling. Moore and Ohtsuka (1997) found the majority of young people in their study had experienced gambling within their family (67.7\%) and among most of their friends (55.3\%). However, none of the prior research studies examined whether the subjective norms were different based on gender. The results of the current study found no such gender differences. This result could imply that the differences in gambling behavior by gender may be related to gambling attitudes rather than subjective norms.

It is surprising that little research has examined social influence on gambling behavior, despite the fact that social reasons are among the most frequently reported reasons for gambling among college students (Neighbors, Larimer, Lostutter, \& Cronce, 2001). Results of this study indicate that men's subjective norms were no different than the subjective norms of women. However, the results of this study may not be consistent with behavioral patterns expected of men and women in America culture because men experience fewer social constraints regarding gambling than women (Neighbors et al., 
2001). Further research should concentrate on other social factors that may affect gambling attitudes of college men and women.

Student Athletes versus Other Students. The results from this study indicated that student athletes did not report significantly different subjective norms than other college students. Prior research has indicated that subjective norms may be important in influencing college student athletes. A recent study by the NCAA (2004) found potential problem student athlete gamblers were more likely to have friends and parents who gambled. Over $10 \%$ of student athletes with potential gambling problems reported that one or more of their parents had a gambling problem. These same student athletes with potential gambling problems claimed to have a much higher percentage of friends who gamble as well. Despite the possible importance of subjective norms for college student athletes, they were not different on this factor from other students. Due to time constraints, athletes may tend to associate with each other rather than non-student athletes, and since athletes receive some form of gambling education from the athletic department, maybe their peers could actually be a "barrier" to gambling behavior. Regardless, student athletes appear to be affected by the same types of subjective norms as other students.

\section{Gambling Attitudes and Gambling Intentions}

The results indicated attitudes related to gambling significantly and positively predicted gambling intentions. The R-square for the regression equation was .050, meaning $5 \%$ of the variance in gambling intentions was accounted for by gambling attitudes. According to Ajzen and Fishbein (1980, p.62), "a person's behavior is determined by his intention to perform the behavior and this intention is, in turn a 
function of his attitude toward the behavior." The present study sought to determine if gambling attitudes of college students were significant and positively related to gambling intentions of college students. The results indicate that the more positive the attitude toward gambling, the greater the intention to gamble. However, the variance predicted was low, indicating that other factors might be more important in predicting intention to gamble among college students. Such factors as motivation, locus of control, sensation seeking, impulsivity, boredom, and others may lead the athlete to change their attitudes towards gambling when examined under conditions prescribed by the TRA.

\section{Subjective Norms and Gambling Intentions}

The results indicated subjective norms significantly and positively predicted gambling intentions. The R-square for the regression equation was .023, meaning just over $2 \%$ of the variance in gambling intentions was accounted for by subjective norms. The results of the current study are consistent with previous literature. Hira and Munson (2000) found student gambling was positively related to parental gambling and peer gambling. Moore and Ohtsuka (1999) found respondents believed their families and friends approved of gambling, and gambling occurred the most in families and friends of students who gambled.

However, the low R-square observed implies our model has captured only a small percentage of the total variance. When college students are encouraged to gamble by peers and friends, their tendency to become pathological gamblers increases. While this may be true, researchers must explore the low amount of variance and determine if subjective norms are truly a meaningful factor in gambling intention in the selected 
sample. The results of the current study suggest there might be several other factors associated with problem gambling or perhaps better instruments/methods to ascertain it. Gambling Intentions and Gambling Behavior

Hypothesis 7 proposed gambling intentions would significantly and positively predict gambling behavior in terms of specific types of gambling activities. Hypothesis 7 was accepted because gambling intentions significantly and positively predicted gambling behavior in terms of specific gambling types. The R-square for the regression equation was .020 , meaning $2 \%$ of the variance in gambling behavior in terms of specific forms of gambling types was accounted for by gambling intention.

Very few of the respondents in the current study regularly engaged in any type of gambling, with playing cards being the most frequent participant activity. However, more than half of the respondents indicated they played cards for money $(58.2 \%)$ or bet on horses (53.2\%) either occasionally or more than once a week. These results were consistent with Moore and Ohtsuka, (1997) and Rockey et al. (1997). These results may be attributed to the proximity of specific types of gambling located near the university in this study.

In addition, there recently has been a nationwide increase in gambling in the form of internet poker playing. College students now enjoy the luxury of having computers at their fingertips. With this luxury however, comes the added pressure of dealing with the numerous internet gambling sources that have popped up here recently. These internet gambling services prey on college students who are just establishing their finances with banking institutions. Often these students have received credit cards from the banking institution with unusually higher than normal credit limits. This sets up the college 
student for possible gambling problems. The internet gambling service entices the college student with a few free tries and this often leads to the establishment of an account with the gambling service. Once the account is established the college student starts gambling and over time the losses begin to accumulate and the credit card bill grows to a point which the college student has a dilemma. These dilemmas have resulted in an increase in early bankruptcies, suicides, dropouts, and financial disasters. However, the access to internet gambling is relatively new, so future research is needed to better understand this issue. In addition, there are other recent phenomenon that may impact college student gambling, including more television coverage and Texas Hold'em Poker Tournaments on campuses across America and the impact of these should be studied as well.

The ultimate goal of the TRA is to predict and understand an individual's behavior. These predictions and understandings have been applied in different fields in order to intervene and promote positive behaviors. Applications vary from attempts to increase safety-belt use (Tramifow \& Fishbein, 1994), influence career choice (Strader \& Kutz, 1990; Vincent, Peplau, \& Hill, 1998), understand and predict gambling behavior (Moore \& Ohtsuka, 1999), increase condom use for HIV-prevention intervention (Fishbein, Middlestadt \& Tramifow, 1992), and change the process of homelessness (Wright, 1998). The general findings are behavioral intentions can predict behaviors with much accuracy (Ajzen, 1988, 1991).

While the results of the current study suggest the TRA can be used to predict gambling behavior, there may be a better theoretical framework to use in future research. One of the limitations of this theory comes from the nature of the self-reporting used to 
determine a subject's attitudes. No direct observation is used in the application of this theory; only self-reported information is used. Self-reported data is very subjective and is not necessarily always accurate. Ajzen and Fishbein (1977) also noted the theory was limited by the degree of correspondence between the factors. In order for the theory to predict behavior, attitude and intention must agree on action, target, context, and time.

The greatest limitation of the theory generally stems from the assumption that behavior is under volitional control. However, this aspect would suggest that gambling could be examined using the TRA, because gambling behavior is usually thought out before the actual behavior is performed. In fact, Cummings and Corney (1987) argued the TRA would have good explanatory power when examining gambling phenomena, and would provide a methodological framework for measurement of social factors likely to affect gambling behavior. Later, Moore and Ohtsuka (1999) found the TRA was a useful model for examining the gambling behavior of Australian students, and the model predicted a large portion of variance. Therefore, the use of a psychosocial model such as the TRA for predicting gambling behavior would appear to be beneficial to the field of gambling research.

While the effect sizes were in the small to medium range, a large portion of the variance in gambling intentions and gambling behavior were not predicted by the independent variables. It is possible this result may have occurred because students did not always answer honestly. Even though the responses were confidential, students, particularly student-athletes, may have had some incentive to intentionally reduce their reported gambling intentions and behavior. Given the concerns about gambling by NCAA student athletes in the United States, this explanation may account for the 
difference between the results in the current study and results in Moore and Ohtsuka (1999). Future research could try to better control for socially desirable answers to determine if this explanation is accurate. In general, the differences in the results of the two studies regarding the usefulness of the TRA suggest the need for more research to determine what may increase or decrease this usefulness.

I it also possible that the TRA is not the best model for examining gambling behavior. There are many possibilities when choosing a theoretical framework for studying gambling behavior. Two of these theories are the Theory of Planned Behavior and the Social Learning Theory. The Theory of Planned Behavior (Ajzen, 1988, 1991) proposes a model about how human action is guided. It predicts the occurrence of a specific behavior provided the behavior is intentional (Ajzen, 1988). This theory goes one step further than the TRA by adding perceived behavioral control to the model (Ajzen, 1988). Perceived behavioral control is the extent to which a person feels able to enact the behavior (Ajzen, 1988). It has two aspects: how much a person has control over the behavior and how confident a person feels about being able to perform or not to perform the behavior (Ajzen 1988). It is determined by control beliefs about the power of both situational and internal factors to inhibit or facilitate the performing of the behavior (Ajzen, 1988). Given the impact of locus of control in the current study, it is possible that understanding feelings of control are critical in predicting gambling behavior, suggesting that this theory may be useful.

The Social Learning Theory of Bandura (1977) explains human behavior in terms of continuous reciprocal interaction between cognitive, behavioral, and environmental influences. The theory spans attention, memory, and motivation and both cognitive and 
behavioral frameworks. In gambling, the individual models his/her behavior after someone else thus learning the behavior as the act of gambling progresses. Individuals are more likely to adopt a modeled behavior if it results in outcomes they value (Bandura, 1977). Individuals are also more likely to adopt a modeled behavior if the model is similar to the observer and has admired status and the behavior has functional value (Bandura, 1977). However, subjective norms were not a strong predictor in the current model, which would seem to suggest that this theory may not be the best choice.

In addition, it is also possible that the TRA is a better model than appears to be the case based on the results of the current study. One could speculate that each specific type of gambling (i.e., pari mutual gambling, lottery playing, casino-style gambling, etc.) may need its own instrument to ensure respondents are reporting attitudes, intentions, subjective norms, and behaviors with regards to the same, the specific gambling type. Because different types of gambling may appeal to different people for different reasons, examining general gambling attitudes, subjective norms, intentions, and behavior, as was done in the current study, may result in a less predictive model. Specifying the type of gambling when measuring each factor may result in a more predictive model that would be very useful to gambling researchers.

\section{Intrinsic Motivation on Gambling Attitudes and Gambling Intentions}

Research question 8 was answered using three different hypotheses. All of these hypotheses dealt with intrinsic motivation. Intrinsic motivation stems from the satisfaction of two needs, a need to feel self-determined and a need to be competent in one's environment. Gamblers find pleasure and satisfaction in surpassing themselves in the course of their betting. The researchers chose intrinsic motivation because they 
believed it would affect the relationship between gambling attitudes and gambling intentions.

Intrinsic Motivation to Know. Hypothesis 8a examined the moderating impact of intrinsic motivation to know on the relationship between gambling attitudes and gambling intentions. The results indicated intrinsic motivation to know significantly moderated the relationship between gambling attitude and gambling intentions. The change in R-square in the regression equation was .011, meaning just over $1 \%$ of the variance in gambling attitude as it interacts with gambling intention was accounted for by the moderating variable, intrinsic motivation to know. However, caution should be used when examining this result because the effect size was small and the alpha level failed to reach the level of significance after applying the Bonferroni correction.

Intrinsic motivation to know is common among gamblers who enjoy learning, exploring, or trying to understand something new about gambling. People who see themselves as intrinsically motivated to engage in an effort activity are less likely to make the attribution that they are engaging in the activity only to obtain some extrinsic incentive and are rather more likely to attribute their participation to the enjoyment, satisfaction, and/or interest inherent in the effort activity (Deci \& Ryan, 1985; Lepper 1981; Lepper \& Greene, 1978).

Intrinsic Motivation to Accomplish. Hypothesis $8 \mathrm{~b}$ examined the moderating impact of intrinsic motivation to accomplish on the relationship between gambling attitudes and gambling intentions. The results indicated intrinsic motivation to accomplish significantly moderated the relationship between gambling attitude and gambling intentions. The change in R-square in the regression equation was .024, 
meaning $2.4 \%$ of the variance in gambling attitude as it interacts with gambling intention was accounted for by intrinsic motivate to accomplish.

Intrinsic motivation to accomplish things is exemplified by gamblers who find pleasure and satisfaction surpassing themselves in the course of their betting activities. In other words, a blackjack player would experience intrinsic motivation to accomplish by improving his/her ability to count cards in blackjack. The nature of gambling allows little opportunity for the individual to control the outcome of the game. Students possessing an intrinsic motivation to accomplish, view gambling as a test of their self-control or ability to control the game.

Intrinsic Motivation to Experience Stimulation. Hypothesis 8c was proposed to examine the potential moderating impact of intrinsic motivation to experience stimulation on the relationship between gambling attitudes and gambling intentions. However, this hypothesis was not tested due to the low reliability of the scale. Researchers should look into the possibility of better developing this scale so it too could also be used in future gambling studies. Additional items could be generated, measured, subjected to factor analysis in order to develop a better scale.

\section{Locus of Control}

Locus of control is considered an important aspect of one's personality. The concept was developed by Julian Rotter in the 1960s. Rotter believed behavior was guided by rewards and punishment and through these individuals come to hold beliefs about what causes their actions. These beliefs determine what kinds of attitudes and behaviors individuals develop. Beliefs are also known as attribution. Attribution refers 
to how an individual explains events that happen to themselves or others. Attribution styles have been found to characterize and explain why people react so differently.

Internal Locus of Control. Research question 9 was examined using three different hypotheses. Hypothesis 9a examined the moderating impact of internal locus of control on the relationship between gambling attitudes and gambling intentions. The results indicated internal locus of control moderated the relationship between gambling attitudes and gambling intention. However there was a negative correlation $(r=-.129)$ between internal locus of control and total gambling intention. The change in R-square of the regression equation was .048, meaning almost $5 \%$ of the variance in gambling intention is explained by the interaction of the gambling attitudes and the moderating variable of internal locus of control.

Because the relationship between internal locus of control and gambling intention was negative ( $r=-.129)$, the relationship between gambling attitude and gambling intention is strengthened when students report a low internal locus of control (i.e., a higher external locus of control). In other words, the relationship between gambling attitudes and gambling intention is strengthened when students believe their environment has control over them rather than vice versa. When students do not feel they have control over their life's events, the relationship between gambling attitudes and gambling intention is more salient. Therefore, they are more likely to attribute their success or failure in gambling to luck rather than skill. This finding has implications for how to reduce problem gambling behavior of students.

Chance Locus of Control. Hypothesis $9 \mathrm{~b}$ examined the moderating impact of chance locus of control on the relationship between gambling attitudes and gambling 
intentions. The results indicated chance locus of control significantly moderated the relationship between gambling attitudes and gambling intentions. The R-square of the regression equation was .078 , meaning almost $8 \%$ of the variance in gambling intention is explained by the interaction of gambling attitudes and the moderating variable, chance locus of control. Students with high chance locus of control believe taking the chance itself is the important aspect of gambling (Clarke, 2004). When students believe in the importance of taking chances, the relationship between gambling attitudes and gambling intentions increases. Taken together with the prior result, this finding suggests positive attitudes toward gambling are more likely to lead to gambling intentions when students believe that success in life is based on luck and that one has to take chances to be lucky, while those who believe they have control over their lives and risks do not increase chances for success.

Powerful Others Locus of Control. Hypothesis 9c examined the moderating impact of powerful others locus of control on the relationship between gambling attitudes and gambling intentions. The results indicated powerful others locus of control significantly moderated the relationship between gambling attitudes and gambling intentions. The R-square of the regression equation was .101, meaning over $10 \%$ of the variance in gambling intention is explained by the interaction of gambling attitudes and the moderating variable of powerful others locus of control. Gambling intentions, gambling attitudes, powerful others locus of control, and the attitudes/powerful others locus of control interaction were significantly correlated. However a trivial negative correlation $(r=-.060)$ was found between powerful others locus of control and total gambling attitude. Still, this result indicated powerful others locus of control would play 
a role in a college student decision to gamble, because they feel their control over their own behavior is controlled by powerful others like friends, peers, and family. It is important to note that the magnitude of this negative correlation is relatively small, so the importance of this relationship should not be overestimated.

The findings of the current study are consistent with the study of Browne and Brown (2001). The results relative to the external component of locus of control indicate students believe their own behavior does not matter much and rewards in life are generally outside of their control and are determined by others. Therefore, when students believe their own behavior does not matter much and rewards in life are generally outside their control and determined by others, the relationship between gambling attitude and gambling intention increases. In other words, the results of the current study indicate gambling attitudes have a greater impact on gambling intentions if the student perceives their life is controlled by powerful others in their lives.

\section{Recommendations}

The current research was designed to examine the gambling behavior of student athletes and other students using a modified form of the TRA. This research may provide practitioners with additional information about gambling behaviors of college students. The current study found males reported statistically more positive attitudes towards gambling than females but did not report statistically different subjective norms. These findings are novel due to the lack of research based on gender prior to this study. However, further research into this area is needed. In particular, research is needed to determine why males developed more attitudes toward gambling, and the degree to which this explains differences in gambling behavior between men and women. 
This study also compared the attitudes and subjective norms of student athletes with those of other students. Student athletes reported no significant differences in attitudes or subjective norms when compared to other students. While this finding was consistent with prior research (Cummings \& Corney, 1987; Moore \& Ohtsuka, 1997, 1999; Neighbors et al., 2001), a few factors suggest more research is needed to better understand possible differences between these groups. First, there was limited representation from the university's football team in the sample of the current study. In contrast, much of the previous researchers on college athletics had focused on football players (Cullen \& Latessa, 1996; Rockey et al., 1997). Second, the university has a well developed gambling education program that may have impacted the results in this study. While such programs appear to be common, it is impossible in the current study to determine the relative impact of those programs. More research is needed across sports and the possible impact of such gambling education programs.

The current study also found gambling attitudes and subjective norms both significantly and positively predicted gambling intentions. However, the variance predicted by each was low, indicating other factors might be more important in predicting gambling intentions of college students. Practitioners examining these findings should be aware of possible additional predictors such as sensation seeking, impulsivity, boredom, competitiveness, and passion. All of these predictors have been used in prior research. However, more research on these factors is still needed to determine the effectiveness of these predictors.

Gambling intentions significantly and positively predicted gambling behavior in terms of types of gambling activities. The variance predicted in the dependent variable 
was low, more factors likely impact gambling behavior. In addition, more research is needed to better understand the relationship between gambling intentions and gambling behavior. For example, future research could seek to determine if the lower variance predicted may be attributed to the measuring instrument, social desirability in the responses, and/or the sample that was used in the current study.

The significant impact of the moderating variables on the relationship between gambling attitudes and intentions suggests intrinsic motivation and locus of control can increase or decrease the impact of gambling attitudes on gambling intentions. The results of the current study support the notion of adding intrinsic motivation to the TRA model as a moderator. In addition, understanding the importance of gambling motivations gives practitioners some possible strategies for trying to limit gambling intentions and ultimately gambling behavior. Because of the importance of intrinsic motivation to accomplish, those seeking to reduce gambling behavior could either attempt to get people focused more on the importance of other accomplishments or convince them that gambling related accomplishments are not very important.

All three locus of control variables, internal locus of control, chance locus of control, and powerful others locus of control were also found to be significant moderators of the relationship between gambling attitudes and gambling intentions. This finding supports using the variable locus of control as a moderator in future gambling research using the TRA. In addition, understanding that gambling attitudes have a greater impact on gambling intentions when students believe they have less control over their environment and when outcomes are more related to luck provides some strategies for those who are seeking to reduce gambling behavior. Those seeking to reduce gambling 
behavior should focus on teaching individuals that they are in control of their lives and good things are more likely to happen because of what they do than because of chance or powerful others.

Further research is needed to add to the body of information that exists on gambling among college athletes and other students. Athletic departments and student affairs offices need to develop educational programs to help athletes and other students cope with the increasing availability of gambling opportunities across America. Research should be developed to determine the effectiveness of treatment programs for problem gambling on the college campus. As cited by Lesieur et al., (1991), Bourn (1998), Moore and Ohtsuka (1997), and Rockey et al. (1997), college students are two to three times more likely to develop pathologic gambling problems than the adult population in general. It is therefore necessary to conduct research into the most effective method to educate college students on the perils of addictive gambling behavior. College administrators must be willing to appropriate the funds to initiate the programs necessary to combat this problem. However, Bailey and Dickens (1997) found the student affairs profession has not yet recognized gambling as an issue needing immediate attention. The increasing availability of gambling opportunities suggests participation will become a problem on our nation's campuses, and more research to develop strategies to deal with this problem is needed.

In addition to the need for more research to better understand what predicts gambling intentions and behavior among college student athletes and other students, there are a number of future studies that would be useful to researchers and practitioners. Future research should compare the prevalence rate of student athlete gambling to other 
student gambling and seek to determine the reasons for any differences. In addition, research should focus on specific teams (e.g., football, basketball, baseball, softball, volleyball, etc.) to better understand any differences across sports. While the current study examined two demographic variables as independent variables, future research could examine other demographic variables such as ethnicity, residence, class, age and martial status to determine possible direct and interaction effects.

Also, the current study chose to use only two moderators to examine the interactions between gambling attitudes and gambling intentions. Future research should focus on additional psychological traits such as sensation seeking, aptitude, self-esteem, impulsivity, boredom, venturesomeness, passion, chasing, coping, or escape as moderating variables that may influence gambling behavior among student athletes and other students. The impact of such psychological traits as sensation seeking, arousal, impulsivity, boredom, and self-esteem have not as yet been clearly identified. While research into personality traits among gamblers have been largely inconsistent it is possible that those variables may be useful when examining specific types of gambling. For example, Zuckerman (1979) suggested a relationship may exist between gambling and sensation seeking. Because of the desire for high arousal among sensation seekers this factor maybe useful in explaining risk-taking, thrill-seeking, and chasing. Another psychological trait, passion, refers to an internal pressure that forces the gambler to perform an activity (Rousseau et al., 2002). However, gambling differs from other passionate activities because gambling can be very detrimental and gambling takes place in locations where testing might be difficult. Impulsivity like sensation seeking is related 
to gambling behavior. Impulsive gamblers do not look ahead at the consequences of their actions (Clarke, 2004).

Finally, the current study examined students at only one university. Future research should focus on comparing the gambling behavior of student athletes and other students at multiple universities that are located within the various degrees of proximity to gambling venues.

\section{Conclusions}

This study suggests numerous avenues for future research. The present findings serve as the basis for the construction of a gambling model that could lead to important findings in the field of gambling behavior amongst college student athletes and other students on the college campus. Each of the questions addressed in the current study is worthy of additional attention. Potential moderating variables of the relationship between gambling attitudes and gambling intentions have important implications for prevention and treatment interventions aimed at college student athletes and other students.

Developing a solid theoretical framework has been an objective of the gambling research field for years. The addition of other psychological traits to the conceptual model such as sensation seeking and impulsivity could strengthen the TRA even further. Those studying and seeking to deal directly with gambling issues are faced with the same moral and policy dilemmas as those addressing alcohol consumption, cigarette smoking, and similar activities that occur on the campus of America's universities and colleges. This research represents an important step towards accomplishing this objective, but much work is still needed. 


\section{REFERENCES}

Abbott, D.A. \& Cramer, S.L. (1993). Gambling attitudes and participation: A Midwestern survey. Journal of Gambling Studies, 9, 247-263.

Abt, V., McGurrin, M., \& Smith, J. (1985). Toward a synoptic model of gambling behavior. Journal of Gambling Behavior, 1, 79-88.

Ackerman, R.L. \& Smith, J. (1985). The proliferation of legalized gambling: Implications for student affairs. NASPA Journal, 33 136-144.

Ajzen, I. (1988). Attitudes, personality, and behavior. Milton Keynes: Open University Press.

(1991). The theory of planned behavior. Organizational Behavior and Human Decision Processes, 50, 179-211.

Ajzen, I. \& Fishbein, M. (1977). Attitude-behavior relations: A theoretical analysis and review of empirical research. Psychological Bulletin, 84(5), 888-918.

--------. (1980). Understanding attitudes and predicting social behavior.

New Jersey: Prentice Hall.

Ajzen, I. \& Madden, T.J. (1986). Prediction of goal-directed behavior: Attitudes, interventions, and perceived behavioral control. Journal of Experimental Social Psychology, 23, 453-474.

Alberta Alcohol and Drug Abuse Commission (1998). Adult gambling and problem gambling in Alberta. Edmonton: Alberta Alcohol and Drug Abuse Committee.

Allegrante, J.P., Morimer, R.G., O’Rourke, T.W. (1980). Social psychological factors in motorcycle safety research: Implications for public policy. Journal of Safety Research, 12, 115-126.

American Gaming Association (2001). Bureau of Indian Affairs, State Gaming Commissions.

American Psychiatric Association (1980). Diagnostic and Statistical Manual of Mental Disorders. Washington, D.C.: Author. 
------. (1994). Diagnostic and Statistical Manual of Mental Disorders $\left(3^{r d}\right.$ ed. Rev.).Washington, DC: Author.

. (2000). Diagnostic and Statistical Manual of Mental

Disorders $\left(4^{\text {th }}\right.$ ed., TR) Washington, DC: Author.

Anastasi, A. (1976). Psychological testing ( $4^{\text {th }}$ Ed.). New York: Collier MacMillan International Edition.

Andrew, D.P.S. (2004). The effect of congruency of leadership behaviors on motivation, commitment, and satisfaction of college tennis players. Unpublished doctoral dissertation, Florida State University.

Babbie, E.R. (2001). The practice of social research $\left(9^{\text {th }}\right.$ ed.). Belmont, CA:

Wadsworth/Thompson Learning.

Bailey, E.A. \& Dickens, C.S. (1997). Facing a new challenge: Chief student affair officer's response to casino gambling in Mississippi. NASPA Journal, 34(4), 250261.

Baldessarini, R.J., Finklestein, S., \& Arana, G.W. (1983). The predictive power of diagnostic tests and their effects of prevalence of illness. Arch General Psychiatry, 40, 569-573.

Ball, I.L., Farnhill, D., \& Wangeman, J.F. (1984). Sex and age differences in sensation seeking: Some National comparisons. British Journal of Psychology, 75, 257265 .

Bandura, A. (1977). Social learning theories. Englewood Cliffs, NJ: Prentice Hall.

Baron, R.M. \& Kenny, D.A. (1986). The moderator-mediator variable distinction in social psychological research: Conceptual, strategic, and statistical considerations. Journal of Personality and Social Psychology, 51(6), 1173-1182.

Beaudoin, C.M. \& Cox, B.J. (1999). Characteristics of problem gambling in a Canadian context: A preliminary study using a DSM-IV-based questionnaire. Canadian Journal of Psychiatry, 4, 483-486.

Bentler, P.M. \& Speckart, G. (1979). Models of attitude-behavior relations. Psychological Reports, 86, 452-464.

Blaszczynski, A.P., McConaghy, N., \& Frankova, A. (1990). Boredom proneness in pathological gambling. Psychological Reports, 67, 35-42. 
--------. (1991). Control versus abstinence in the treatment of pathological gambling: A two to nine year follow-up. British Journal of Addictions, 86, 299-306.

Blszczynski, A.P., \& McConaghy, N. (1988). Assessed psychopathology in pathological gamblers. Psychological Reports, 62, 547-552.

Blaszczynski, A.P., Wilson, A., \& McConaghy, N. (1986). Sensation seeking and pathological gambling. British Journal of Addictions, 81, 113-117.

Blume, S.B. (1987). Treatment for the addictions in a psychiatric setting. Journal of Gambling Behavior, 3, 237-247.

---------. (1989). Treatment for the addictions in a psychiatric setting. British Journal of Addictions, 84, 727-729.

Bourn, D.F. (1998). Gambling behavior among college student athletes, non-athletes, and former athletes. Unpublished Master's Thesis. Springfield College.

Bowan, C.H. \& Fishbein, M. (1978). Understanding public reactions to energy proposals: An application of the Fishbein model. Journal of Applied Social Psychology, 3, 319-340.

Boyd, W.H. (1976). Excitement: The gamblers drug. In W.Eadington (ed.) Gambling and society: Interdisciplinary studies on the subject of gambling. Springflied, IL: Thomas Books.

Breen, R.B. \& Zuckerman, M. (1999). Chasing in gambling behavior: Personality and cognitive determinants. Personality and Individual Differences, 27, 1097-1111.

Brown, R.I. (1987). Classical and operant paradigms in the management of gambling addictions. Behavior Psychology, 15, 111-122.

(1996). Arousal and sensation seeking components in the general explanation of gambling and gambling addictions. The International Journal of Addictions, 21, 1001-1016.

Browne, B.A. \& Brown, D.J. (1994). Predictors of lottery gambling among American College Students. The Journal of Social Psychology, 134(3), 339-347.

Cambridge International Dictionary (1999). NY: Cambridge University Press.

Campbell, F. \& Lester, D. (1999). The impact of gambling opportunities on compulsive gambling. The Journal of Social Psychology, 139, 126-127. 
Carlton, P.L. \& Manowitz, P. (1992).Behavioral restraint and symptoms of attention deficit disorder in alcoholic and pathological gamblers. Neuropsychobiology, 25, 44-48.

Carr, R.D. (1996). Video lottery and treatment for pathological gambling: A natural experiment in South Dakota. South Dakota Journal of Medicine, 31.

Carruthers, C. (1999). Pathological gambling: Implications for therapeutic recreation practice. Therapeutic Recreation Journal, 4, 1-19.

Chantal, Y., Vallerand, R.L., \& Vallieres, E.F. (1994). On the construction and validation of the Gambling Motivation Scale (GMS). Society and Leisure, 17, 189-212.

Chantal, Y. \& Vallerand, R.L. (1996). Skill versus luck: A motivational analysis of gambling involvement. Journal of Gambling Studies, 12, 407-418.

Chow, S.L., Leung, G., \& Chan, V. (2004). A prediction/screening instrument for problem gamblers. eCommunity International Journal of Mental Health \& Addiction, 1(2).

Chung, T., Langenbucher, J., Labouvie, E., Pandina, R.J., \& Moos, R.H. (2001). Changes in alcoholic patients' coping responses predict 12-month treatment outcomes. Journal of Consulting and Clinical Psychology, 69, 92-100.

Ciaffone, B. (1991). A comparative study of state laws on social gambling. In Eadington and Cornelieus, op. cit. 183-204.

Clarke, D. (2004). Impulsiveness, locus of control, motivation, and problem gambling. Journal of Gambling Studies, 20(4), 319-345.

Cohen, J. (1988). Statistical power analysis for the behavioral sciences (2nd ed.) Hillsdale, NJ: Lawrence Erlbaum Associates.

Coulobe, A., Ladouceur, R., Desharnais, R., \& Jobin, J. (1992). Erroneous perceptions and arousal among regular and occasional video poker players. Journal of Gambling Studies, 8, 235-244.

Coventry, K. \& Brown, R.I.F. (1993). Sensation seeking, gambling, and gambling addictions. Addiction, 88, 541-554.

Cox, B.J., Enns, M.W., \& Michaud, V. (2004). Comparisons between the South Oaks Gambling Screen and a DSM-IV-Based interview in a community survey of problem gambling. Canadian Journal of Psychiatry, 49(4), 258-263. 
Cross, M.A. \& Vollano, A.G. (1999). The extent and nature of gambling among college student athletes. Ann Arbor: MI: University of Michigan Department of Athletics.

Cullen, F.T. \& Latessa, E.J. (1996). The extent and sources of NCAA rule infractions: A national self-report study of student-athletes. A report to the National Collegiate Athletic Association.

Cummings, W.T. \& Corney, W. (1987). A conceptual model of gambling behavior: Fishbein's Theory of Reasoned Action. Journal of Gambling Studies, 3, 190-201.

Curry, T.J. \& Jiobu, R.M. (1995). Do motives matter? Modeling gambling on sports among athletes. Sociology of Sport Journal, 12, 21-35.

Custer, R.L. (1980). An overview of compulsive gambling. In P.A. Carone, S.F. Yoes, S.N. Kiefer, \& L. Krinsky (eds.), Addictive disorders update: Alcoholism, Drug Abuse, Gambling. NY: Human Sciences Press.

Custer, R.L. \& Milt, H. (1985). When luck runs out. NY: Facts on File Publications.

Darbyshire, P., Oster, C., \& Carrig, H. (2001). The experience of persuasive loss: Children and young people in a family where parental gambling is a problem. Journal of Gambling Studies, 17(1), 23-45.

Davis, F.D. (1989). Perceived usefulness, perceived ease of use, and user acceptance of information technology. MIS Quarterly, 13(3), 319-340.

Deci, R.L. \& Ryan, R.M. (1985). Intrinsic motivation and self-determination in human behavior. NY: Plenum Press.

(1991). A motivational approach to self-integration in personality. In R. Deinsthier (ed.) Nebraska Symposium on Motivation, 38. Perspectives on Motivation, 237-288. Lincoln, NB: University of Nebraska Press.

Derevensky, J.L. \& Gupta, R. (2000). Prevalence estimates of adolescents gambling: A comparison of the SOGS-RA, DSM-IV-J and the GA20 Questions. Journal of Gambling Studies, 16, 227-251.

Devereux, E. (1979). Gambling. NY: MacMillan.

Dickerson, M. (1993). Internal and External determinants of persistent gambling: problems in generalizing from one to another. In: Eadington, W.R. and Cornelius, J.A. (eds.). Gambling behavior and problem gambling. Institute for the Study of Gambling and Commercial Gaming, Reno.

-------. (1995). Compulsive Gambling. London, UK: Longman. 
------. (1997). The Australian experience of the development of strategies to address gambling related problems in the community: Implications for other jurisdictions. Paper presented at the $10^{\text {th }}$ International Conference on Gambling and Risk Taking, Montreal, Canada.

Dickerson, M.G., Hinchy, J., \& Fabre, J. (1987). Chasing, arousal, and sensation seeking in off-course gamblers. British Journal of Addictions, 82, 673-680.

Dunne, J.A. (1985). Increasing public awareness of pathological gambling: A history of the National Council on Compulsive Gambling. Journal of Gambling Behavior, $1(1), 8-16$.

Eadington, W.R. (1989). Contributions of casino style gambling to local communities. Annuals of the American Academy of Political and Social Science. 53-65.

Edwards, J.M. \& Endler, N.S. (1989). Appraisal of stressful situations. Personality and Individual Differences, 10, 7-10.

Endler, N.S. \& Parker, J.D.A. (1989). Coping with frustrations to self-realization: Stress, anxiety, crises, and adjustment. In E. Krau (Ed.), Self-realization, success, and adjustment. New York: Praeger.

Endler, N.S. \& Parker, J.D.A. (1990b). Multidimensional assessment of coping: A critical evaluation. Journal of Personality and Social Psychology, 58, 844-854.

Engwall, D., Hunter, R., \& Steinberg, M. (2003). Gambling and other risk behaviors on university campuses. http//:www.responsiblegambling.org/articles

Etzel, E.F., Ferrante, A.P., \& Pinkney, J.W. (Eds.). (1991). Counseling college student -athletes: Issues and intervention. Morgantown, WV: Fitness Information Technology, Inc.

Eysenck, H.J. \& Eysenck, S.B.G. (1991). Manual of the Eysenck Personality Scales (EPS Adult) London: Hodder \& Stoughton.

Farmer, R. \& Sundberg, N. (1986). Boredom proneness - The development and correlates of a new scale. Journal of Personality Assessment, 50, 4-17.

Field, A. (2000). Discovering statistics using SPSS for windows. London: Sage.

Findlay, J.M. (1986). People of chance. NY: Oxford University Press.

Firestone, R. (1993). The psychodynamics of fantasy, addiction, and addictive attachments. The American Journal of Psychoanalysis, 53, 335-352. 
Fishbein, M. (1980). A theory of reasoned action: Some applications and implications. In H. E. Howe (Ed.). 1979 Nebraska Symposium on Motivation. Lincoln, NB: University of Nebraska Press.

Fishbein, M. \& Ajzen, I. (1975). Belief, attitude, intention, and behavior: An introduction to theory and research. Reading, MA: Addison-Wesley.

Fishbein, M., Middlestadt, S.E., \& Tramifow, D. (1992). Social norms for condom use: Implications for HIV prevention interventions of a KABP survey with heterosexuals in eastern Carribean. Advances in Consumer Research, 20, 292-296.

Fisher, S. (2000). Developing the DSM-IV-MR-J criteria to identify adolescent problem gambling in non-clinical populations. Journal of Gambling Studies, 16, 253-273.

Frank, M.L. (1990). Underage gambling in Atlantic City casinos. Psychological Reports, 67, 907-912.

Freiberg, M. (1995). Prelude to Purgatory: Thomas Hutchinson in Provincial Massachusetts Politics, 1760-1770.

Gaboury, A. \& Ladouceur, R. (1989). Erroneous perceptions and gambling. Journal of Social Behavior and Personality, 4, 411-420.

Gamblers Anonymous (1984) Twenty Questions. http:/www.gamblersanonymous.org.

Gerson, E. M. (1983).Scientific work and social worlds. Knowledge, 4, 357-379.

Gerstein, D.R., Voltberg, R.A., Toce, M.T., \& Howard, H. (1999). Gambling impact and behavior study: Report to the National Gambling Impact Study Commission. Chicago, IL: National Opinion Research Center at the University of Chicago.

Gilliland, J. (2003). Putting gambling in its place: A geographical study of VLT accessibility and play by Montreal youth. Youth Gambling International, 3(3), 12.

Gilovich, T. \& Douglas, C. (1986). Biased evaluations of randomly determined gambling outcomes. Journal of Experimental Social Psychology, 22, 228-241.

Goodman, R. (1995). The luck business: The devastating consequences and broken promises of Americas gambling explosion. NY: The Free Press.

Govoni, R., Frisch, G., \& Stinchfield, R. (2001). A critical review of screening and assessment instruments for problem gambling. Problem Gambling Research Group, University of Windsor, Ontario, Canada. 
Grahm, J.R. \& Lowenfeld, B.H. (1986). Personality dimensions of the pathological gambler. Journal of Gambling Behavior, 2, 58-66.

Griffiths, M.D. (1990). The acquisition, development, and maintenance of fruit machine gambling in adolescents. Journal of Gambling Studies, 6, 193-204.

(1994). Beating the fruit machines: Systems and ploys both legal and illegal. Journal of Gambling Studies, 10, 287-292.

---------. (1996). Pathological gambling: A review of the literature. Journal of Psychiatric and Mental Health Nursing, 3, 347-353.

Hair, J.F., Anderson, R.E., Tatham, R.L., \& Black, W.C. (1998). Multivariate Data Analysis, Prentice Hall: New Jersey.

Hendriks, V., Meerkerk, G., Van Oers, H., \& Garretsen, H. (1997). The Dutch instant lottery: Prevalence and correlates of at-risk playing. Addiction, 92(3), 35-346.

Hira, T.K. \& Monson, K.W. (2000). A social learning perspective of gambling behavior among college students at Iowa State University, USA. Journal of Consumer Studies and Home Economics, 24(1), 1-8.

Huck, S.W. (2004). Reading Statistics and research (4 ${ }^{\text {th }}$ ed.) Boston, MA: Pearson.

Jacobs, D.F. (1986). A general theory of addictions: A new theoretical model. Journal of Gambling Behavior, 2, 15-31.

-------. (1989a). Editorial comment. Journal of Gambling Behavior, 2, 257-260.

--------. (1998). Illegal and undocumented: A review of teenage gambling and the plight of children of problem gamblers in America. In H.F. Shaffer, S.A. Stein, B. Gambino, T.N. Cummings (Eds.). Compulsive gambling: Theory, research, and practice (pp. 249-292). Lexington, MA: Lexington.

--------. (2001). Implications of childhood trauma among pathological gamblers, alcoholics, and drug addicts: Implications for theoretical practice. Paper presented at Innovation 2001 Conference, Canadian Foundation of Compulsive Gambling, Ontario, Canada.

Joreskog, K. \& Sorbom, D. (1989). LISREL-VII Users Reference Guide, Scientific Software Inc., Mooresville, IN. 
Kallick-Kaufmann, M., Suits, D., Dielman, T., \& Hybels, J. (1979). Survey of American gambling attitudes and behavior. Research Report Series, Survey Research Center, Institute for Social Research. Ann Arbor, MI: University of Michigan Press.

Kassinove, J.L. (1998). Development of the Gambling Attitudes Scales: Preliminary findings. Journal of Clinical Psychology, 54, 763-771.

Kelly, J. (1999). Internet Gaming Law, manuscript, to be published.

Kentucky Legislative Research Committee (2003). Compulsive Gambling in Kentucky, Report \# 316, Legislative Research Committee, Frankfort, KY.

Kentucky Lottery Corporation (1998). Attitudes and players survey. University of Louisville, Urban Studies Institute, Louisville, KY.

Keteyian, A. (1986, March 10). The straight-arrow verdict. Sports Illustrated, pp. 71-77.

Knapp, T.J., Rasmussen, C.A., \& Niaghi, B. (2003). Win one for the students: Sports wagering by college students. College Student Journal, 4, 201-214.

Korn, D.A. \& Shaffer, H.J. (2002). Gambling and related mental disorders: A public health analysis. Annual Review of Public Health, 23, 171-212.

Koestner, R. \& Zuckerman, M. (1994). Causality orientations, failures, and achievement. Journal of Personality, 62, 321-346.

Kratzmann, M. (2002). When the stakes are high: Gambling and schools. Addiction Prevention \& Treatment Services, Capital Health.

Kuley, N. \& Jacobs, D. (1987). The relationship between dissociative-like experiences and sensation seeking among social and problem gamblers. Journal of Gambling Behavior, 4, 197-227.

Kusyszyan, I. (1977). Existence, effectiveness, esteem from gambling to a new theory of human motivation. International Journal of the Addictions, 25(2), 159-177.

Ladouceur, R., Arsenault, C., Dube, D., Freeston, M.H., \& Jacques, C. (1997). Psychological characteristics of volunteers in studies on gambling. Journal of Gambling Studies, 13, 69-84.

Ladouceur, R., Boisvert, J. \& Dumont, A. (1994). Cognitive-behavioral treatment for adolescent gamblers. Behavior Modification, 18, 230-242. 
Ladouceur, R., Bouchard, R., Jacques, C., Ferland, F., Leblond, J., \& Walker, M. (2000). Is the SOGS an accurate measure of pathological gambling among children, adolescents, and adults? Journal of Gambling Studies, 16, 1-23.

Ladouceur, R., Dube, D., \& Bujold, A. (1994). Prevalence of pathological gambling and related problems among college students in the Quebec metropolitan area. Canadian Journal of Psychiatry, 39, 289-293.

Lazarus, R.S. \& Folkman, S. (1984). Stress, appraisal, and coping. New York: Springer.

Lefcourt, H.M. (1976). Locus of control: Current trends in theory and research. Hillsdale, NJ: Erlbaum.

(1991). Locus of control. In J.P. Robinson, P.R. Shaver, \& L.S. Wrightsman (Eds.), Measures of personality and social psychological attitudes ( $2^{\text {nd }}$ ed., pp. 413-499). San Diego, CA: Academic Press.

Lepper, M.R. (1981). Intrinsic and extrinsic motivation in children: Detrimental effects of superfluous social controls. In W. Collins (Ed.). Aspects of the development of competence: The Minnesota Symposium on Child Psychology, 14, 155-160. Hillsdale, New Jersey: Erlhaum.

Lepper, M.R., \& Greene, D. (Eds.) (1978). The hidden costs of rewards: New perspectives on the psychology of human motivation. Hillsdale, New Jersey: Lawrence Erlhaum.

Lesieur, H.R. (1984). The chase: career of the compulsive gambler. Schenkman, Cambridge, MA.

-------. (1998). Costs and treatment of pathological gambling. Annals of the American Academy of Political and Social Science, 556, 153-171.

Lesieur, H.R., Cross, J., Frank, M., Welch, C. M., Rubenstein, G., Moseley, K., \& Mark, M. (1991). Gambling and pathological gambling among university students. Addictive Behaviors, 16, 517-527.

Lesieur, H.R. \& Blume, S. (1987). The South Oaks Gambling Screen (SOGS): A new instrument for the identification of pathological gamblers. American Journal of Psychiatry, 144, 1144-1188.

-------. (1991). Evaluation of patients treated for pathological gambling in a combined alcohol, substance abuse, and pathological gambling treatment unit using the Addiction Severity Index. British Journal of Addictions, 86, 1017-1028.

(1993). Revising the South Oaks Gambling Screen in different settings. Journal of Gambling Studies, 9, 213-219. 
Lesieur, H.R. \& Klein, R. (1987). Pathological gambling among high school students. Addictive Behaviors, 12, 129-135.

Lesieur, H.R. \& Rosenthal, R.J. (1991). Pathological gambling: A review of the literature. (Prepared for the American Psychiatric Association Task Force on DSM-IV. Committee on Disorders of Impulse Control not Elsewhere Classified). Journal of Gambling Studies, 7, 5- 39.

Lester, D. (1988). Legal gambling and crime. Psychological Reports, 83, 382.

Lightey, O.W. \& Hulsey, C.D. (2002). Impulsivity, coping, stress, and problem gambling among university students. Journal of Counseling Psychology, 49(2), 202-211.

Liljequist, L. (2000). Psychological causes, correlates and costs of gambling. Department of Psychology. Murray State University.

Linder, R.M. (1950).The psychodynamics of gambling. Annuals of American Academy of Political and Social Science, 269, 93-107.

Lorenz, V.C. (1990). An overview of pathological gambling. Baltimore, MD: National Center for Pathological Gambling.

MacAndrew, C. (1965). The differentiation of male alcoholic outpatients from nonalcoholic outpatients by means of the MMPI. Quarterly Journal of Studies on Alcohol, 26, 238-246.

Markland, D. (2000). Mediating and moderating variables: A conceptual clarification. Journal of Sports Sciences, 18, 373-374.

McCelland, G., Caswell, J., Beck B., Holladay, C.G., Mitchell, A.A., \& O'Connor, K.W. (2002). Gambling, its effects and prevalence on college campuses. Journal of Gambling Studies, 7(1) 5-39.

McCombs, A. (1991). Motivation and lifelong learning. Educational Psychologist, 26, 117-127.

McHoskey, J.W. (1999). Machialvellianism, intrinsic-extrinsic goals, and social interest: A self-determination theory analysis. Motivation and Emotion, 23, 267-283.

McMillen, J. \& Wenzel, M. (2004). Problem gaming continuum. The Australian National University.

Measuring Problem Gambling in Canada (2002). A request for proposals. Interprovincial task force on problem gambling. Ottawa, Canada. Unpublished report 
Miller, T.W., Adams, J.M., Kraus, R.F., Clayton, R., Miller, J.M., Anderson, J. \& Ogilvie, B. (2001). Gambling as an addictive disorder among athletes. Clinical Issues in Sports Medicine, 31(3), 145-152.

Mississippi Council on Problem and Compulsive Gambling (1999). Mississippi's youth at play: Educating Mississippi's teens on the issue of problem gambling. Jackson, MS.: Mississippi Council on Problem and Compulsive Gambling.

Miyazaki, A.D., Brumbaugh, A.M., \& Sprott, D.E. (2001) Promoting and countering consumer misconceptions of random events: The case of perceived control and state-sponsored lotteries. Journal of Public Policy and Marketing, 20(2), 254.

Moore, M.S. \& Ohtuska, K. (1997). Gambling activities of young Australians:

Developing a model of behavioral. Journal of Gambling Studies, 13(3), 207-236.

(1999). The prediction of gambling behavior and problem gambling from attitudes and perceived norms. Social Behavior and Personality, 27, 455-466.

Murray, J.B. (1994). Review of research on pathological gambling. Psychological Reports, 72, 719-810.

National Collegiate Athletic Association (2001). NCAA study of substance use habits of college student-athletes. http://www.ncaa.org.

----------. Executive summary for the national study on collegiate sports wagering and associated health risks. http://www.ncaa.org/gambling/2003national study/slideshow.

National Gambling Impact Study (1999). The National Gambling Impact study Commission: Final Report http:/www.govinfo.library.unit.edu/ngisc/reports/fullprint

National Institute of Law Enforcement and Criminal Justice (1977). The development of the law of gambling: 1776-1976. Washington, DC: U.S. Government Printing Office.

National Research Council (1999). Pathological gambling: A critical review. Washington, DC: National Academy Press.

Neighbors, C., Larimer, M.E., Lostutter, T.W., \& Cronce, J.M. (2001). Exploring college student gambling motives. Journal of Gambling Studies, 18, 361-370.

Neighbors, C., Lostustter, T., Cronce, J., \& Latimer, M. (2002). Exploring college student gambling motivation. Journal of Gambling Studies, 10, 361-370. 
Neighbors, C., Lostutter, T. W., Larimer, M., \& Takushi, R.Y. (2002). Measuring gambling outcomes among college students. Journal of Gambling Studies, 18, 339-360.

Neighbors, C., Vietor, N.A., \& Knee, C.R. (2002). A motivational model of driving anger and aggression. Personality and Social Psychology Bulletin, 28, 324-335.

Nowicki, S., Jr., \& Duke, M.P. (1974). A locus of control scale for non-college as well as college adults. Journal of Personality Assessment, 38, 136-137.

Nunnally, J.C., \& Bernstein, I.H. (1994). Psychometric theory (3 ${ }^{\text {rd }}$ ed.). New York: McGraw-Hill.

Oh, H. \& Hsu, C.H.C. (2001). Volitional degrees of gambling behaviors. Annals of Tourism Research, 28(3), 618-637.

Oskamp, S. (1991). Attitudes and opinions (2 ${ }^{\text {nd }}$ Ed.). NJ: Prentice Hall.

Oster, S. (1992). Parameters of undergraduate gambling. Published thesis. University of Nevada, Las Vegas.

Oxford English Dictionary (1989). (2 ${ }^{\text {nd }}$ Ed.) Oxford: Clarendon Press.

Pavalko, R. (2000). Risky business: America's fascination with gambling. Belmont, CA: Wadsworth.

Platz, L. (1999). Recreation and gambling behaviors among college students. University of Nevada, Las Vegas, Las Vegas, NV. Dissertation.

Platz, L. \& Miller, M. (2001). Gambling in the context of other recreation activity: A quantitative comparison of causal and pathological student gamblers. Journal of Leisure Research. 37, 383-395.

Podsakoff P.M., MacKenzie, S.B., Lee, J. \& Podsakoff, N.P. (2003). Common method biases in behavioral research: A critical review of the literature and recommended remedies. Journal of Applied Psychology, 88(5), 879-903.

Porter, T.M. (1995). Trust in numbers: The pursuit of objectivity in science and public life. Princeton, NJ: Princeton University Press.

Potenza, M.N., Fiellin, D.A., Heninger, G.R., Rounsaville, B.J., \& Mazure, C.M. (2002). Gambling: An addictive behavior with health and primary care implications. Journal of Internal Medicine, 17(9), 721-732.

Raylu, N. \& Oei, T.P. (2003). Role of culture in gambling and problem gambling. Clinical Psychological Review, 23(8), 1087-1114. 
Renau, L.S. (1995). Jockeys, belles, and bluegrass kings: Official guide to Kentucky racing. Louisville, KY: Churchill Downs Press.

Reynolds, W.M. (1982). Development of reliable and valid short forms of the MarloweCrowne Social Desirability Scale. Journal of Clinical Psychology, 23, 119-125.

Rockey, D.L., Beason, K.R., Lee, S., Stewart, C. \& Gilbert, J. (1997). Comparisons of the economic impact of college student expenditures among three locations: A college community, a gambling destination, and a urban leisure destination. The Journal of the Mississippi Alliance for Health, Physical education, Recreation, and Dance, 14(1), 3- 4.

Rose, I.R. (1995). Gambling and the law: Endless fields of dreams. Journal of Gambling Studies, 11(1), 15-33.

Rosenthal, R.J. (1987). The psychodynamics of pathological research: Methods and data analysis (2 $2^{\text {nd }}$ Ed.). NY: McGraw Hill Publishing Company.

Rossen, F. (2001). Youth gambling: A critical review of the public health literature. Centre for Gambling Studies, University of Auckland, Australia.

Rotter, J.B. (1966). Generalized experiences for internal versus external control of reinforcement. Psychological Monographs: General and Applied, 80(1).

Rousseau, F.L., Vallerand, R.J., Rotelle, C.F., Mageau,G.A., \& Provencher, P.J. (2002). Passion and gambling: On the validation of the Gambling Passion Scale (GPS). Journal of Gambling Studies, 18, 45-66.

Salant, P. \& Dillman, D.A. (1994). How to conduct your own survey. Wiley \& Sons, New York.

Sapp, S.G. \& Harrod, N.J. (1993). Reliability and validity of a brief version of Levenson's locus of control scale. Psychological Reports, 72, 539-550.

Saum, B. (1999). A growing consensus of research reveals that the rates of pathological and problem gambling among college students are higher than any other segment of the population. Testimony before the Senate Judiciary Subcommittee on Technology, Terrorism and Government Information 2.

Schaef, A.W. (1987). When society becomes an addict. San Francisco, CA: Harper and Row.

Schneider, G. \& Stedman, L. (2002). Gambling's rise takes human toll, Compulsive bettors often find financial ruin, not fortune. The Courier-Journal, Special Edition on Gambling Addiction, p.1. 
Selzer, J. (1992). Borderline omnipotence in pathological gambling. Psychiatric Nursing, 53(9B), 204.

Shaffer, H.J. (2003). A public health perspective on gambling: The four principles. $A G A$ Responsible Gaming Lecture Series, 2(1), 1-7.

Shaffer, H.J. \& Gambino, B. (1989). The epistemology of "addictive disease": Gambling as a predicament. Journal of Gambling Behavior, 5, 211-219.

Shaffer, H.J. \& Hall, M.N. (1997). Estimating the prevalence of disordered behavior in the United States and Canada: A meta-analysis. Boston, MA: Harvard College.

Shaffer, H.J., Hall, M.N., \& Bilt, J.V. (1999). Estimating the prevalence of disordered gambling behavior in the United States and Canada: A research synthesis. American Journal of Public Health, 89, 1369-1378.

Shapira, N.A., Ferguson, M.A., Frost-Pineda, K., \& Gold, M.S. (2002). Gambling and problem gambling prevalence among adults in Florida. Report to the Florida Council on Compulsive Gambling, Inc.

Sharpe, L. \& Tarrier, N. (1993). Towards a cognitive behavioral theory of problem gambling. British Journal of Psychiatry, 162, 407-412.

Shavelson, R. (1996). Statistical reasoning for the behavior sciences. Needham Heights, MA: Allyn \& Bacon.

Sluske, W.S., Jackson, K.M., \& Sher, K.J. (2003). The natural history of problem gambling from age 18 to 29. Journal of Abnormal Psychology, 112, 263-274.

Songer-Nocks, E. (1976). Situational factors affecting the weighting of predictor components in the Fishbein model. Journal of Experimental Social Psychology, $12,56-69$.

Specker, S.M., Carlson, G.A., Christianson, G.A., \& Marcotte, M. (1995). Impulse control disorders and attention deficit disorder in pathological gamblers. Annals of Clinical Psychiatry, 7, 175-179.

Stedman, L. (2002). Kentucky allocates no money. The Courier-Journal, Special Edition on Gambling Addiction, p. 10.

Stevens, J.P. (1992). Applied multivariate statistics for the social sciences (2 ${ }^{\text {nd }}$ Ed.). Hillsdale, NJ: Erlbaum.

Stinchfield, R. (2001). Reliability, validity, and classification accuracy of the South Oaks Gambling Screen (SOGS). Addictive Behavior, 27, 1-19. 
Strader M.K., \& Kutz, B.M. (1990). Effects of persuasive communication on beliefs, attitudes, and career choice. The Journal of Social Psychology, 130(2) 141-150.

Sullivan, G. (1972). By chance a winner: The history of lotteries. NY: Dodd \& Mead Co.

Tabachnick, B.G. \& Fidell, L.S. (2001). Using multivariate statistics ( $4^{\text {th }}$ ed.). Boston, MA: Allyn \& Bacon.

Tabor, J.J. (1987). Compulsive gambling: An examination of relevant models. Journal of Gambling Behavior, 3, 219-223.

Thomas, J.R., Nelson, J.K., \& Silverman, S.J. (2005). Research methods in physical activity ( $5^{\text {th }}$ ed.). Champaign, IL: Human Kinetics.

Thompson, W., Gazel, R., \& Rickman, D. (1996). The social costs of gambling in Wisconsin. A report prepared for the Wisconsin Political Research Institute.

Toneatto, T. (1999). Cognitive psychopathology of problem gambling. Substance Use and Misuse, 34, 1593-1604.

Toneatto, T., Blitz-Miller, T., Calderwood, K., Dragonetti, R., \& Tsanos, A. (1997). Cognitive distortions in heavy gambling. Journal of Gambling Studies, 13, 253266.

Tramifow, D., \& Fishbein, M. (1994a). The importance of risk in determining the extent to which attitudes affects intentions to wear seat belts. Journal of Applied Social Psychology, 24(1), 1-11.

Ursa, M.P. \& Uribelarrea, L.L. (1998). 20 Questions of gamblers anonymous: A psychometric study within the population of Spain. Journal of Gambling Studies , 14, 3-15.

Vincent, P.C., Peplau, L.A., \& Hill, C.T. (1998). A longitudinal application of the theory of reasoned action to women's career behavior. Journal of Applied Psychology, $28,761-778$.

Vogt, W.P. (2004). Dictionary of statistics and methodology: A non-technical guide for the social sciences $\left(2^{\text {nd }}\right.$ ed.). Thousand Oaks, CA: Sage Publications.

Vogt, W.P. (2005). Dictionary of statistics and methodology: A non-technical guide for the social sciences $\left(3^{\text {rd }}\right.$ ed.). Thousand Oaks, CA: Sage Publications.

Volberg, R.A. (1994). The prevalence and demographics of pathological gamblers: Implications for public health. American Journal of Public Health, 84, 237-241. 
-------. (1996). Problem gambling in the United States. Journal of Gambling Studies, 12, 111-128.

(1998). Gambling and problem gambling among adolescents in New York. Albany, NY: Gemini Research.

Volberg, R.A. \& Banks, S. (1990). A review of two measures of pathological gambling in the United States. Journal of Gambling Studies, 6, 153-163.

Volberg, R.A. \& Steadman, H.J. (1989). Refining prevalence estimates of pathological gambling. American Journal of Psychiatry, 1, 502-505. (1989). Prevalence estimates of pathological gambling in New Jersey and Maryland. American Journal of Psychiatry, 146, 161-1619.

Walker, M.B. (1992). The psychology of gambling. Pergamon, NY.

Walker, M. \& Dickerson, M.G. (1996). The prevalence of problem and pathological gambling: A critical analysis. Journal of Gambling Studies, 12(2), 233-249.

Watson, D. David, J.P., \& Suis, J. (1999). Personality, affectivity, and coping. In C.R. Synder (Ed.) Coping: The psychology of what works. New York: Oxford University Press.

Weiss, S. (1995). A comparison of maladaptive behaviors of athletes and non-athletes. The Journal of Psychology, 133(3), 315-322.

Welte, J., Wieczorek, W., Barnes, G., Tidwell, M. \& Hoffman, J. (2003). The relationship of ecological and geographic factors to gambling behavior and pathology. Journal of Gambling Studies, 6, 157-171.

Westphal, J.R., Rush, J.A., Stevens, L., \& Johnson, L. J. (2000). Gambling behavior of Louisiana students in grades 6 through 12. Psychiatric Services, 51, 96-99.

White, H.R. \& Labouvie, E.W. (1989). Towards the assessment of adolescent problem drinking. Journal of Studies on Alcohol, 50, 30-37.

Whyte, K. S. (1997). Analysis of the National Gambling Impact Commission. Journal of Gambling Studies, 14, 309-318.

Wills, T.A., Sandy, J.M., Yaeger, A.M., Cleary, S.D., \& Shinar, O. (2001) Coping dimensions, life stress, and adolescent substance use: A latent growth analysis. Journal of Abnormal Psychology, 110, 309-323. 
Winters, K., Dorr, D., \& Stinchfield, R. (1998). Prevalence and risk factors of problem gambling among college students. Psychology of Addictive Behaviors, 12, 127 135.

Wright, B.R.E. (1998) Behavioral intention and opportunities among homeless individuals: A reinterpretation of the theory of reasoned action. Social Psychology Quarterly, 61, 271-286.

Zuckerman, M. (1979). Sensation seeking: beyond the optimal level of arousal. Hillsdale, NJ: Erlbaum.

Zuckerman, M., Eysenck, S., \& Eysenck, H. J. (1978). Sensation seeking in England and America: Cross-cultural, age, and sex comparisons. Journal of Consulting and Clinical Psychology, 46(1), 139-147. 
APPENDIX A 
Gambling in the United States

As of 2006, only two states Utah and Hawaii did not offe $r$ same type of gambling.

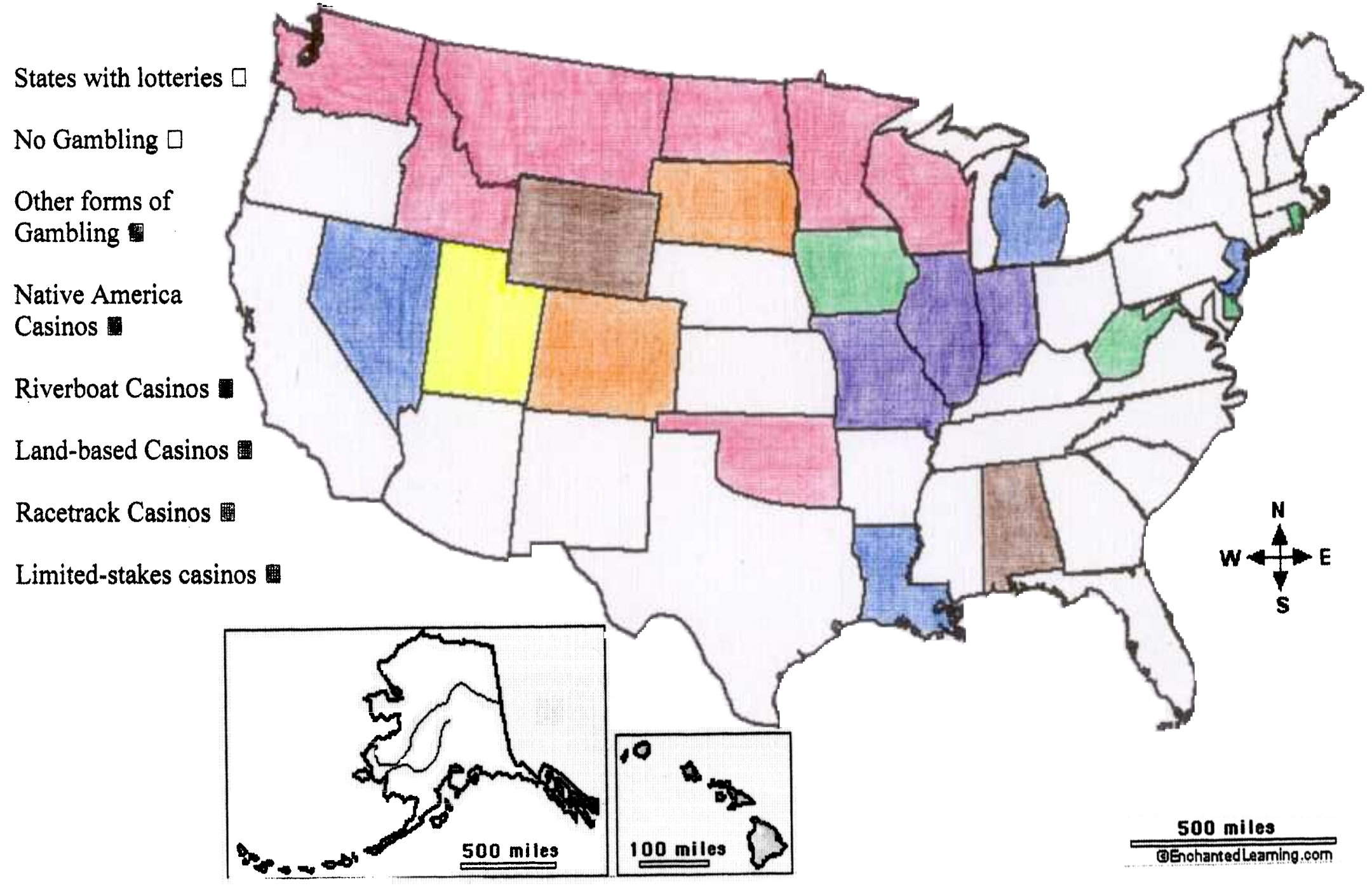


APPENDIX B 


\section{Problem gambling continuum}

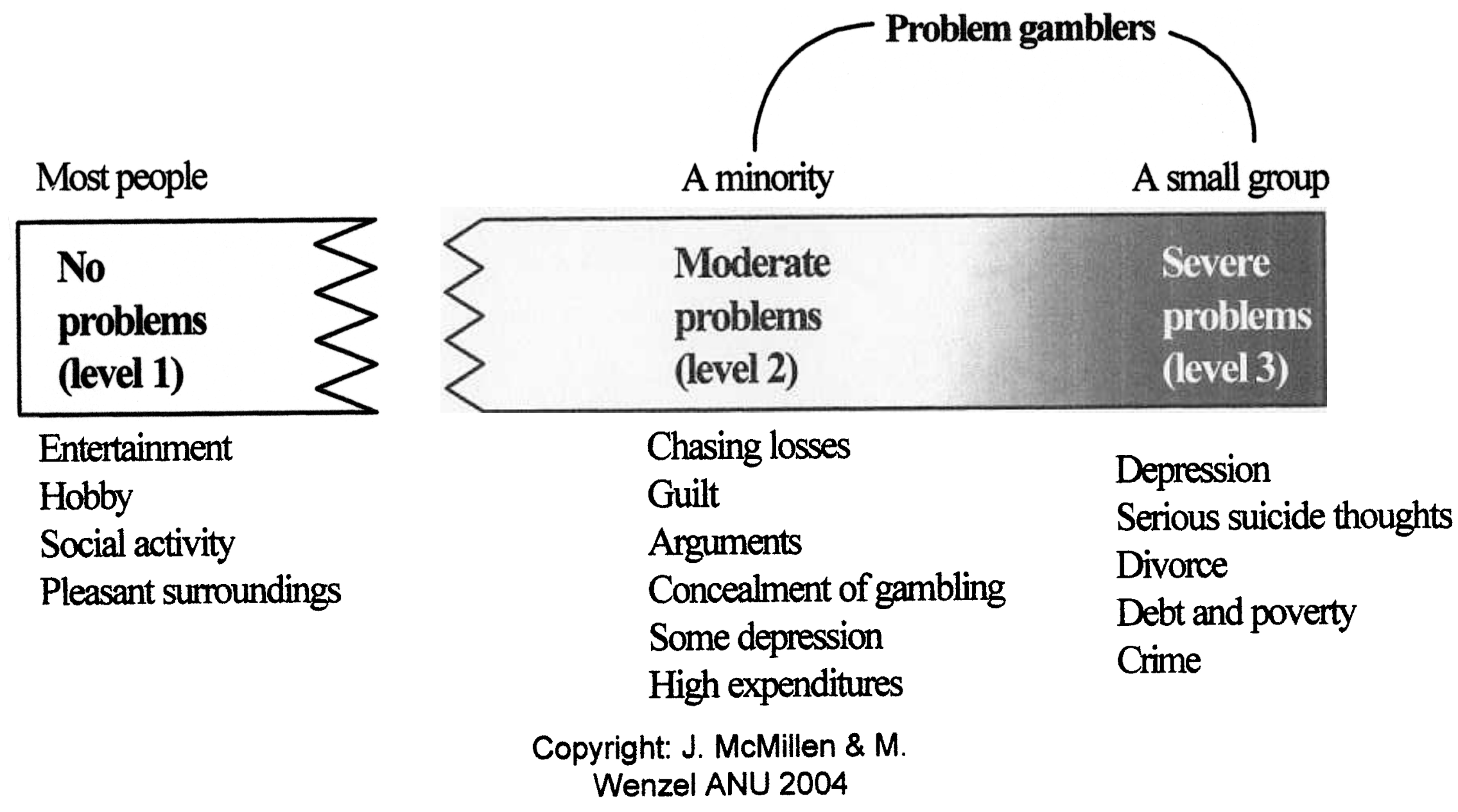


APPENDIX C 


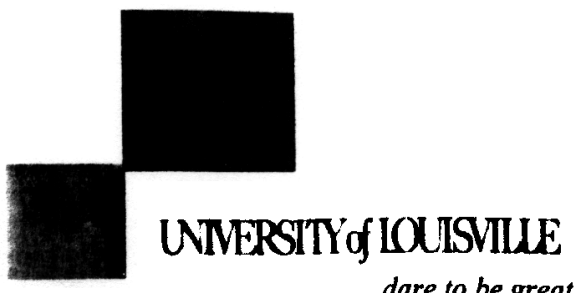
HUMAN SUBJECTS PROTECTION
PROGRAM OFFICE

MedC ent Lolisvilis

MedCenter One, Suite 200

$501 \mathrm{E}$. Brosidway

Louisvilte, Kentucky 40202-1798

dare to be great

Ofice: $\quad 502-852-5188$

Fax: $\quad 502-852-2164$

Monday, November 28, 2005

Daniel Mahony, PhD

Health \& Sport Sciences

RE: 612.05: Using the Theory of Reasoned Action to Examine the Gambling Behavior of College Athletes and Other Students

Dear Doctor Mahony:

The revised preamble for the above referenced study has been received and contains the changes requested in our letter of $11 / 21 / 2005$

This study has been reviewed by the chair of the Institutional Review Board (IRB) and approved through the Expedited Review Procedure, according to 45 CFR 46.110(b), since (7) Research on individual or group characteristics or behavior (including, but not limited to, research on perception, cognition, motivation, identity language, communication, cultural beliefs or practices, and social behavior) or research employing survey, interview, oral history, focus group, program evaluation, human factors evaluation, or quality assurance methodologies.

The following items have been approved:

- Research Protocol

- Revised Preamble

Your study now has final IRB approval through 11/27/2006. The committee will be advised of this action at their next full Board meeting.

Please note that the IRB follows the principles of the Belmont Report, is in compliance with Good Clinical Practice Guidelines as defined by the U.S. Food and Drug Administration and the Department of Health and Human Services under the Code of Federal Regulations (21 CFR Parts 50 and 56; 45 CFR 46) and International Conference on Harmonization ( $\mathrm{CCH}$ ) Guidelines (Section E6).

You should complete and return the Progress Report/Continuation Request Form EIGHT weeks prior to 11/27/2006, in order to ensure that no lapse in approval occurs. Best wishes for a successful study.

Please send all inquires and electronic revised/requested items to our office email address at hsppofc@louisville.edu

Sincerely,

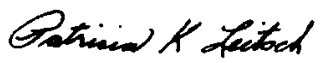

Patricia K. Leitsch, Ph.D., Chair,

Behavioral/Social/Educational Institutional Review Board

PKLJelp 
APPENDIX D 


\section{USING THE THORY OF REASONED ACTION TO EXAMINE THE GAMBLING EHAVIOR OF COLLEGE ATHLETES AND OTHER STUDENTS}

25 October 2005

Dear Student:

You are being invited to participate in a research study sponsored by the Department of Leadership, Foundations and Human Resources Education (ELFH) at the University of Louisville and conducted by Dr. Daniel F. Mahony and Robert G. Thrasher.

The study seeks to find out if the theory of reasoned action can be used to examine gambling behavior of college students. Your participation would consist of completing the survey and submitting it to the proctor. This survey will be given to approximately 500 students in the Department of Health and Sports Sciences and will take about 20 minutes to complete. You are free to decline to answer any question that makes you feel uncomfortable.

It is not clear that you will benefit directly from this study, but it is hoped that your participation will help others in the future. Foreseeable risks to you might be slight discomfort in answering certain questions. And, as in any research, there is always the possibility of unforeseen risks.

Although absolute confidentiality cannot be guaranteed, confidentiality will be protected to the extent permitted by law. The data will be kept under lock and key. The sponsor, the Human Subjects Protection Program Office, and the Institutional Review Board may inspect the research records of this study.

Should the data be published you will not be identified by name.

Your participation in this research is voluntary. You may refuse or discontinue participation at any time without losing any benefits to which you are otherwise entitled.

Should you have any questions you may call the investigator at (502) 582-5705. If you have any questions about your rights as a research subject, concerns or complaints about the research or research staff, you may call the HSPPO at (502) 852-5188 and they will put you in touch with the appropriate chair of the Institutional Review Board to discuss the matter. The IRB is an independent committee composed of members of the University community, staff of the institutions, as well as lay members of the community not connected with these institutions. The IRB has reviewed this study.

By submitting this questionnaire, you are indicating your willingness to participate freely in this research study. You are further indicating that all of your present questions have been answered in a language you understand and you understand all future questions will be answered in a similar manner.

Thank you for considering my invitation to participate in this study.

Sincerely,

Dr. Daniel F. Mahony, PhD 


\title{
STUDENT ATTITUDE AND MOTIVATIONAL SURVEY OF GAMBLING AT THE UNIVERSITY OF LOUISVILLE 2005
}

\section{GAMBLING ATTITUDE SCALE}

\author{
(Moore \& Ohtsuka, 1999)
}

Please respond to the following statements concerning attitude. Circle 1 for strongly agree, $\mathbf{2}$ for moderately agree, 3 for mildly agree, 4 for neither agree nor disagree, 5 for mildly disagree, 6 for moderately disagree, and 7 for strongly disagree.

1. Gambling is a fun activity.

2. Moderate gambling is harmless.

3. Gamblers need counseling.

4. Gambling should be illegal.

5. There is too much gambling today.

6. Gambling destroys families.

7. Gambling is just another hobby.

8. Most people can control their gambling.

9. Gambling is a social evil.

10. I approve of some gambling being legal.

11. Gambling should be controlled by law so people don't overdo it.

12. Basically I approve of gambling.

$\begin{array}{lllllll}1 & 2 & 3 & 4 & 5 & 6 & 7 \\ 1 & 2 & 3 & 4 & 5 & 6 & 7 \\ 1 & 2 & 3 & 4 & 5 & 6 & 7 \\ 1 & 2 & 3 & 4 & 5 & 6 & 7 \\ 1 & 2 & 3 & 4 & 5 & 6 & 7 \\ 1 & 2 & 3 & 4 & 5 & 6 & 7 \\ 1 & 2 & 3 & 4 & 5 & 6 & 7 \\ 1 & 2 & 3 & 4 & 5 & 6 & 7 \\ 1 & 2 & 3 & 4 & 5 & 6 & 7 \\ 1 & 2 & 3 & 4 & 5 & 6 & 7 \\ 1 & 2 & 3 & 4 & 5 & 6 & 7 \\ 1 & 2 & 3 & 4 & 5 & 6 & 7\end{array}$




\section{SUBJECTIVE NORMS SCALE}

(Moore \& Ohtsuka, 1999)

For each of the following items, please circle the number that best represents your feelings towards each item. For example, if you strongly agree with the item circle 1, if you moderately agree circle 2 , if you mildly agree circle 3 , if you neither agree nor disagree circle 4 , if you mildly disagree circle 5 , if you moderately disagree circle 6 , if you strongly disagree circle 7 .

1. Most of my friends approve of gambling.

2. Most of my friends gamble sometimes.

3. My friends often go to places where gambling occurs.

4. My family approves of gambling.

5. People in my family gamble sometimes.

6. People in my family often go to places where gambling occurs $1 \begin{array}{llllll}1 & 2 & 3 & 4 & 5 & 6\end{array}$ 7. My family members spend $\$ 20$ or more a week on gambling. $\begin{array}{lllllll}1 & 2 & 3 & 4 & 5 & 6 & 7\end{array}$ 8. My family members spend $\$ \mathbf{1 0 0}$ or more a week on gambling. $\begin{array}{lllllll}1 & 2 & 3 & 4 & 5 & 6 & 7\end{array}$ 9. My friends would disapprove of me playing the horses. $\quad \begin{array}{lllllll}1 & 2 & 3 & 4 & 5 & 6 & 7\end{array}$ 10. My family would disapprove of me playing the horses. $\quad \begin{array}{lllllll}1 & 2 & 3 & 4 & 5 & 6 & 7\end{array}$ 11. My friends would disapprove of me buying a lottery ticket. $1 \quad 2 \quad 3 \quad 4 \quad 5 \quad 6 \quad 7$

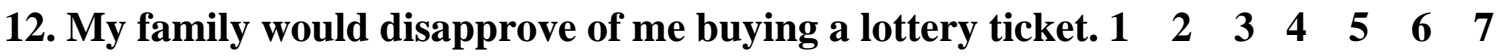
13. My friends would disapprove of me going to a casino. $\begin{array}{lllllll}1 & 2 & 3 & 4 & 5 & 6 & 7\end{array}$ 14. My family would disapprove of me going to a casino. $\quad \begin{array}{lllllll}1 & 2 & 3 & 4 & 5 & 6 & 7\end{array}$ 15. My friends would disapprove of me playing bingo. 16. My family would disapprove of me playing bingo. $\begin{array}{lllllll}1 & 2 & 3 & 4 & 5 & 6 & 7\end{array}$

$\begin{array}{lllllll}1 & 2 & 3 & 4 & 5 & 6 & 7\end{array}$ 


\section{GAMBLING MOTIVATION SCALE}

FOR EACH OF THE FOLLOWING ITEMS, PLEASE CIRCLE THE NUMBER THAT BEST REPRESENTS THE EXTENT TO WHICH THE ITEM CORRESPONDS TO THE RESONS WHY YOU PLAY YOU FAVORITE GAME. FOR EXAMPLE, IF YOU STRONGLY AGREE WITH THE ITEM STRONGLY DISAGREE CIRCLE 7, CIRCLE 1, IF YOU MODERATELY AGREE CIRCLE 2, IF YOU MILDLY AGREE CIRCLE 3, IF YOU NEITHER AGREE NOR DISAGREE CIRCLE 4, IF YOU MILDLY DISAGREE CIRCLE 5, IF YOU MODERATELY DISAGREE CIRCLE 6, IF YOU STRONGLY DISAGREE CIRCLE 7.

INDICATE YOUR FAVORITE FORM OF GAMBLING:

WHY DO YOU PLAY FOR MONEY (BET) AT YOUR FAVORITE GAME?

1. BECAUSE IT IS EXCITING TO PLAY FOR MONEY.

1234567

2. BECAUSE IT MAKES ME FEEL LIKE SOMEBODY IMPORTANT.

1234567

3. FOR THE FEELING OF EFFICACY THAT I GET WHEN I PLAY MY FAVORITE GAME.

1234567

4. BECAUSE, FOR ME, IT IS THE BEST WAY TO RELAX COMPLETELY.

1234567

5. I PLAY FOR MONEY, BUT SOMETIMES I ASK MYSELF IF I SHOULD CONTINUE TO PLAY MY FAVORITE GAME.

6. BECAUSE PLAYING FOR MONEY ALLOWS ME TO TEST MY CAPACITY TO CONTROL MYSELF.

1234567

7. I PLAY FOR MONEY, BUT SOMETIMES I ASK MYSELF WHAT I GET OUT OF IT.

8. TO GET RICH.

1234567

9. TO SHOW OTHERS THAT I AM A DYNAMIC PERSON.

1234567

10. FOR THE PLEASURE I GET AT IMPROVING MY KNOWLEDGE OF THE GAME.

1234567

11. TO BUY SOMETHING THAT I DREAM OF.

1234567

12. BECAUSE IT ALLOWS ME TO ENJOY MYSELF ENORMOUSLY.

1234567

13. BECAUSE IT IS THE BEST WAY I KNOW OF TO ELIMINATE TENSION.

1234567

14. FOR THE STRONG SENSATIONS I FEEL WHEN I PLAY MY FAVORITE GAME.

15. FOR THE SATISFACTION OF LEARNING NEW WAYS OF PLAYING MY FAVORITE GAME.

1234567

16. TO BE ENVIED BY OTHERS.

1234567 
17. BECAUSE IT IS THE HOBBY I HAVE CHOSEN TO CLEAR MY MIND.

18. FOR THE PLEASURE OF KNOWING MY ABILITIES AT THIS GAME.

1234567

19. FOR THE SATISFACTION I FEEL WHEN I CAN CONTROL THE GAME.

1234567

20. FOR THE CURIOSITY OF KNOWING WHAT CAN HAPPEN IN THE GAME

1234567

21. I PLAY FOR MONEY BUT SOMETIMES I FEEL I AM NOT GETTING A LOT OUT OF IT.

1234567

22. TO MAKE MONEY QUICKLY AND EASILY.

1234567

23. BECAUSE IT'S THE BEST WAY I KNOW OF TO MEET MY FRIENDS.

1234567

24. FOR THE FEELING OF CONTROL IT GIVES ME.

1234567

25. I PLAY FOR MONEY BUT I SOMETIMES ASK MYSELF IF IT IS GOOD FOR ME.

1234567

26. BECAUSE WHEN I WIN, I FEEL LIKE SOMEONE IMPORTANT.

1234567

27. TO MAKE A LOT OF MONEY.

1234567

28. FOR THE THRILL OF THE STRONG SENSATIONS IT GIVES ME.

1234567

C YVES CHANTAL, ROBERT J. VALLERAND ET EVELYNE VALLIEES (2003) 
Abbreviated Version : Levenson's (1974) Locus of Control Scale (Adapted by Sapp \& Harrod, 1993)

For each of the following items, please circle the number that best represents the intention to which you believe. For example, if you strongly agree with the item circle 1 , if you moderately agree circle 2 , if you mildly agree circle 3 , if you neither agree nor disagree circle 4 , if you mildly disagree circle 5, if you moderately disagree circle 6, if you strongly disagree circle 7.

\section{Internal Control Items}

1. My life is determined by my own actions. (Own Action) $\quad 1 \quad 2 \quad 3 \quad 4 \quad 5 \quad 6 \quad 7$

2. I am usually able to protect my personal interests. (Protect)1 $2 \begin{array}{llllll}3 & 4 & 5 & 6 & 7\end{array}$

3. I can pretty much determine what will happen in my life. $\begin{array}{lllllll}1 & 2 & 3 & 4 & 5 & 6 & 7\end{array}$ (Determine)

\section{Chance Items}

4. To a great extent, my life is controlled by accidental happenings. $12 \begin{array}{lllll}2 & 3 & 5 & 6 & 7\end{array}$ (Accidental Happenings)

5. Often there is no chance of protecting my personal interest from $\begin{array}{lllllll}2 & 2 & 4 & 5 & 6 & 7\end{array}$ bad luck happening. (Bad Happenings)

6. When I get what I want, it's usually because I'm lucky. $\quad$\begin{tabular}{lllllll}
\hline & 2 & 3 & 4 & 5 & 6 & 7
\end{tabular}

\section{Powerful Others}

7. People like myself have very little chance of protecting our $\quad \begin{array}{lllllll}2 & 2 & 3 & 4 & 5 & 6 & 7\end{array}$ personal interests where they conflict with those of strong

pressure groups. (Pressure Groups)

8. My life is chiefly controlled by powerful others.

(Powerful Others)

9. I feel like what happens in my life is mostly determined by $1 \begin{array}{lllllll}2 & 3 & 4 & 5 & 6 & 7\end{array}$ powerful people. (Powerful People) 


\section{GAMBLING INTENTION SCALE \\ (Moore \& Ohtsuka, 1999)}

For each of the following items, please circle the number that best represents your intention to gamble. For example, if you strongly agree circle 1, if you moderately agree circle 2, if you mildly agree circle 3 , if you neither agree nor disagree circle 4 , if you mildly disagree circle 5, if you moderately disagree circle 6, if you strongly disagree circle 7.

$\begin{array}{lllllllll}\text { 1. In the next week, I intend to buy a lottery ticket. } & 1 & 2 & 3 & 4 & 5 & 6 & 7\end{array}$

2. In the next week, I intend to place a wager on the horses. $\quad \begin{array}{lllllll}2 & 2 & 3 & 4 & 5 & 6 & 7\end{array}$

3. In the next week, I intend to go to the casino.

$\begin{array}{lllllll}1 & 2 & 3 & 4 & 5 & 6 & 7\end{array}$

4. In the next week, I intend to play bingo.

$\begin{array}{lllllll}1 & 2 & 3 & 4 & 5 & 6 & 7\end{array}$

5. In the next week, I intend to play another type of gambling game.

$\begin{array}{lllllll}1 & 2 & 3 & 4 & 5 & 6 & 7\end{array}$

6. In the next month, I intend to buy a lottery ticket.

$\begin{array}{lllllll}1 & 2 & 3 & 4 & 5 & 6 & 7\end{array}$

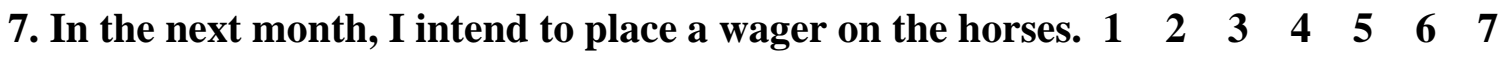

8. In the next month, I intend to go to a casino. $\quad \begin{array}{lllllll} & 2 & 3 & 4 & 5 & 6 & 7\end{array}$

9. In the next month, I intend to play bingo. $\quad \begin{array}{lllllll}2 & 2 & 4 & 5 & 6 & 7\end{array}$

10. In the next month, I intend to play another type of gambling game.

11. In the next year, I intend to buy a lottery ticket.

$\begin{array}{lllllll}1 & 2 & 3 & 4 & 5 & 6 & 7\end{array}$

12. In the next year, I intend to place a wager on the horses. $\begin{array}{lllllll}1 & 2 & 3 & 4 & 5 & 6 & 7\end{array}$

13. In the next year, $I$ intend to go to a casino.

$\begin{array}{lllllll}1 & 2 & 3 & 4 & 5 & 6 & 7\end{array}$

14. In the next year, I intend to play bingo.

$\begin{array}{lllllll}1 & 2 & 3 & 4 & 5 & 6 & 7\end{array}$

15. In the next year, I intend to play another type of gambling game. 
1. PLEASE INDICATE WHICH OF THE FOLLOWING TYPES OF GAMBLING YOU HAVE DONE IN YOUR LIFETIME? FOR EACH TYPE, MARK ONE ANSWER "NOT AT ALL" (NOA), “LESS THAN ONCE A WEEK” (LTOAW) OR “ONCE A WEEK OR MORE” (OAWOM).

PLEASE CHECK ONE ANSWER FOR EACH STATEMENT NOA LTOAW OAWOM

A. PLAYED CARDS FOR MONEY

B. BET ON DOGS, HORSES, OR OTHER ANIMALS

C. BET ON SPORT CARDS WITH BOOKIES

D. WENT TO CASINOS TO GAMBLE

E. PLAYED DICE GAMES, INCLUDING CRAPS FOR MONEY

F. PLAYED THE NUMBERS OR BET ON LOTTERIES FOR MONEY

G. PLAYED BINGO FOR MONEY

H. PLAYED THE STOCK MARKET FOR MONEY

I. PLAYED SLOT MACHINES, POKER MACHINES, OR OTHER GAMBLING MACHINES FOR MONEY

J. BOWLED, SHOT POOL, PLAYED GOLF, OR OTHER GAMES INVOLVING SKILL FOR MONEY

K. PLAYED PULL TABS OR OTHER PAPER GAMES FOR MONEY

L. SOME OTHER TYPE OF GAMBLING: FOR MONEY

2. WHAT IS THE LARGEST AMOUNT OF MONEY YOU HAVE EVER GAMBLED WITHIN ONE WEEK?

NEVER GAMBLED FROM \$1.00 UP TO $\$ 10.00$ FROM \$100.00 UP TO \$1000.00 MORE THAN \$10,000.00
\$1.00 OR LESS

FROM $\$ 10.00$ UP TO $\$ 100.00$ FROM \$1000.00 UP TO \$10,000.00 
PLEASE ANSWER EACH OF THE FOLLOWING QUESTIONS:

1. WHAT IS YOUR GENDER? MALE FEMALE

2. PLEASE INDICATE TOUR CLASS LEVEL? FRESHMAN SOPHOMORE JUNIOR SENIOR GRADUATE

3. PLEASE INDICATE YOUR ETHNICITY?

WHITE AMERICAN AFRICAN AMERICAN ASIAN AMERICAN HISPANIC AMERICAN NATIVE AMERICAN OTHER

4. WHAT IS YOUR MARITAL STATUS?

SINGLE MARRIED DIVORCED WIDOWED OTHER

5. WHAT IS YOUR AGE?

6. WHERE DO YOU LIVE? PARENT'S HOME APARTMENT DORMITORY FRATERNITY HOUSE SORITITY HOUSE

7. ARE YOU A MEMBER OF AN INTERCOLLEGIATE SPORT TEAM AT YOUR UNIVERSITY?

YES__ NO__

IF YES PLEASE INDICATE IF YOU ARE A MEMBER OF THE FOOTBALL / MENS BASKETBALL TEAM OR ANOTHER SPORT

8. WHAT IS YOUR CURRENT ZIP CODE?

\section{Thanks for participating in this study.}




\section{CURRICULUM VITAE}

NAME: $\quad$ Robert Gene Thrasher, Jr.

ADDRESS: 4620 Palma Road

Louisville KY 40272

(502) 937-2953

email: bosethra@aol.com

rgthra02@1ouisville.edu

\section{EDUCATION}

Ph.D., Educational Administration with emphasis in Sport Administration Dissertation entitled, "Using the Theory of Reasoned Action to examine the gambling behavior of college athletes and other students"

Advisor: Daniel F. Mahony, Ph.D.

University of Louisville

2003-2006 (expected graduation May 2006)

Masters of Arts in Teaching (Social Studies) Grades 6-8

Advisor: Marcia Lile

University of Louisville

2001-2006

M.S. Sport Administration

Advisor: Mary Hums, Ph.D.

University of Louisville

2001-2003

B.S. Recreation Education

Advisor: Sherrill Brakmeir

University of Louisville

1976-1979

\section{WORK EXPERIENCE}

Part Time Faculty

University of Louisville

January 9 - May 2, 2006

SPAD 505 - Sport Facility Management 
Head Baseball Coach

Valley High School

August 2004 - November 2005

Head Softball Coach / Preferred Substitute Teacher

Valley High School

October 2003 - October 2004

Sales Account Manager

Acosta Sales Co.

February 1996 - November 2001

Self-Employed Thoroughbred Horse Trainer

May 1982 - December 1995

Director of Student Life / Baseball Coach

Lindsey Wilson College

August 1980 - May 1982

Equipment Coordinator

University of Louisville

July 1979 - August 1980

\section{TEACHING EXPERIENCE}

Adjunct Faculty

University of Louisville

2006

SPAD 505 - Sport Facility Management

Preferred Substitute: Valley High School, Jefferson

County Board of Education: October 2003 to December 2005.

Subject Area: Variety of Classes.

Long-term Substitute Teacher: Stuart Middle School,

Jefferson County Board of Education: January 1987 - May 1987.

Subject Area: Math

Physical Education Activity Classes: Lindsey Wilson College

Spring 1981: Tennis 


\section{PUBLICATIONS}

Funk, D. C., Nakazawa, M., Mahony, D. F., \& Thrasher, R. (in press). The social impact of the national sport lottery and the FIFA World Cup on attendance, spectator motives, and J. League marketing strategies. International Journal of Sport Marketing \& Sponsorship.

Thrasher, R. G. (in progress). Using the theory of reasoned action to examine the gambling behavior of college athletes and other students.

\section{REFEREED RESENTATIONS}

Thrasher, R. G., Mahony, D. F. (advisor), \& Andrew, D. P. S. (advisor). Using the theory of reasoned action to examine the gambling behavior of college athletes and other students. Accepted for a poster presentation at the 2006 North American Society for Sport Management Annual Conference.

Thrasher, R. G. (2004). The impact of the proximity of gambling opportunities on the motivations and attitudes of college students. Poster Presentation at the $5^{\text {th }}$ Annual NCRG Conference on Gambling and Addiction. December 2004. Las Vegas, Nevada,

\section{NON-REFEREED RESENTATIONS}

Thrasher, R. G. (2005). The choices we make: Gambling in college. Oral Presentation to the University of Louisville Football Team, August 2005.

Thrasher, R. G. (2004). A gambling prevalence study of high school students in grades 912: What motivates high school student to gamble and how does this differ from their adult counterparts? Poster Presentation at the Spring 2004 Research Conference (University of Kentucky, University of Louisville, and University of Cincinnati).

\section{MEMBERSHIPS AND LICENSES}

Licensed Thoroughbred Horse Trainer: Kentucky, Ohio, Indiana, West Virginia

Member: Kentucky Council on Problem Gambling

Member: North American Society for Sports Management

Member: University of Louisville Letterman's Club 
Member: National Equipment Managers Association

Member: Kentucky Horseman Benevolent and Protective Association

Member: Valley High School Athletics Booster Club

\section{COMMITTEES AND COUNCILS}

Graduate Student Representative, College of Education and Human Development Standards and Admissions Committee

HPES Representative, Graduate Student Government Council

Chair, Sport Administration Club Scholarship Committee 